CENTRO UNIVERSITÁRIO FEI

GUSTAVO FERRAZ ATTENCIA

\title{
ASSIMILAÇÃO DE TECNOLOGIA DIGITAL NO GERENCIAMENTO DE ATIVOS EM PROJETOS COMPLEXOS
}

São Bernardo do Campo 
Dissertação apresentada ao Centro Universitário FEI, como parte dos requisitos necessários para obtenção do título de Mestre em Engenharia Mecânica. Orientado pela Professora Dra. Claudia Aparecida de Mattos.

São Bernardo do Campo 
Ferraz Attencia, Gustavo.

ASSIMILAÇÃO DE TECNOLOGIA DIGITAL NO GERENCIAMENTO DE ATIVOS EM PROJETOS COMPLEXOS /

Gustavo Ferraz Attencia. São Bernardo do Campo, 2019.

107 f. : il.

Dissertação - Centro Universitário FEI. Orientador:

Prof. Dr. Claudia Aparecida de Mattos.

1. Assimilação de tecnologia. 2. Gestão de ativos. 3. Smart asset management. 4. Tecnologia digital. 5. Projetos complexos. I. Aparecida

Elaborada pelo sistema de geração automática de ficha catalográfica da FEI com os dados fornecidos pelo autor. 
centro

Aluno: Gustavo Ferraz Attencia

Matrícula: $217310-2$

Título do Trabalho: Assimilaçắo de tecnologia digital no gerenciamento de ativos em projetos complexos.

Área de Concentraçăo: Produçăo

Orientador: Profa Dra Claudia Aparecida de Mattos

Data da realizaçăo da defesa: $25 / 10 / 2019$

ORIGINAL ASSINADA

Avaliaçäo đa Banca Examinadora:

\begin{tabular}{|l|}
\hline \\
\hline \\
\hline \\
\hline \\
\hline \\
Săo Bernardo do Campo, $/$
\end{tabular}

\begin{tabular}{|l|l|}
\hline \multicolumn{2}{|c|}{ MEMBROS DA BANCA EXAMINADORA } \\
\hline \multirow{2}{*}{ Profa Dra Claudia Aparecida de Mattos } & Ass.: \\
\hline & \\
Profa Dra Kumiko Oshio Kissimoto & Ass.: \\
\hline Profa Dra Ana Lúcia Figueiredo Facin & \\
\hline
\end{tabular}

A Banca Julgadora acima-assinada atribuiu ao aluno o seguinte resultado:

APROVADO 凶 REPROVADO

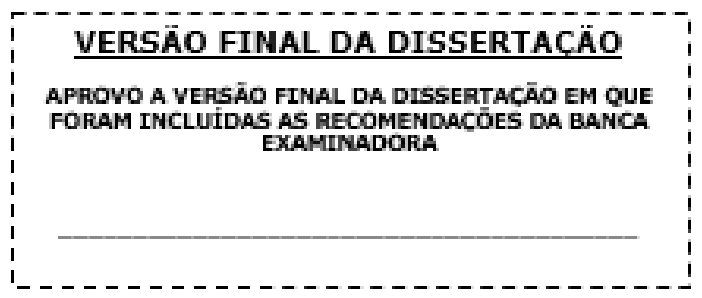


O presente trabalho foi realizado com apoio da Coordenação de Aperfeiçoamento de Pessoal de Nível Superior - Brasil (CAPES) - Código de Financiamento 001. 


\section{AGRADECIMENTOS}

Deixo aqui os meus sinceros agradecimentos a todas as pessoas que me apoiaram na conclusão desse trabalho. A minha família que me deu forças para chegar até aqui, em especial a minha esposa Fábia e meus filhos João Vitor e Gabriel que conviveram com a minha ausência nos momentos em que me dediquei a esse trabalho. Aos meus pais, que me aconselharam desde os primeiros passos desta longa caminhada. Agradeço a Deus que me iluminou e que me deu forças em todos os momentos.

O meu especial agradecimento a professora Dra. Claudia Aparecida de Mattos, minha orientadora, que compartilhou o seu conhecimento e me guiou para encontrar os melhores

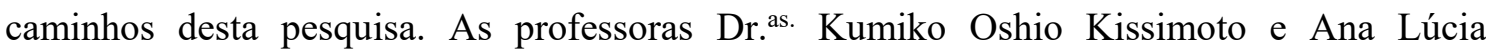
Figueiredo Facin, que também me ajudaram a enxergar a melhor trajetória para essa caminhada. A todos os professores do Centro Universitário FEI que, com excelência, ministraram aulas que jamais serão esquecidas.

Aos colegas do curso de mestrado que contribuíram com as suas experiências e enriqueceram os momentos que passamos juntos. Aos profissionais que me deram a honra de entrevista-los para consolidar essa pesquisa.

Muito obrigado! 


\section{RESUMO}

O desenvolvimento de novas soluções tecnológicas deve proporcionar melhores resultados econômicos e operacionais para as empresas, ter capacidade de assimilar essas tecnologias pode ser uma característica fundamental para as organizações. A gestão de ativos representa uma parcela importante na composição de vários modelos de negócio, em especial no ambiente de projetos complexos, não apenas sob o aspecto de custo, mas também sob o aspecto de resultado. De acordo com esse contexto, o presente trabalho tem como objetivo analisar a assimilação de tecnologia na gestão de ativos inteligentes em projetos complexos, através de estudo de caso múltiplos, identificando as tecnologias utilizadas assim como os possíveis fatores que afetam a assimilação de tecnologia na gestão de ativos. Foram utilizados os conceitos Technology-Organization-Enviroment - TOE framework e Technology Acceptance Model (TAM) para analisar os principais fatores que influenciam a assimilação de tecnologia na gestão de ativos inteligentes em grandes projetos de construção civil. A contribuição do estudo está na integração dos conceitos de gestão de ativos e assimilação de tecnologia. Esta integração permite estruturar um framework teórico de assimilação de tecnologias em projetos complexos através da identificação de fatores de assimilação em cada fase do ciclo de gestão dos ativos.

Palavras-chave: Assimilação de tecnologia. Gestão de ativos. Smart asset management. Tecnologia digital. Projetos complexos. 


\begin{abstract}
The development of new technological solutions should provide better economic and operational results for companies and the ability to assimilate these technologies can be a fundamental characteristic for organizations. Asset management represents an important part of the composition of various business models, especially in complex projects, not only in terms of cost but also in terms of results. According to this context, the present work aims to analyze the assimilation of technology in the management of intelligent assets in complex projects, through a multiple case study, identifying the technologies used as well as the possible factors that affect the assimilation of technology in the management of assets. The TechnologyOrganization-Environment-TOE framework and Technology Acceptance Model (TAM) to analyze the main factors that influence the assimilation of technology in the management of intelligent assets in large construction projects. The contribution of the study is the integration of the concepts of asset management and technology assimilation. This integration allows to structure a theoretical framework of technology assimilation in complex projects, by identifying assimilation factors in each phase of the asset management cycle.
\end{abstract}

Keywords: Assimilation of technology. Asset management. Smart asset management. Digital technology. Complex projects. 


\section{LISTA DE FIGURAS}

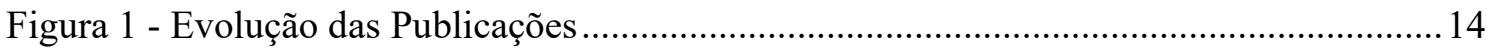

Figura 2 - Tipos de Publicações de 1987 a 2018 ..................................................................... 15

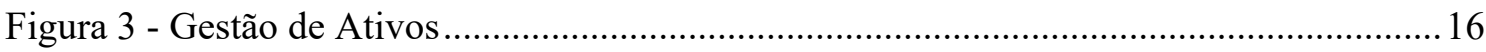

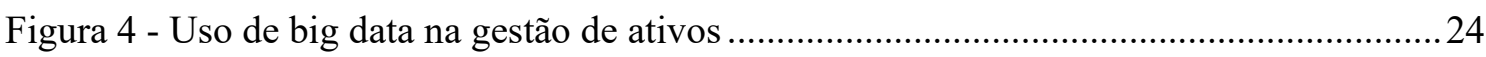

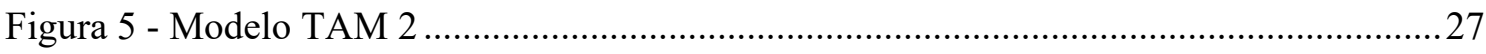

Figura 6 - Classificação de projetos por complexidade versus incerteza ................................. 38

Figura 7 - Matriz de relacionamento: complexidade, tamanho e incerteza.............................. 38

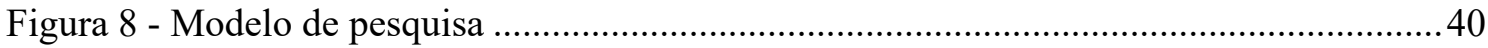

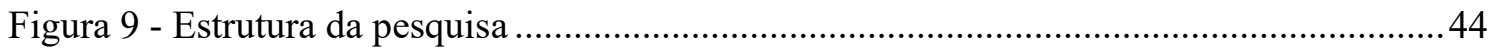

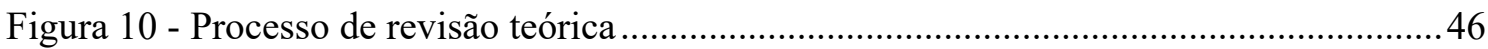

Figura 11 - Classificação de projetos por complexidade versus incerteza ...............................48

Figura 12 - Mercado global de equipamentos de construção 2017 ........................................49

Figura 13 - Classificação do projeto A por complexidade versus incerteza.............................58

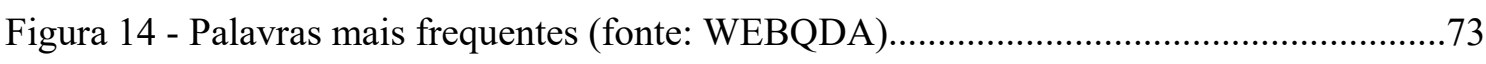

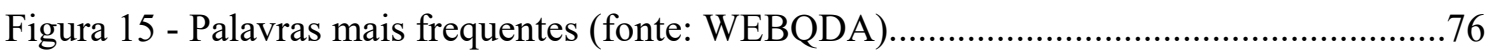

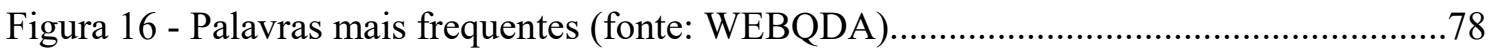

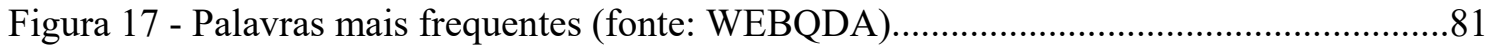

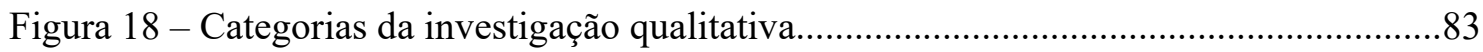

\section{LISTA DE QUADROS}

Quadro 1 - Desdobramento das dimensões da classificação de projetos ................................. 39

Quadro 2 - Fatores que afetam a assimilação de tecnologia (TOE) ........................................42

Quadro 3 - Características do questionário utilizado na pesquisa ..........................................52

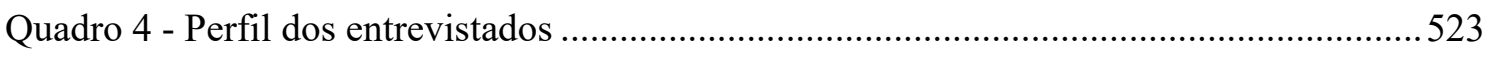

Quadro 5 - Fatores que impactaram a assimilação de tecnologia..........................................75

Quadro 6 - Fatores que impactaram a assimilação de tecnologia........................................77

Quadro 7 - Fatores que impactaram a assimilação de tecnologia...........................................79

Quadro 8 - Fatores que impactaram a assimilação de tecnologia...........................................82

Quadro 9 - Fatores que impactaram a assimilação de tecnologia.........................................84

Quadro 10 - Ciclo de vida dos ativos e fatores que podem impactar a assimilação de tecnologia 85 


\section{SUMÁRIO}

1 INTRODUÇÃO

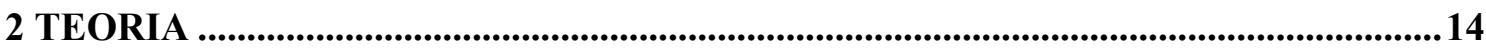

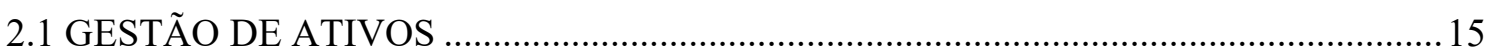

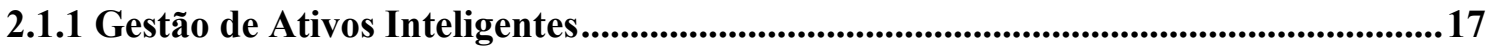

2.1.2 Tecnologias digitais na gestão de ativos...............................................................19

2.1.3 Análise de dados para tomada de decisão ...............................................................23

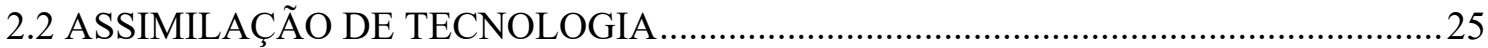

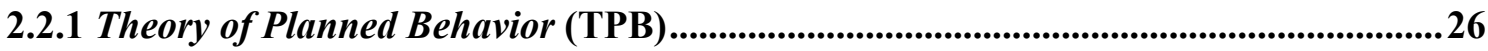

2.2.2 Technology Acceptance Model (TAM).....................................................................26

2.2.3 Unified Theory of Acceptance and Use of Technology (UTAUT) ..............................27

2.2.4 Diffusion of Innovation (DOI) .................................................................................................28

2.2.5 Technology-Organization-Environment (TOE) ..............................................................29

2.2.5.1 Contexto Tecnológico ........................................................................................................29

2.2.5.2 Contexto Organizacional......................................................................................................... 30

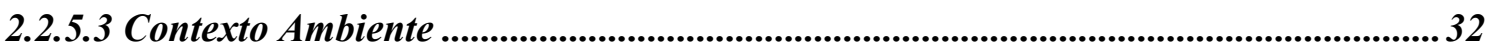

2.3 ASSIMILAÇÃO DE TECNOLOGIA DIGITAL NA GESTÃO DOS ATIVOS ...............32

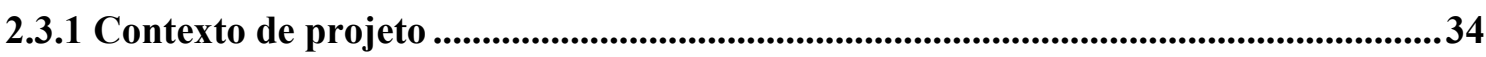

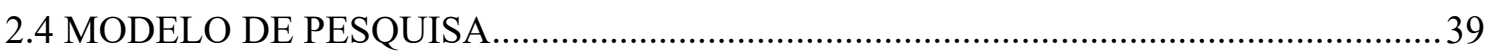

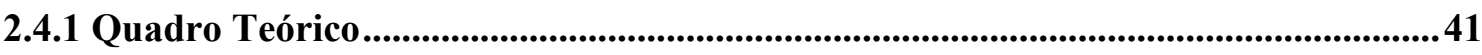

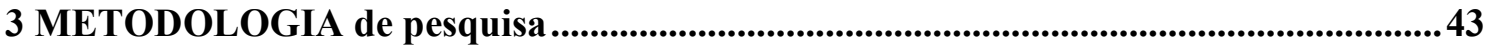

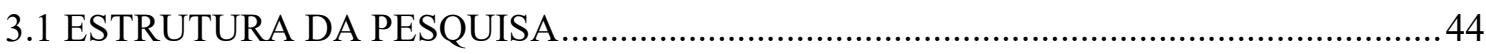

3.2 CONSTRUÇÃO DO REFERENCIAL TEÓRICO .........................................................45

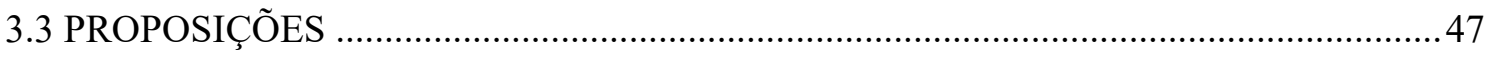

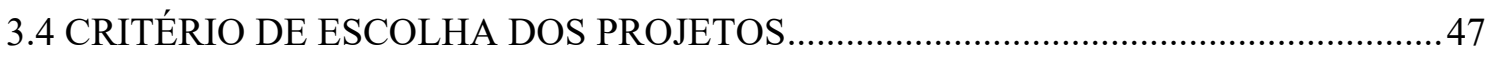

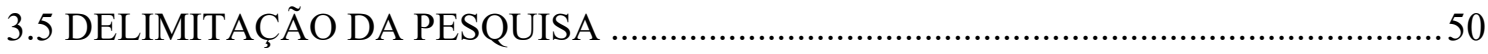

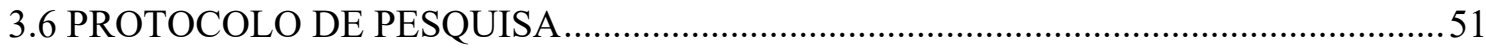

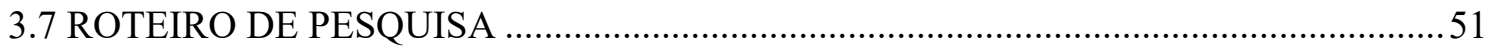

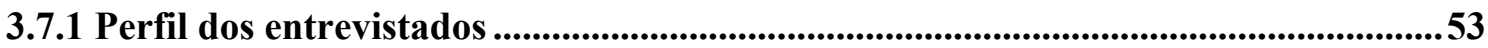




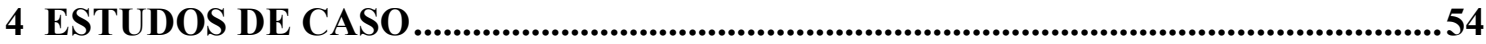

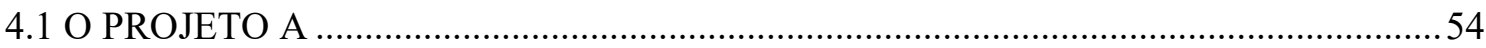

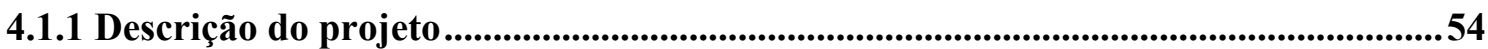

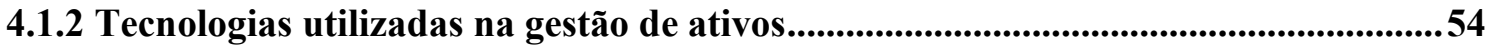

4.1.3 Análise do projeto A ..........................................................................................................57

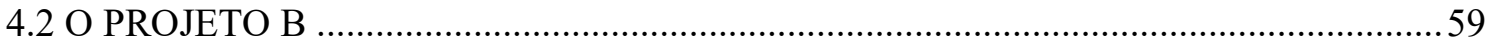

4.2.1 Descrição do projeto................................................................................................................59

4.2.2 Tecnologias utilizadas na gestão de ativos...................................................................60

4.2.3 Análise do projeto $B$....................................................................................................61

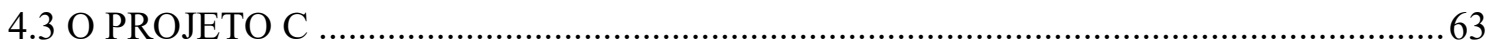

4.3.1 Descrição do projeto...............................................................................................................63

4.3.2 Tecnologias utilizadas na gestão de ativos......................................................................63

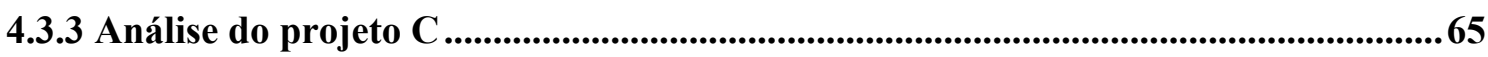

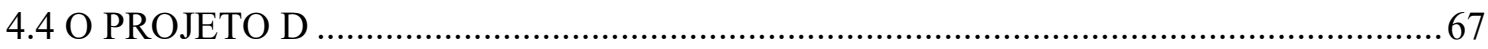

4.4.1 Descrição do Projeto....................................................................................................................68

4.4.2 Tecnologias utilizadas na gestão de ativos......................................................................68

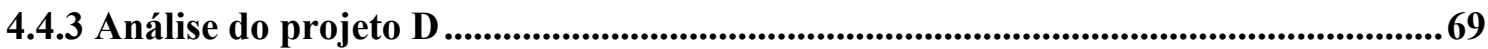

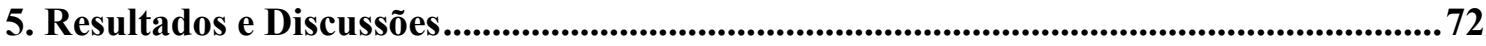

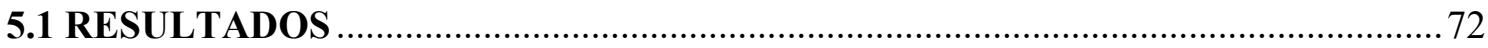

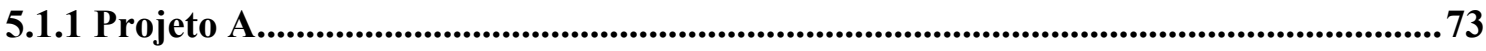

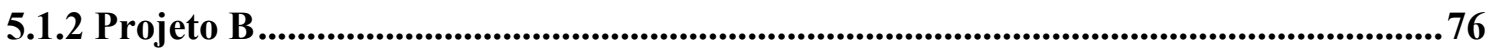

5.1.3 Projeto C ........................................................................................................................................ 77

5.1.4 Projeto D......................................................................................................................................8

5.1.5 Sumário dos resultados ........................................................................................................82

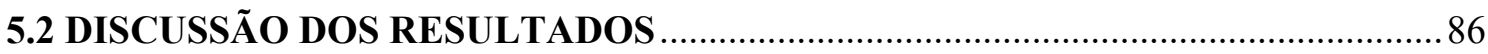

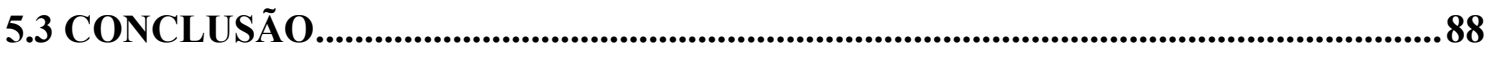

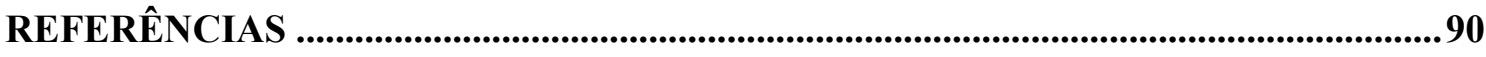

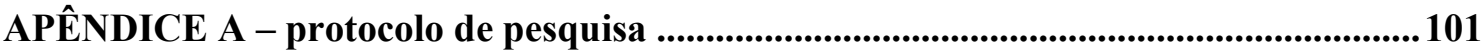




\section{INTRODUÇÃO}

O uso de tecnologia está mudando a forma de gerir os negócios e para garantir os melhores resultados é necessário saber extrair as vantagens competitivas das ferramentas tecnológicas disponíveis no mercado. A gestão de ativos representa uma parcela importante no resultado das empresas e soluções envolvendo IOT (internet of things), RFID (Radio Frequency Identification), AI (Artificial intelligence), Big Data, entre outras tecnologias são cada vez mais utilizadas para se obter vantagem competitiva. Entretanto, em um ambiente de projetos complexos, como é o caso de grandes projetos de construção civil voltado para infraestrutura, a assimilação de tecnologias na gestão de ativos se torna um desafio ainda maior para as empresas.

Além dos recursos tecnológicos embarcados nos equipamentos, que possibilitam melhorar seu desempenho, o gerenciamento das informações relacionadas aos ativos tem um papel importante para análise de risco e tomada de decisão. A evolução tecnológica no campo de IOT (internet of things), por exemplo, garante uma oferta de informações relevantes para os stakeholders e saber tratar e analisar os dados para tomar decisões se torna um diferencial competitivo (KINNUNEN et al., 2017). Nel e Jooste (2016), reforçam essa abordagem e indicam em seu estudo que o nível tecnológico dos equipamentos e do gerenciamento de ativos permite alavancar a rentabilidade nas empresas. Atualmente, se pode contar com dados em tempo real sobre variáveis fundamentais para à operação e para o gerenciamento dos ativos inteligentes. Têm-se, portanto, que a evolução tecnológica oferece às empresas uma vasta gama de soluções, entretanto o uso e a combinação dessas soluções é pouco explorado, mesmo apresentando um grande potencial para o desenvolvimento dos processos e consequente melhoria de resultados. Nesse contexto, a gestão dos ativos inteligentes é um conceito novo e necessita de estudo e análise profunda sobre sua implementação. Embora uma variedade de métodos seja utilizada com o objetivo de fornecer recursos de diagnóstico e prognóstico úteis, utilizando dados em tempo real, a maioria tem um baixo nível de autonomia. As ferramentas existentes facilitam a tomada de decisão, porém não suportam a tomada de decisão autônoma parcial ou total, o que demonstra também a necessidade de desenvolvimento tecnológico (ARTIKIS et al., 2014). Bousdekis et al. (2015) indicam em seu estudo que apesar do grande número de pesquisas analisando as tecnologias em prognóstico e diagnóstico em manutenção, a maioria delas não examinam a automatização de decisões, não fornecendo recomendações para ações de manutenção. Embora existam muitos trabalhos de pesquisa lidando com as 
previsões, poucos propõem métodos para utilizar esta previsão em tempo real acompanhado com conhecimento especializado para fornecer recomendações de manutenção.

De acordo com Lee et al. (2006), os dados gerados pelos equipamentos são pouco aproveitados para melhorar a sua gestão. Apesar da implantação de sistemas de informação que suportam o gerenciamento de ativos, as empresas relatam inconsistências nas informações decorrentes de falhas estratégicas, de gestão e operação (HAIDER, 2012). Reforçando essa lacuna, o estudo de Love et al. (2016), relata que pesquisas futuras são necessárias para determinar a melhor forma de inserção dos sistemas de informação na gestão de ativos, devendo se atentar para os aspectos relacionados a assimilação de tecnologia. Por outro lado, segundo $\mathrm{Mu}$, Kirsch e Butler, (2015) assimilar tecnologias requer ampla adaptação, tanto da tecnologia como das empresas. Uma parcela significativa das empresas não consegue atender a essa adaptação e, portanto, muitos dos benefícios não são alcançados com a adoção de diferentes sistemas corporativos. Han et al. (2018) relatam que as empresas utilizam métodos ineficientes, em vez de usar a tecnologia para gerenciar de forma eficaz seus ativos. Adicionalmente, destaca-se que o uso de tecnologias digitais para a coordenação e troca de informação torna-se limitado no contexto dos projetos (JACOBSSON; LINDEROTH, 2010), pois a pressão por melhores prazos, impede o aprendizado através de projetos e reduz as possibilidades de criação de rotinas padronizadas nas operações. Dado o potencial reconhecido da tecnologia digital para trazer melhorias em outros setores, muitas iniciativas foram realizadas para desenvolver ferramentas apropriadas para suportar várias tarefas durante o ciclo de vida de projetos (MARTÍNEZ-ROJAS; MARÍN; VILA, 2015). Os grandes projetos de construção civil, representam um ambiente complexo para inovação pois possuem diversos fatores organizacionais e ambientais que são variáveis e que muitas vezes estão fora do controle do gerente (WHITTY; MAYLOR, 2009). Nesse ambiente, a assimilação de tecnologia na gestão de ativos demonstra características particulares que precisam ser estudadas entender a assimilação das tecnologias digitais voltadas para a gestão dos ativos no contexto de projetos torna-se um ponto fundamental para alavancar a produtividade, entretanto este é um tema ainda escasso na literatura (SAMAD; SEPASGOZAR; DAVIS, 2018).

Assim, baseado no que foi apresentado até o momento, elaborou-se a pergunta de pesquisa que norteou o desenvolvimento do trabalho:

Como as tecnologias digitais são assimiladas em diferentes fases do ciclo de vida da gestão de ativos em projetos complexos? 
Com base nesta pergunta, o objetivo geral deste estudo consiste em analisar a assimilação das tecnologias digitais relacionadas a gestão de ativos, através de estudo de caso múltiplos, identificando as tecnologias utilizadas assim como os possíveis fatores que afetam o a assimilação de tecnologia no contexto de projetos complexos. Dentre as teorias que abordam o problema de pesquisa, o framework TOE (Technology-Organization-Enviroment) proposto por Tornatzky e Fleischer (1990) que é baseado nos contextos tecnológico, organizacional e ambiental das empresas, combinado com outras teorias como o modelo TAM desenvolvido por Davis (1985) e depois aprimorado por Venkatesh e Davis (2000) denominado TAM 2 que apresenta três características principais que afetam a aceitação de tecnologia no âmbito pessoal, sendo elas: facilidade de uso percebida; utilidade percebida e intenção comportamental, podem suportar o entendimento dos fatores que contribuem para assimilação das tecnologias digitais e para uma implementação bem-sucedida.

O trabalho está estruturado de maneira que a pesquisa possa ser replicada e aperfeiçoada por outros pesquisadores, buscando assim o desenvolvimento da teoria, contribuindo para geração de conhecimento, além de buscar a contribuição prática para as organizações. Na seção seguinte é apresentado o embasamento teórico relacionado a pesquisa, que abrange os temas: gestão de ativos, assimilação de tecnologia na gestão de ativos, contexto de projeto e o modelo teórico da pesquisa. O capítulo 3 aborda a metodologia de pesquisa, abrangendo a escolha do método de pesquisa utilizado, os detalhes provenientes da amostra pesquisada, a delimitação de escopo da pesquisa e o protocolo de pesquisa. O capítulo 4 apresenta os estudos de caso propriamente dito, para que se possa compreender os detalhes de cada caso e as informações coletadas baseadas no protocolo de pesquisa. O capítulo 5 abrange a discussão dos dados coletados e faz uma análise crítica baseada na literatura. O capítulo 6 apresenta as conclusões, limitações e sugestões de novas pesquisas. 


\section{TEORIA}

$\mathrm{Na}$ economia do conhecimento, a informação é uma ferramenta que gera vantagem competitiva, as empresas buscam aplicações de tecnologia que sejam fáceis e economizem tempo e custos para as partes interessadas (AWA; UKOHA; IGWE, 2017). De acordo com Campos et al. (2016), as tecnologias de informação e comunicação são importantes facilitadores para a melhoria da tomada de decisões e da geração de conhecimento dentro de uma organização. Empresas que não conseguem acompanhar o desenvolvimento tecnológico podem perder sua vantagem competitiva e a sua capacidade de competir sob as mesmas condições que seus concorrentes, levando à redução de participação de mercado e de lucratividade. Fitzgerald et al. (2013) mencionam que o uso de novas tecnologias digitais (mídias sociais, tecnologias móveis, internet of things (IoT), big data, cloud computing, digital twin) permitem melhorias nas organizações como melhorias nos processos e criação de novos modelos de negócios. Neste contexto, um tema que vem se destacando é a gestão de ativos inteligentes, pelo fato de que as tecnologias embarcadas podem permitir um melhor monitoramento dos ativos e também das operações em que esses ativos são utilizados.

Para indicar os estudos nesta área, a figura 1 ilustra a evolução das publicações relacionadas ao tema ao longo do período entre 1987-2018. A busca foi feita utilizando a expressão $<$ smart asset management $>$ e teve como fonte a base de dados Scopus.

Figura 1 - Evolução das Publicações

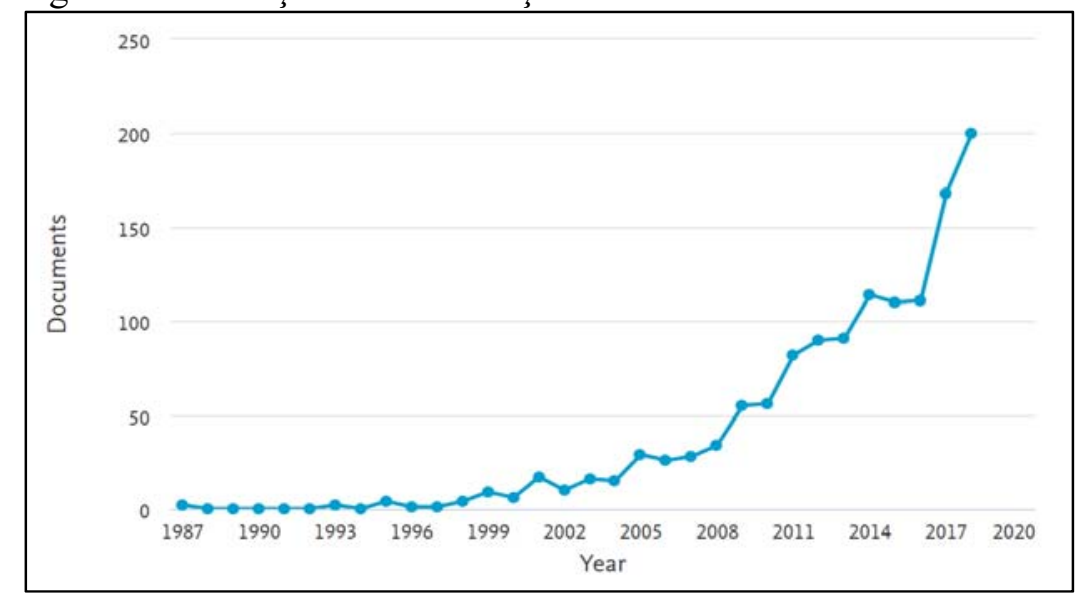

Fonte: Scopus, 2019 
Figura 2 - Tipos de Publicações de 1987 a 2018

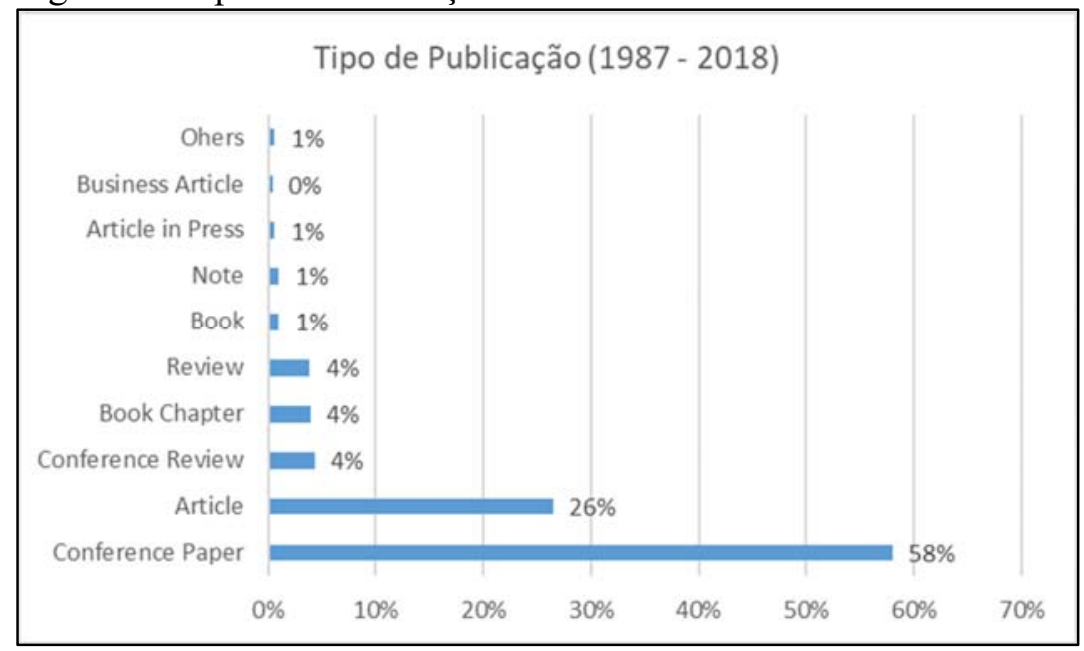

Fonte: Scopus, 2019

O presente capítulo apresenta o embasamento teórico da pesquisa através de uma revisão da literatura sobre os temas: gestão de ativos, assimilação de tecnologia na gestão de ativos, contexto de projeto e o modelo teórico da pesquisa.

\subsection{GESTÃO DE ATIVOS}

Do ponto de vista de infraestrutura, de acordo com o Manual Internacional de Gerenciamento de Infraestrutura (IIMM, 2012), um ativo é definido como "... um componente físico de uma instalação de fabricação, produto ou serviço que tem valor, permite que os serviços sejam prestados e tenham uma vida econômica superior a doze meses". As especificações padrão do British Standards Institute (BSI PAS 55-1; 2004), fornecem uma definição mais focada na empresa, como "... planta, máquina, propriedade, edifícios, veículos e outros itens e sistemas relacionados que possuem uma função ou serviço comercial distinto e quantificável ".

De acordo com o British Standards Institute (BSI PAS 55-1; 2004), a gestão de ativos é definida como "[...] atividades e práticas sistemáticas e coordenadas através das quais uma organização gerencia de forma otimizada seus ativos e os respectivos desempenhos, riscos e despesas associadas ao seu ciclo de vida com o propósito de alcançar seu plano estratégico organizacional ".

O gerenciamento de ativos também é definido como "o conjunto de disciplinas, metodologias, procedimentos e ferramentas derivadas de objetivos comerciais visando a otimização dos custos, desempenho e riscos expostos à disponibilidade, eficiência, qualidade, 
longevidade, regulação, segurança e conformidade ambiental dos ativos de uma organização (WOODHOUSE, 2006).

De acordo com Ouertani, Kumar e Mcfarlane (2008), a gestão de ativos pode ser analisada sobre o ponto de vista da informação e da tomada de decisão. A informação está diretamente ligada ao gerenciamento de dados e ao monitoramento do recurso ao longo do seu ciclo de vida. Os dados estão relacionados a problemas de rastreabilidade e o ponto de tomada de decisão refere-se à realização de diagnósticos e análises que subsidiarão a ação a ser tomada. A gestão de ativos é um processo que dependente de grandes quantidades de dados dos quais informações relevantes podem ser utilizadas para a tomada de decisões durante o ciclo de vida dos ativos (BROUS; JANSSEN; HERDER, 2018).

O gerenciamento de ativos é geralmente entendido como o conjunto de atividades associadas aos objetivos de negócio que buscam identificar quais ativos são necessários; fornecimento de sistemas de apoio logístico e manutenção de ativos; e descarte ou renovação de ativos, de forma a atender com eficácia e eficientemente o objetivo desejado (HASTINGS, 2010).

A figura 3 representa de forma sucinta o processo de gestão de ativos de acordo com o seu ciclo de vida.

Figura 3 - Gestão de Ativos

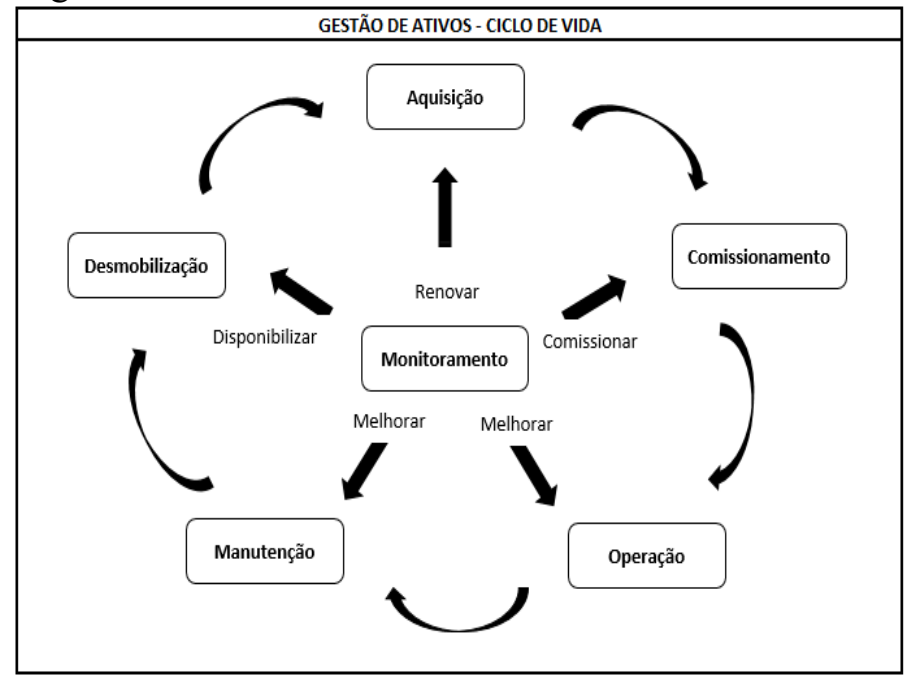

Fonte: Adaptado de Ouertani, Kumar e Mcfarlane, 2008, p. 30

Assumindo uma perspectiva do usuário, o ciclo de vida do ativo pode ser indicado como a sucessão de cinco fases principais: Aquisição: que compreende todas as atividades envolvidas na análise técnica e financeira, justificativa e planejamento para aquisição de novos ativos; 
Comissionamento: que representa as atividades associadas à instalação, teste e comissionamento de ativos; Operação: que consiste em uma fase de muita importância que é o uso e a forma como esse ativo é aplicado para atingir os objetivos; Manutenção: todas as atividades envolvidas na conservação e manutenção mais efetiva da disponibilidade de ativos, longevidade, qualidade e desempenho; Desmobilização: que compreende todas as atividades envolvidas com o descomissionamento, definição de substituição, remanufatura e venda. Todas as fases do ciclo de vida são importantes sobre o ponto de vista de gestão das informações para tomada de ação no contexto da gestão de ativos (OUERTANI; KUMAR; MCFARLANE, 2008).

\subsubsection{Gestão de Ativos Inteligentes}

Conforme Nel e Jooste (2016), o conceito de Gestão de Ativos Inteligentes, que tem sua origem na teoria de Gestão de Ativos, enfatiza a noção de processos orientados tecnologicamente para melhorar a captura e o processamento de informações para auxiliar na tomada de decisões estratégicas. A gestão dos ativos inteligentes pode oferecer uma estrutura para validar e melhorar o desempenho de ativos, coletando e incorporando informações de ativos confiáveis no processo decisório. A maioria das empresas, usa uma variedade de ativos em suas operações, no entanto, as empresas utilizam métodos ineficientes, como inspeções no local uma ou duas vezes por ano, em vez de usar a tecnologia para gerenciar seus ativos (HAN et al., 2018). Os mesmos autores indicaram que a gestão de ativos com tecnologia embarcada permite melhorar a precisão e fornecer informações de posição em tempo real, reduzindo assim a mão de obra, tempo e custo para o trabalho de gerenciamento.

De acordo com Osladil e Kozubík (2015), a gestão de ativos inteligentes está diretamente relacionada a tecnologias emergentes como big data, IOT, etc., a fase analítica dos dados vem representando grandes avanços inclusive com o uso de ferramentas robustas que otimizam os modelos de previsibilidade.

Segundo Hassanain, Froese e Vanier (2003) espera-se que as ferramentas de gestão de ativos forneçam no mínimo as seguintes funcionalidades: identificação de ativos; identificação de requisitos de desempenho; avaliação do desempenho dos ativos; planejamento da manutenção; gerenciamento de operações de manutenção; análise de custos do ciclo de vida; análise do ciclo de vida e previsão de vida útil a longo prazo; e repositório central para informações de ativos. De acordo com Van den Berg e de Best (2006), do ponto de vista tecnológico relacionado a “campos inteligentes", os componentes principais são: confiabilidade 
dos dados; ferramentas para interpretar os dados e transformá-los em informações viáveis; e conselheiros operacionais qualificados que podem usar as informações de acordo com os melhores interesses da organização.

A implementação de tecnologias centradas em dados é um dos principais conceitos para fabricação inteligente. Soluções orientadas para dados contribuem para o desenvolvimento de operações e manutenções de ativos (O’DONOVAN et al., 2015).

A integração de dados orientados por sensores, a computação em nuvem e a mobilidade estão impulsionando uma necessidade dentro da gestão de ativos com a implantação e uso padronizado de uma gama de tecnologias. Muitas organizações de gerenciamento de ativos estão explorando essas tecnologias como uma nova maneira de reunir dados em sistemas de monitoramento (HUA et al., 2014).

De acordo com o Institute of Asset Management, o conceito de Gestão de Ativos Inteligentes (Smart Asset Management - SAM), enfatiza os processos orientados tecnologicamente na gestão de ativos para melhorar a captura e o processamento de informações para sustentar a tomada de decisão. Com o desenvolvimento de ferramentas tecnológicas e análise estatística dos dados, a gestão de ativos requer uma nova abordagem que proporcione o uso de informações de maneira eficaz.

De acordo com Berger (2011), graças à disponibilidade de informação, existe uma ligação clara entre a gestão de desempenho e as ferramentas tecnológicas. Dessa forma, os ativos inteligentes também desempenham um papel importante para o gerenciamento de desempenho (NEELY; GREGORY; PLATTS, 1995).

O gerenciamento de ativos inteligentes, traz uma mudança na gestão de ativos, onde busca-se uma abordagem mais proativa, que coleta informações automaticamente para que estejam disponíveis em um ponto central para processamento. O maior recurso do SAM é, portanto, sua capacidade de interpretar informações de ativos em tempo real, permitindo que decisões de gerenciamento de ativos sejam baseadas em conhecimento diretamente da fonte (NEL; JOOSTE, 2016). De acordo com os mesmos autores, a gestão de ativos inteligentes proporciona uma série de benefícios às empresas, contudo existem implicações de custo relacionadas a hardware, capacidade computacional, licenças de software, alocação de recursos humanos para operar hardware e software e requisitos adicionais de segurança. O impacto desses fatores nas organizações precisa ser investigado para compreender totalmente as implicações da incorporação do SAM. É necessário entender não apenas quais os ativos podem ser automatizados, mas o porquê deve-se buscar essa automatização, para que efetivamente seja possível gerar valor com a gestão de ativos inteligentes. Pollard (1996) mencionou em seus 
estudos que a informação é uma fonte de aprendizado, desde que seja organizada, processada e disponível para as pessoas certas em um formato de tomada de decisão, caso contrário torna-se um fardo, não um benefício.

A integração é outro fator fundamental para todos os sistemas modernos, onde sistemas discretos devem ser integrados a sistemas maiores para permitir soluções que forneçam melhor controle dos dados e um gerenciamento mais eficaz. Para alcançar níveis aceitáveis de integração, é importante usar padrões (EDMONDSON et al., 2018). A sinergia e integração dos ativos permite que eles operem numa rede de ativos, gerando troca de informações entre eles e contribuindo para análise e tomada de ação decorrente das informações geradas por essa rede. Isso cria a impressão de inteligência artificial, onde os ativos podem pensar por si mesmos (LANGEL; LIYANAGE, 2009). A integração dos dados e informações em estruturas de gestão de ativos é um componente fundamental para a tomada de decisões e também no conceito de implementação de SAM (BOULEAU et al., 2008).

Na gestão de ativos inteligentes, os ativos precisam gerar informações essenciais para a tomada de decisões. Estas informações geralmente são obtidas com entradas sensoriais, acumulando informações nas áreas desejadas. O SAM implica ainda no uso de respostas automatizadas, baseadas em recursos digitais, para melhorar o controle de ativos organizacionais, onde um ambiente técnico-organizacional pode ser criado para permitir que a tecnologia ajude a implementar o gerenciamento de desempenho através da intercomunicação entre ativos (LANGEL; LIYANAGE, 2009).

Berger (2010) sugere que a gestão de ativos inteligentes seja uma das tendências mais significativas do novo século, que compreende na transformação de ativos físicos (equipamentos de fábricas, instalações e veículos) em ativos inteligentes.

\subsubsection{Tecnologias digitais na gestão de ativos}

Conforme discutido por Martinez, et al. (2018), as tecnologias digitais não são mais consideradas simples ferramentas, mas atuam como atores ativos na criação de valor. Tecnologias digitais podem ser consideradas como atores que levam a nova proposta de valor (HERTERICH; UEBERNICKEL; BRENNER, 2015). Estudos indicam as novas oportunidades de criação de valor em torno da digitalização, como: automação dos sistemas de manufatura, inteligência de mercado, mitigação de riscos, inovação de serviços (RUMASZEWSKA; HELO; GUNASEKARAN, 2017). 
Dentre as tecnologias presentes na gestão dos ativos, destaca-se a telemetria que consiste em uma tecnologia de monitoramento remoto, que permite o acompanhamento a distância de parâmetros de um sistema qualquer, essa tecnologia está se tornando comum no gerenciamento de frotas (WRÓBEL, 2017). Os dados provenientes da telemetria podem ser armazenados e trabalhados em plataformas, disponibilizando ao gestor do ativo as informações necessárias para a tomada de decisão no que diz respeito a localização e suas condições.

Segundo Ouertani, Kumar e Mcfarlane (2008), muitas soluções de telemetria podem ser geradas com o sistema de identificação por radiofrequências (Radio Frequency Identification RFIDs), que consiste basicamente em uma "etiqueta" que possui um pequeno circuito integrado, memorizado, uma antena a bordo e um leitor que pode interpretar a etiqueta através da antena para recuperar informações contidas na memória da etiqueta. Os sistemas de localização em tempo real (Real-Time Location Systems - RTLS) emergiram como um método alternativo e econômico para rastrear a localização e o status dos ativos. Outro tipo de tecnologia de rádio que pode ser aplicada a comunicações de curto alcance é o ultra wideband (UWB), que é uma técnica de comunicação sem fio com largura de banda igual ou maior que $500 \mathrm{MHz}$, que pode gerar uma localização bidimensional (2D) precisa dos tags, com três ou mais receptores; e localização tridimensional (3D), com quatro ou mais receptores. Em comparação com o GPS e o RFID, os sistemas UWB podem localizar e identificar múltiplos alvos ao mesmo tempo, o que os torna superiores para a aplicação em projetos de construção (YANG, 2013).

O scanner a laser, também conhecido como detecção e alcance a laser (LADAR), vem sendo muito utilizado em projetos de construção e gestão de ativos relacionados a infraestrutura, porque pode capturar dados tridimensionais precisos usando apenas algumas varreduras. Nos últimos anos, as câmeras digitais de alta resolução, as amplas capacidades de armazenamento de dados e a disponibilidade de conexões de Internet permitem capturar e transmitir informações sobre o desempenho dos ativos em escala maciça (GOLPARVAR-FARD et al., 2015).

Os sensores complementam as tecnologias de localização e comunicação e podem ser usados para fornecer informações sobre a condição do ativo, eles permitem medir muitos parâmetros incluindo umidade, temperatura, aceleração, corrente elétrica, pressão, velocidade, etc. Existem diversos tipos de sensores que podem ser conectados através de cabo ou sem fio, analógicos ou digitais com um grau variável de inteligência e capacidade de armazenamento de dados (OUERTANI; KUMAR; MCFARLANE, 2008). Os sensores basicamente transformam uma propriedade física ou fenômenos em um sinal elétrico e, se necessário, o sinal elétrico é convertido para um sinal digital. Os dados provenientes dos sensores podem ser enviados para 
um banco de dados em vários formatos, tais como: estruturado, não estruturado e semiestruturado (ZHANG, 2014). Na gestão de ativos, por exemplo, há uma necessidade de monitoramento das condições através de sensores para manter o equipamento em condições perfeitas, reduzindo o tempo de parada.

A internet das coisas, IOT (internet of things), permite a comunicação de ativos através da internet, onde os sensores embarcados possibilitam o diagnóstico e tomada de decisão em tempo real (ASHTON, 2009). Com o desenvolvimento de sensores, IOT e rede de dados, muitas das variáveis preditivas têm sido monitoradas de forma online nos ativos, gerando assim informações fundamentais para a sua manutenção. A chamada e-maintenance permite a integração de tecnologias como monitoramento eletrônico, diagnóstico e prognóstico em tempo real, o que permite o controle e avaliação a distância em tempo real dos sistemas (MACCHI et al., 2014). A tecnologia de diagnóstico está sendo cada vez mais aprimorada no sentido da análise e saneamento dos dados para que as informações sejam precisas e para que não gerem alarmes falsos (KOTHAMASU; HUANG; VERDUIN, 2006). IoT pode permitir uma gestão de ativos mais eficaz e eficiente, através da análise dos dados, planejamento e ações efetivas de acordo com as necessidades dos usuários (ARCHETTI; GIORDANI; CANDELIERI, 2015). Brous e Janssen (2015), indicam em seu estudo que IoT pode beneficiar organizações de gerenciamento de ativos fornecendo dados de qualidade, gerando as informações necessárias para que os gerentes de ativos possam tomar as decisões certas no momento certo. Brous et al. (2017), demonstram em seu estudo que novas tecnologias como IOT permitem a geração de dados que ajudam a automatizar o processo de gerenciamento de ativos, contudo o nível de adoção dessas tecnologias permanece baixo.

O desenvolvimento de big data destaca-se por sua crescente capacidade tecnológica para capturar, agregar e processar cada vez mais volume, velocidade e variedade de dados. As tecnologias como data mining, learn machine e ferramentas estatísticas são utilizados a muito tempo, porém o que difere o conceito de big data é a quantidade e os tipos de dados que precisam ser processados e analisados. O principal objetivo da mineração de dados e algoritmos de learn machine é transformar dados em conhecimento e encontrar padrões ocultos (AGNELLUTTI, 2014).

A manutenção eletrônica é considerada não apenas nas fases de produção e operação, mas também como parte integrante de toda a gestão do ciclo de vida do ativo. Assim sendo, além das questões de produção, a e-maintenance também deve incluir o design de produto, com atenção ao processo de reciclagem de uma forma que constitua uma ferramenta útil para a 
melhoria dos processos no contexto do gerenciamento do ciclo de vida de manutenção (IUNG et al., 2009).

A importância da adoção da tecnologia de informação e comunicação móvel na manutenção é destacada pelo fato de que a manutenção eletrônica desencadeou uma mudança radical nas práticas de campo. Avanços nas tecnologias sem fio e disponibilidade de serviços de baixo custo e dispositivos móveis fáceis de usar, permitem que isso se torne realidade por meio de sistemas acessíveis (CAMPOS et al., 2016).

As tecnologias eletrônicas integradas a novos produtos de manutenção, tais como monitoramento eletrônico, diagnóstico eletrônico e prognóstico eletrônico, permitirão o controle e avaliação em tempo real do desempenho do sistema. (HOLMBERG et al., 2010).

Atualmente, mesmo grandes empresas de manufatura não usam sensores para medir indicadores de degradação de equipamentos ou, mesmo se o fizerem, não desenvolveram uma estratégia completa de manutenção baseada nas condições (CBM) para utilizar seus benefícios. No entanto, a CBM está se tornando essencial para todos os negócios de manufatura, à medida que os produtos se tornam mais complexos, a qualidade e confiabilidade tornaram-se questões de alta significância (PENG; DONG; ZUO, 2010). Os custos de manutenção preventiva baseada no tempo aumentaram e a CBM começou a evoluir como uma nova alavanca para gestão de manutenção. Diversas estruturas de manutenção têm sido propostas na literatura descrevendo as etapas envolvidas na CBM (LEE et al., 2006). Jardine, Lin e Banjevic (2006) descrevem três etapas principais: primeiro, aquisição de dados para coletar os dados; segundo, processamento de dados para manipular os dados; e terceiro, tomada de decisão de manutenção para decidir sobre a política de manutenção ideal.

Peng, Dong e Zuo (2010) descreveram em detalhes uma estrutura de suporte à decisão de manutenção composto por cinco etapas principais: primeiro, a seleção de recursos, que é realizada com o auxílio de dados históricos, como análise de componentes principais, algoritmos e máquina de suporte de vetores (SVM); segundo, treinamento de dados (análise); terceiro, diagnósticos e prognósticos, usando dados em tempo real; quarto, confiabilidade e vida útil remanescente (RUL), onde o resultado é verificado e sua precisão é avaliada para dar feedback aos passos segundo e quinto; e quinto, cronograma de manutenção, que considera a função custo que é extraído da relação entre o custo de manutenção, RUL e confiabilidade do sistema.

A manutenção eletrônica e-maintenance refere-se à convergência de tecnologias emergentes de informação e comunicação, que levam em conta os recursos, serviços e 
gerenciamento para permitir a tomada de decisões de forma proativa e está diretamente ligada a gestão de ativos inteligentes (MULLER; MARQUEZ; IUNG, 2008).

Em complemento às tecnologias emergentes, a simulação também se caracteriza como uma ferramenta relevante para a previsão dos processos que ocorrem no mundo físico (NEGRI, FUMAGALLI; MACCHI, 2017). A digitalização ou réplica digital, também chamado de “digital twin”, tem papel importante na gestão de ativos, pois permite simular o ciclo de vida do ativo de forma a possibilitar a análise das fases da vida e respectivas interferências, facilitando assim a tomada de decisão (MACCHI et al., 2018). Em particular, objetos conectados inteligentes, que fazem parte do Digital Twin, permitem que os fabricantes efetuem a coleta e exploração de dados desenvolvendo novos serviços e melhorando as suas relações com clientes.

Os sistemas de transporte autônomo, que utilizam sistema de navegação GPS de alta precisão, radar de ondas milimétricas e tecnologia de giroscópio de fibra óptica para controlar equipamentos não tripulados representam um grande avanço tecnológico e as empresas precisam se preparar para assimilar esse tipo de tecnologia (SAMAD; SEPASGOZAR; DAVIS, 2018).

\subsubsection{Análise de dados para tomada de decisão}

A análise de dados produzidos por uma empresa é de extrema importância para tomada de decisão, especialmente na gestão de ativos, onde a manutenção preventiva e preditiva é aplicada e um grande volume de dados é produzido. O uso efetivo dos dados oferece vantagens, como aumento da eficiência organizacional, melhor qualidade de serviço, identificação e desenvolvimento de novos produtos e serviços (MANYIKA et. al., 2012).

No entanto, as empresas atualmente armazenam esses dados e não investem na análise para tomada de decisão (CAMPOS et al., 2017). Não é fácil rastrear as relações de causa e efeito no gerenciamento de dados, pois existem aspectos técnicos e sociológicos (BROUS; PAULIEN; JANSSEN, 2015).

Big data analytics, através de ferramentas de análise inteligente, promete garantir a tomada de decisão rápida (YANG, 2013). De acordo com Campos et al. (2017), o uso de big data na gestão de ativos pode ser resumido em três fases, sendo a primeira responsável pela coleta, armazenamento, compreensão e organização dos dados; a segunda fase se caracteriza pela análise dos dados através de ferramentas sofisticadas de análise e mineração de dados, fornecendo diagnósticos e prognósticos decorrentes de big data; a terceira fase é responsável 
por fazer a conexão com os usuários finais, essa fase apresenta resultados analíticos e gráficos de tendência para facilitar a tomada de decisão. Essa estrutura pode ser representada pela figura 4.

Figura 4 - Uso de big data na gestão de ativos

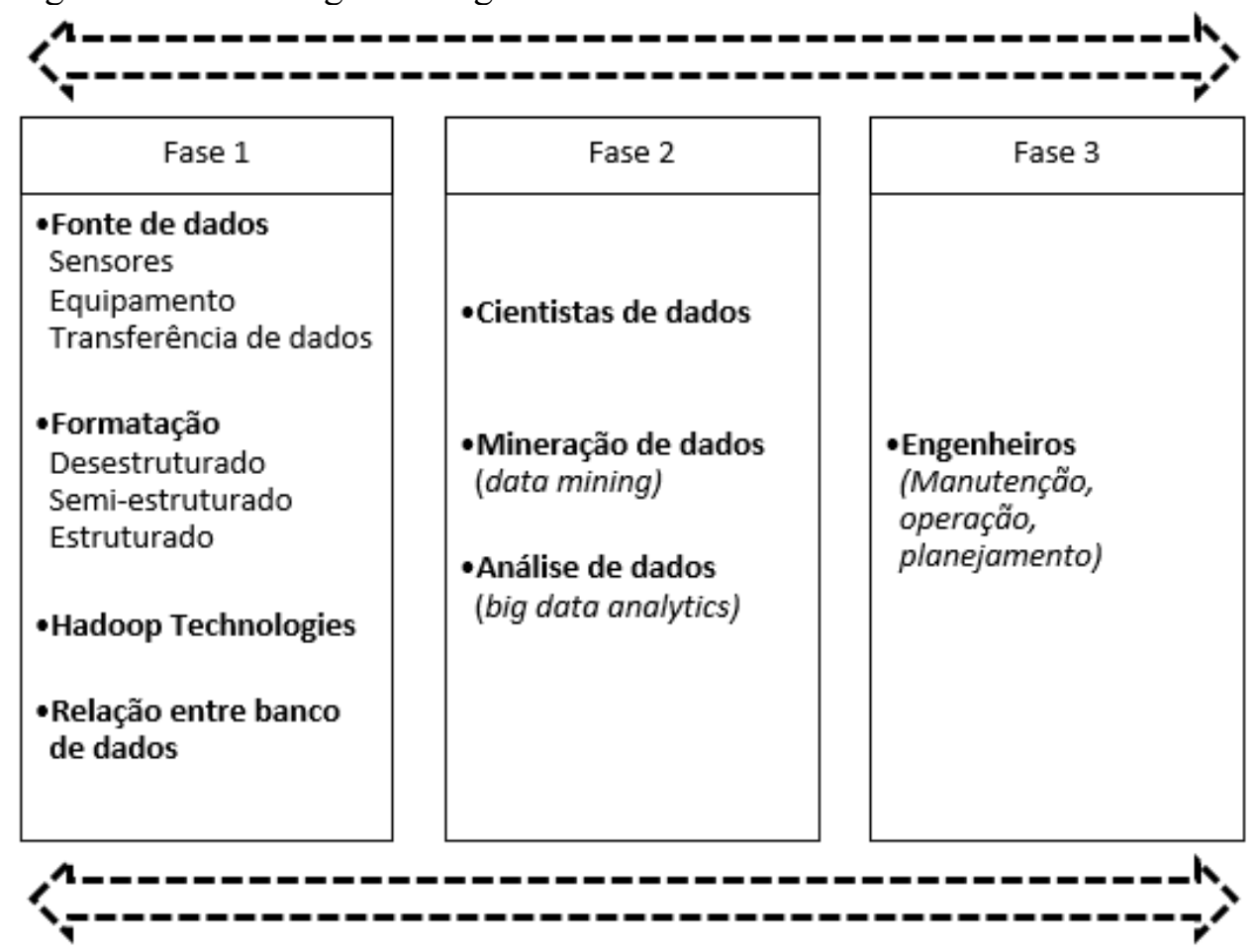

Fonte: Adaptado de Campos et al., 2017, p. 371

A análise de dados pode ser compreendida como uma série contínua em que os dados são transformados em informações e posteriormente em conhecimento. (MANDINACH, 2012). O estudo desenvolvido por Brynjolfsson, Hitt e Kim (2011), demonstrou de forma conclusiva que a tomada de decisão baseada em dados representa um aumento de produtividade e maior retorno sobre o ativo. Isso destaca o fato de que, cada vez mais, as decisões de negócios estão baseadas em sistemas informatizados. Apesar de todo o avanço e investimento em big data, o seu resultado pode ser inútil, até mesmo prejudicial, a menos que os funcionários possam incorporar esses dados na tomada de decisão (SHAH; HOME; CAPELLA, 2012). De forma a vencer esse desafio, pesquisas estão sendo desenvolvidas na área de interpretação de dados e tomada de ação autônoma.

De acordo com Roda e Macchi (2016), a tomada de decisão na gestão de ativos deve ser pautada na análise do ciclo de vida do ativo, na sua interdependência, sua relevância, sua análise de risco e seu histórico. Ressaltam ainda a importância de assegurar que as decisões e 
comunicações devam transcender todas as camadas da empresa (nível estratégico, tático e operacional). De forma complementar, os autores Brous, Marijn e Paulien (2018) argumentam que o gerenciamento de ativos consiste em um processo empresarial altamente dependente do alto volume de dados, a partir dos quais informações relevantes podem ser obtidas e usadas para a tomada de decisão durante o ciclo de vida dos ativos. Dessa forma, destaca-se a importância da assimilação de tecnologia em todo o processo de gestão de ativos.

\subsection{ASSIMILAÇÃO DE TECNOLOGIA}

Segundo Mu, Kirsch e Butler (2015) assimilar tecnologias corporativas requer ampla adaptação, tanto da tecnologia e da organização. Uma parcela significativa das empresas não consegue atender a essa adaptação mencionada anteriormente e, portanto, muitos dos benefícios não são alcançados com a adoção de diferentes sistemas corporativos como discutido por Carr (2005). Existem vários estudos e teorias sobre inovação tecnológica e assimilação de tecnologia. Segundo Hoti (2015), as teorias mais estudadas são Technology Acceptance Model (TAM) (DAVIS 1986; DAVIS et al., 1989), Theory of Planned Behavior (TPB) (AJZEN, 1985; AJZEN, 1991), Unified Theory of Acceptance and Use of Technology (UTAUT) (VENKATESH et al., 2003), Diffusion of Innovation (DOI) (ROGERS, 1995) e a TechnologyOrganization-Environment (TOE) framework (TORNATZKY; FLEISCHER, 1990). Segundo o mesmo autor, a teoria defendida por Tornatzky e Fleischer (TOE) permite analisar de forma mais holística a assimilação de tecnologia nas empresas. Segundo Aboelmaged (2014), muitos autores já utilizaram o conceito TOE para estudar e entender a implantação de tecnologias nas empresas. Enquanto os modelos TAM, TPB e UTAUT estão no nível do indivíduo, os modelos DOI e TOE estão no nível empresarial (OLIVEIRA; MARTINS, 2011).

Vale mencionar que além das teorias citadas acima, ainda é possível encontrar na literatura outras teorias que abordam a assimilação e aceitação de tecnologia.

As características dos principais modelos e teorias relacionadas a assimilação de tecnologia com destaque a TOE - Technology-Organization-Environment e a TAM Technology Acceptance Model, utilizadas como base para essa pesquisa, estão discutidas a seguir: 


\subsubsection{Theory of Planned Behavior (TPB)}

O modelo TPB desenvolvido por Ajzen (1985), indica que o comportamento real de uma pessoa ao executar uma determinada ação é diretamente influenciado por sua intenção comportamental e determinada por três tipos de crença sobre o comportamento: atitude, norma subjetiva, e o controle comportamental percebido (PBC).

A intenção comportamental é uma indicação da força de vontade de uma pessoa para tentar realizar um determinado comportamento. Atitude é definida como o grau em que uma pessoa faz uma avaliação favorável ou desfavorável sobre o comportamento em questão. A norma subjetiva denota a pressão organizacional ou social percebida para realizar ou não o comportamento em questão. O terceiro antecedente da intenção comportamental é o grau de PBC, refletindo a percepção de uma pessoa da facilidade ou dificuldade de realizar o comportamento, que é assumida a considerar a experiência passada e os obstáculos esperados.

Estudos de adoção de tecnologia têm usado o TPB como um modelo teórico básico, além disso esse modelo foi amplamente estudado com diversas aplicações e influenciou a formação do modelo de aceitação de tecnologia (TAM) (CURRAS-PEREZ et al., 2014).

\subsubsection{Technology Acceptance Model (TAM)}

O modelo TAM desenvolvido por Davis (1985) e depois aprimorado por Venkatesh e Davis (2000) denominado TAM 2 apresenta três características principais que afetam a aceitação de tecnologia, sendo elas: Facilidade de uso percebida; Utilidade percebida e Intenção comportamental.

Conhecendo a importância da tecnologia no contexto das empresas, é de fundamental relevância analisarmos os fatores que afetam a sua aceitação por parte do indivíduo, esses fatores quando bem trabalhados podem potencializar os resultados advindos da tecnologia. Em 1985, Fred Davis propôs um modelo conceitual para aceitação da tecnologia denominado TAM (Technology acceptance model). Segundo Marangunié e Granié (2014), o modelo emergiu da pesquisa de teorias no campo da psicologia (TRA - teoria da ação racional e TPB - teoria do planejamento comportamental) e evoluiu para compreender fatores do comportamento humano em direção ao potencial de aceitação ou rejeição da tecnologia, o modelo presume um papel mediador de duas variáveis chamadas facilidade de uso percebida e utilidade percebida em uma relação complexa entre características do sistema (variáveis externas) e o uso potencial do sistema. 
O modelo TAM passou por atualizações no decorrer do tempo, primeiramente foi acrescida a variável atitude em relação ao uso, essa variável posteriormente foi substituída pela variável intenção comportamental. O modelo continuou a ser aprimorado por outros pesquisadores e se tornou popular, sendo citado na maioria das pesquisas relacionadas a aceitação de tecnologia (LEE et al., 2006). Venkatesh e Davis (2000) propuseram uma extensão do modelo denominado TAM 2, eles indicaram variáveis externas que influenciam a utilidade percebida, como: norma subjetiva: a influência dos outros sobre a decisão de usar ou não a tecnologia; imagem: o desejo do usuário de manter um ambiente favorável entre outros; relevância no trabalho: o grau em que a tecnologia foi aplicável; qualidade de saída: a medida em que a tecnologia executou adequadamente as tarefas requeridas; e demonstrabilidade do resultado: a produção de resultados. Além disso, a experiência e a voluntariedade foram incluídas como fatores moderadores da norma subjetiva

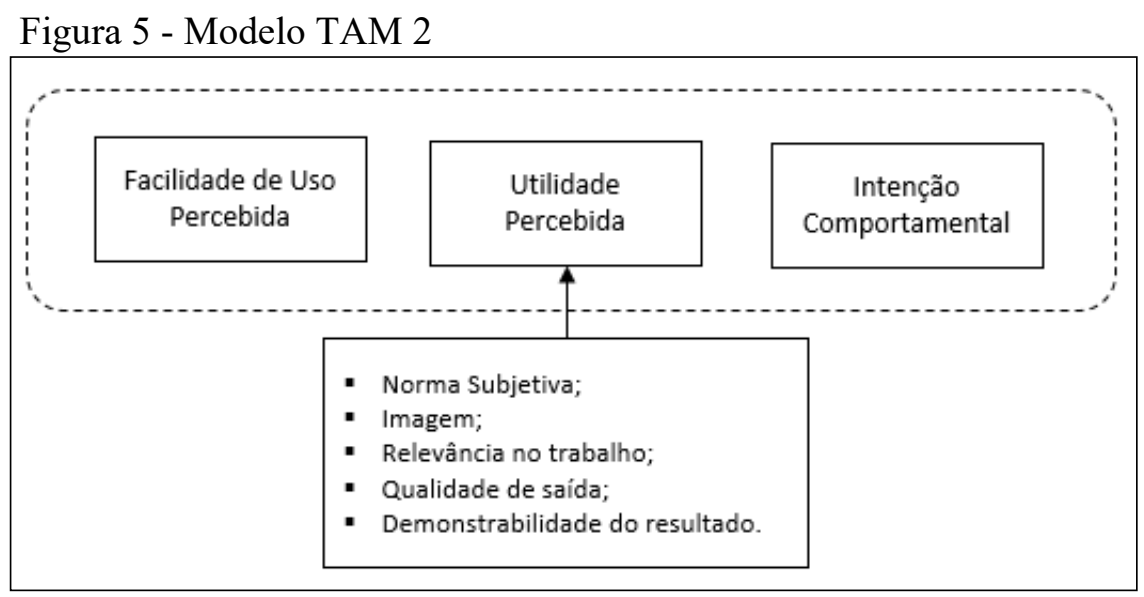

Fonte: Adaptado Venkatesh e Davis, 2000, p. 188

De acordo com Oliveira e Martins (2011), o modelo TAM é útil para entender por que indivíduos aceitam tecnologias.

\subsubsection{Unified Theory of Acceptance and Use of Technology (UTAUT)}

Venkatesh et al. (2003) propuseram a UTAUT depois de comparar, testar e integrar os principais influenciadores dos modelos e teorias relacionadas a adoção e uso de tecnologia. Dentre as teorias utilizadas para compor a UTAUT, pode-se citar: o Modelo de Aceitação de Tecnologia (TAM); a Teoria da Ação Racional (TRA); a Teoria do Comportamento Planejado (TPB); Teoria da Difusão da Inovação (IDT); o Modelo de Utilização de PC (MPCU). 
O modelo UTAUT consiste em quatro estruturas principais (expectativa de desempenho, expectativa de esforço, influência social e condições facilitadoras) e também quatro moderadores (gênero, idade, experiência e voluntariedade). No entanto, Venkatesh, Thong e Xu (2012) propuseram a UTAUT2 estendendo a UTAUT original com três fatores adicionais: preço, motivação hedônica e hábito.

Assim como os demais modelos apresentados até o momento a UTAUT também possui uma abordagem voltada para o indivíduo e não para empresa.

\subsubsection{Diffusion of Innovation (DOI)}

O processo de inovação nas organizações é complexo, com base na teoria diffusion of innovation - DOI, desenvolvida por Rogers (1995), no nível empresarial, a inovação é relativa a variáveis independentes como características individuais, características estruturais organizacionais internas e externas. Uma característica individual descreve a atitude líder para a mudança, como características internas da estrutura organizacional, temos: a centralização, formalização, interconexão, folga organizacional e tamanho; as características externas da organização refere-se principalmente a abertura do sistema. Os indivíduos são vistos como possuindo diferentes graus de disponibilidade para adotar inovações, e, portanto, observa-se geralmente que a parcela da população que adota uma inovação é aproximadamente normalmente distribuída ao longo do tempo. Quebrar essa distribuição normal em segmentos leva à segregação dos indivíduos em cinco categorias de inovação: inovadores, usuário iniciais, maioria inicial, maioria atrasada, retardatários (ROGERS, 1995).

A teoria aborda o nível individual e empresarial, de forma a buscar o entendimento de como, porquê e qual a taxa de novas ideias e disseminação de tecnologia. O DOI vê inovações como sendo comunicada através de certos canais ao longo do tempo e dentro de um sistema social (ROGERS, 1995).

O modelo DOI é reconhecido por muitos pesquisadores por suas características de inovações tecnológicas que podem influenciar a atitude de potenciais adaptadores ou rejeitadores da inovação (HOTI, 2015). Segundo o mesmo autor, o modelo DOI também deve ser complementado com outros contextos ou fatores para uma abordagem mais holística, dessa forma, a estrutura TOE, por incluir o contexto ambiente (não incluído na teoria DOI), torna-se mais capaz de explicar a adoção de tecnologia no nível empresarial (HOTI, 2015). 


\subsubsection{Technology-Organization-Environment (TOE)}

Para analisar o contexto nas empresas que afetam a implementação de inovações, Tornatzky e Fleischer (1990) desenvolveram o conceito "TOE” que é baseado nos contextos tecnológico, organizacional e ambiental. A tecnologia deve ser confiável e deve garantir a melhoria do resultado. $\mathrm{O}$ contexto da organização pode trazer alguns fatores que favorecem ou não a inovação, dentre eles o tamanho da empresa, a qualidade na gestão de recursos humanos, a estrutura organizacional, estrutura de comunicação entre outros. O conceito TOE assume que o processo de inovação nas empresas é estabelecido através da correta combinação entre fatores internos e externos (ARPACI et al., 2012).

A teoria DOI, em que Rogers (1995) enfatizou características individuais, e ambas as características internas e externas da organização, como drivers para a inovação organizacional, possui os mesmos conceitos do modelo TOE no que se refere a tecnologia e organização, mas o TOE também inclui um importante componente, o contexto ambiente. O contexto ambiente apresenta ambos os desafios e oportunidades para a inovação tecnológica. Dessa forma o modelo TOE é mais capaz de explicar a difusão da inovação nas empresas (HSU; KRAEMER; DUNKLE, 2006).

Oliveira e Martins (2011), indicam que o framework TOE fornece uma estrutura analítica útil para o estudo da adoção e assimilação de diferentes tipos de inovação de TI. Os autores reforçam o amplo uso dessa teoria em estudos anteriores, contudo ainda existem lacunas de pesquisas uma vez que os fatores específicos identificados nos três contextos (tecnológico, organizacional e ambiental) podem variar de acordo com o contexto.

\subsubsection{Contexto Tecnológico}

O contexto tecnológico considera as tecnologias disponíveis e importantes para a empresa, tanto interna quanto externa, que pode ser útil na melhoria da produtividade organizacional. Zhu, Kraemer e Xu (2003) em seu trabalho com relação ao contexto tecnológico, aponta algumas características de segunda ordem: infraestrutura de TI, habilidades de internet e consciência; segundo o autor, as três variáveis de primeira ordem no contexto tecnológico são: questões de segurança; confiabilidade; e capacidade.

Nambisan e Wang (1999) indicam que no contexto tecnológico, a segurança é definida tanto como a percepção, ou julgamento, e medo de salvaguardar mecanismos para a movimentação e armazenagem de informações através de bases de dados e meios de 
transmissão. Joshi, Singh e Phippen (2004) assinalaram a segurança como um grande obstáculo para a adoção de tecnologias de serviços na web. As organizações são dependentes de seus sistemas de informação para as operações do dia-a-dia, além de armazenarem informações muitas vezes confidenciais sobre o seu negócio. Comprometer a segurança desses sistemas pode ser muito caro para a organização.

A confiabilidade é outro fator fundamental de uma tecnologia, Lippert (2001) sugeriu que a confiabilidade percebida de uma inovação tecnológica tem um efeito profundo sobre a sua adoção. A confiança sobre a solução implantada é uma característica complexa e difícil de mensurar, embora sua importância na tomada de decisão baseada em dados seja amplamente reconhecida (SICARI et al., 2015). Dados confiáveis são considerados essenciais para o processo de tomada de decisão na gestão de ativo (HAIDER; KORONIOS; QUIRCHMAYR, 2006).

No contexto tecnológico, o benefício direto percebido e benefício indireto percebido são fatores importantes para assimilação, o benefício percebido refere-se ao nível de reconhecimento de vantagem que uma tecnologia pode fornecer para a organização (ROGERS, 2010). De acordo com Kuan e Chau (2001) benefícios diretos referem-se a benefícios operacionais, ou seja, melhorias feitas para o funcionamento interno da organização, influenciando diretamente na eficiência dos processos, reduzindo tempo, custos do processo, etc. Benefícios indiretos referem-se a benefícios estratégicos, que visam melhorar a vantagem competitiva, a imagem, o posicionamento no mercado, o relacionamento com clientes e parceiros. A assimilação de tecnologia também é influenciada pelos benefícios percebidos relacionados a redução de custo atribuída ao uso da tecnologia (CHAN; CHONG, 2013)

O contexto tecnológico é sem dúvida um dos fatores mais relevantes para assimilação de tecnologia nas empresas. As tecnologias tendem a facilitar os processos, garantir segurança, confiabilidade e rapidez, tornando as empresas e os processos mais produtivos (TORNATZKY; FLEISCHER, 1990).

Kuan e Chau (2001) indicam que as decisões de adoção de tecnologia em uma empresa dependem não apenas das características da tecnologia, como também é essencial examinar os fatores em termos de contextos interorganizacionais e ambientais.

\subsubsection{Contexto Organizacional}

De acordo com Tornatzky e Fleischer (1990), o contexto organizacional refere-se às características da empresa e pode ser representado pelo escopo da empresa, o seu tamanho, a 
centralização, formalização, complexidade, qualidade, disponibilidade de recursos humanos etc., esses são fatores chaves para garantir a assimilação efetiva de uma tecnologia.

As grandes empresas têm mais recursos, maiores economias de escala, e podem assumir riscos maiores associados à adoção de inovação. No entanto, as pequenas empresas são mais ágeis e flexíveis do que as grandes empresas (ZHU; KRAEMER; XU, 2003).

Dentre os fatores organizacionais a capacidade de mensurar os ganhos oriundos da inovação tecnológica é de fundamental importância para assimilação de tecnologia (IACOVOU; BENBASAT; DEXTER, 1995). As medidas de desempenho das empresas, historicamente, focam em indicadores financeiros, tais como receita de venda ou retorno sobre o investimento. Muitos pesquisadores, portanto, sugerem a necessidade do uso de medidas não financeiras, em especial, os indicadores com base no consumidor, embora tenha havido pouco consenso sobre exatamente que medida usar (CHAN, 2000). Wua e Chen (2014) demonstram em seu estudo o efeito time-lag do processo de medição de desempenho em investimentos em TI, os autores avaliam os resultados nas quatro dimensões do Balance Score Card (BSC), demonstrando a importância da correta avaliação do investimento e o reflexo da implantação no processo de difusão da tecnologia. Para que qualquer tecnologia seja bem-sucedida, o usuário final precisa perceber que ela é benéfica. (HUANG; TSENG, 2015).

Wright (2017), também indica que é extremamente crítico para as empresas mensurarem a vantagem competitiva que as novas tecnologias oferecem em relação às tecnologias existentes.

De acordo com os estudos de Dal-woo et al. (2015), a capacidade financeira e tecnológica de uma empresa são aspectos organizacionais importantes para assimilação de tecnologia. As empresas observam criticamente o ambiente e estimam o tempo mais adequado para investir em uma tecnologia específica. Portanto, a adoção de tecnologia é baseada em informações e decisões individuais e organizacionais para primeiro aceitar e utilizar, e posteriormente gerar informações para a solução de problemas (MUSAWA; WAHAB, 2012).

De acordo com Sila (2013), o comprometimento da alta gerência e o apoio à inovação são particularmente importantes durante a fase de implementação, quando a coordenação entre as divisões organizacionais e a resolução de conflitos é crítica. A má comunicação, sobre os benefícios estratégicos decorrentes do uso de novas tecnologias, entre a alta gerência e os funcionários, é um fator que prejudica a assimilação de tecnologia (KNIGHT, 2015). De fato, a alta administração de uma empresa é significativa para a adoção de qualquer inovação tecnológica, e cabe a ela apoiar com os recursos necessários (OLIVEIRA; THOMAS; ESPADANAL, 2014). 


\subsubsection{Contexto Ambiente}

O contexto ambiental representa como as empresas são influenciadas pelo mercado, os seus concorrentes, a capacidade da empresa para acessar os recursos fornecidos por outros, exigência dos clientes e interações com o governo.

Porter e Millar (1985) analisaram a estratégia sobre a pressão competitiva como um direcionador de adoção de TI, eles sugeriram que, ao adotar sistemas de informação, as empresas podem ser capazes de alterar as regras de concorrência, afetar a sua estrutura, e alavancar novas maneiras de superar os seus concorrentes, mudando assim o ambiente competitivo. Mercados competitivos favorecem a adoção de novas tecnologias, uma vez que as empresas buscam inovações tecnológicas para reduzir seus custos, dessa forma a implementação bem-sucedida de inovações tecnológicas em uma organização também depende da relação mútua entre as características inovadoras predominantes nas empresas do setor (ZHU; KRAEMER; XU, 2006).

$\mathrm{Xu}$, Zhu e Gibbs (2004) afirmam que os governos podem incentivar a adoção, especificamente adopção dos negócios, através do desenvolvimento de leis comerciais e fiscais que são benéficas para a organização. Delmas (2002) sugeriu que, se as agências reguladoras exigem a adoção de normas especializadas, as empresas podem experimentar maiores custos de transação, a fim de cumprir o objetivo necessário. Zhu, Kraemer e Xu, (2003), notam que durante a coleta de dados e análise das razões sobre a não adoção de tecnologia, muitas vezes foi percebido que as organizações parceiras foram responsáveis.

Segundo Mu, Kirsch e Butler (2015), a teoria defendida por Tornatzky e Fleischer (TOE) permite analisar de forma mais holística a assimilação de tecnologia nas empresas. Por considerar o contexto ambiente (não incluído na teoria DOI), esse modelo torna-se capaz de explicar a adoção de inovação na empresa (OLIVEIRA; MARTINS, 2011). Portanto o modelo TOE foi utilizado como base para avaliar a assimilação de tecnologia no contexto de gerenciamento de ativos inteligentes.

\subsection{ASSIMILAÇÃO DE TECNOLOGIA DIGITAL NA GESTÃO DOS ATIVOS}

Na pesquisa sobre a adoção e uso da Tecnologia da Informação e Comunicação (TIC), pouca distinção é feita entre o uso da tecnologia em organizações permanentes e seu uso em organizações temporárias, por exemplo, em projetos de construção (JACOBSSON; LINDEROTH, 2010). A construção civil apresenta características únicas que a diferenciam de 
outras indústrias, esse segmento é caracterizado por projetos dinâmicos, com número elevado de mão-de-obra, com alterações de escopo durante a sua implantação, entre outros fatores que o diferenciam. Além disso, durante o ciclo de vida do projeto, alto volume de documentos com dados relevantes é produzido e trocado. Esses dados têm formatos diversos e são armazenados em diferentes bancos de dados (DBs) e aplicativos (mesmo em papel). Frente à estas características, a adoção de novas tecnologias, torna-se relevante e necessária, e também bastante desafiadora, pois não é a presença da tecnologia que irá garantir melhores resultados aos projetos, mas sim a forma como ela está sendo utilizada. (MARTÍNEZ-ROJAS; MARÍN; VILA, 2015).

Jacobsson e Linderoth (2010) desenvolveram um estudo destacando esta distinção, buscando entender como a interação entre elementos contextuais, estruturas, atores e a própria tecnologia influencia a adoção e o uso de tecnologia em um projeto de construção. Os autores destacam em sua pesquisa que se não houver a percepção imediata dos benefícios a partir da adoção e uso, a tecnologia não será assimilada.

Brous, Marijn e Paulien (2018) demonstram em seu estudo que a gestão de ativos requer uma mudança na cultura para adoção de novas tecnologias, os processos de decisão estão sendo alterados para lidar em tempo real com os dados provenientes dos ativos e os gerentes precisam se adaptar e desenvolver novas habilidades e capacidades para poder interpretar os dados.

Samad, Sepasgozar e Davis (2018) desenvolveram um estudo para o entendimento das possíveis metodologias para a adoção de tecnologia digital em projetos, investigando como os clientes tomam decisões para adotar a tecnologia e como os fornecedores as apoiam nesse processo de decisão. Lacunas significativas e claras no entendimento da adoção de tecnologia de construção no nível organizacional foram identificadas, particularmente no que diz respeito ao envolvimento do fornecedor no processo. $\mathrm{O}$ estudo analisou como a indústria segue processos de decisão específicos ligados ao processo de pré-adoção para investigação e o processo de pós-adoção para implementação.

Avaliar a disponibilidade de uma empresa para adotar inovações é um pré-requisito essencial para evoluir e acompanhar as demandas do mercado no ambiente volátil de hoje (ABOELMAGED, 2014). O estudo desenvolvido pelo mesmo autor, avalia o conceito de adoção de tecnologia no contexto de e-maintenance, levando em consideração o framework TOE. O estudo aborda uma parcela importante da gestão de ativos que é a manutenção e confirma os fatores que afetam a assimilação de tecnologia neste ambiente. A estrutura do TOE foi examinada em diferentes disciplinas e contextos para provar sua força teórica, suporte 
empírico e utilidade na adoção e implementação de várias formas de inovações (ABOELMAGED, 2014).

Atualmente, as organizações estão experimentando novas fontes de dados e há uma expectativa geral de que a IoT ofereça um valor agregado significativo para a tomada de decisões sobre a gestão dos ativos. As organizações podem adotar de forma efetiva e sustentável essas novas fontes de dados em seus processos de tomada de decisão se os dados que são medidos puderem monitorar os fatores importantes do próprio ativo. A adoção da IoT requer uma infraestrutura de TI que possa facilitar as novas fontes de dados e requer um bom entendimento dos dados coletados e de seus aspectos de qualidade. A adoção da IoT requer o gerenciamento adequado dos dados para garantir a conformidade com leis e regulamentos. A governança de dados é necessária para garantir que a IoT possa fornecer dados confiáveis para a tomada de decisões na gestão dos ativos. (BROUS et al., 2017).

A tecnologia e a organização influenciam de muitas maneiras, e os esforços analíticos para tratá-los como unidades conceituais distintas estão sendo cada vez mais questionados (BOOS et al., 2013). Assim, é importante entender como a adoção de IoT afeta a tomada de decisões em processos de negócios de gerenciamento de ativos, afim de obter os benefícios esperados e mitigar riscos e incertezas (BROUS; JANSSEN; PAULIEN, 2018).

\subsubsection{Contexto de projeto}

De acordo com o guia PMBOK®, PMI (2008), a definição de projeto pode ser sintetizada como um esforço temporário empreendido para criar um produto, serviço ou resultado exclusivo, possuindo uma data de início e de término. O PMI (2008) desdobra o gerenciamento de projetos na integração e aplicação de 39 processos que são agrupados em 5 grupos, sendo: (1) Iniciação; (2) Planejamento; (3) Execução; (4) Monitoramento e controle; e (5) Encerramento.

A NBR ISO 10006, que aborda as diretrizes para qualidade de gerenciamento de projetos, define projeto como um processo único, consistindo em um grupo de atividades coordenadas e controladas com data de início e fim, com o intuito de alcançar um objetivo específico, sendo necessário para tal a inclusão das limitações de tempo, custo e recursos envolvidos (XAVIER, 2009).

A presente pesquisa avalia a assimilação de tecnologia na gestão de ativos no contexto de projetos, especificamente grandes projetos de construção voltados para infraestrutura, que também são classificados como projetos complexos devido ao tamanho e a quantidade de 
interferências que afetam o seu resultado (HU et al., 2015). Os projetos de infraestrutura são frequentemente executados com foco no controle, com o planejamento e monitoramento rigorosos, e com o objetivo de minimizar as mudanças (GIEZEN, 2012). Contudo, grandes projetos de infraestrutura convivem com mudanças decorrentes de clima, de geologia, alterações de escopo e requisitos do cliente (ERIKSSON; LEIRINGER; SZENTES, 2017). Pesquisas recentes sobre megaprojetos no setor de infraestrutura indicam a necessidade de adotar uma abordagem de gerenciamento de projetos mais flexível de forma a gerenciar as mudanças em vez de evitá-las (KOPPENJAN et al., 2011). Karrbom e Hallin (2014) reforçam o conceito que aponta para uma abordagem focada na flexibilidade, também conhecido como gerenciamento de projetos "soft" para o gerenciamento de projetos complexos.

A inovação pode reduzir a duração e melhorar o desempenho de projetos de construção (OZORHON et al., 2016). No entanto, é necessário avaliar os riscos com a adaptação em projetos complexos, pois as reações em cadeia de redesenho podem se propagar através dos subsistemas com potenciais danosos (GIL; MIOZZO; MASSINI, 2012). Da mesma forma, pesquisas anteriores indicam que os benefícios decorrentes de investimentos em tecnologia em projetos não podem ser avaliados isoladamente, a avaliação deve associar seus efeitos diretos e indiretos em vários processos de trabalho conectados, desde o planejamento até a operação e manutenção (SANKARAN et al., 2016).

De acordo com O'Brien et al. (2016), as tecnologias associadas a projetos de construção civil podem ser agrupadas em três categorias principais: ferramentas avançadas de sensoriamento para levantamento e coleta de dados, modelagem n-dimensional e ferramentas de simulação para projeto e construção digital e ferramentas de gerenciamento de dados para gerenciamento de fluxo de trabalho digital.

Os avanços tecnológicos nos softwares de projeto, sensores em equipamentos e sistemas de posicionamento estão permitindo que as partes interessadas usem informações digitais para a entrega de projetos e para o gerenciamento de ativos (HANNON, 2007).

Thomas et al. (2004) através de análise estatística indicou a associação positiva entre as tecnologias da informação no projeto, o seu custo e a economia no cronograma. De acordo com os estudos de O'Connor e Yang (2004) o uso da tecnologia nos níveis de projeto proporcionam maiores benefícios relacionados ao cronograma do projeto. Ao apresentar uma análise de custobenefício para o projeto 3D, Parve (2015) observou que os investimentos tangíveis em infraestrutura tecnológica foram compensados pela economia no número reduzido de solicitações de informações e requisições de mudança no decorrer do projeto. 
Sankaran e O’Brien (2018), indicam que projetos complexos, com orçamentos maiores, são capazes de absorver os custos de implantação e alavancar as oportunidades oferecidas pelas tecnologias. Projetos menores, por outro lado, podem enfrentar restrições de recursos para implantar tecnologias.

A tecnologia da informação tem um papel importante em projetos de infraestrutura, melhorando a colaboração, a coordenação e o intercâmbio de dados entre os participantes envolvidos no projeto, contudo esses benefícios estão sendo explorados de forma lenta quando comparados a outros setores (SARDROUD, 2015). Infelizmente, muitos dados relevantes são trocados em documentos de texto não estruturados o que dificulta a tarefa de armazenamento dos dados (AL QADY; KANDIL, 2013). Além disso, muitos dados não são armazenados, mas sim apenas trocados verbalmente entre os profissionais do projeto, assim importantes experiências permanecem na mente das pessoas e quando os engenheiros e especialistas concluem o projeto, normalmente levam o conhecimento com eles e as informações valiosas para os projetos subsequentes se perdem (KANAPECKIENE et al., 2010). Estudos anteriores correlacionam esses problemas a complexidade dos projetos de infraestrutura, sua natureza temporária, meios ineficientes de comunicação, pela fragmentação e falta de integração dos processos, além da falta de clareza sobre o retorno de investimento em TI no curto prazo. (SARDROUD, 2015).

Os dados coletados no decorrer do projeto fornecem aos profissionais as informações necessárias para tomar decisões com facilidade e rapidez (YANG et al. 2013). Além disso, os dados históricos são fundamentais para o processo de planejamento, orçamentação, definições metodológicas, segurança do trabalho etc. (MARTÍNEZ-ROJAS; MARÍN; VILA, 2015).

Projetos de construção são considerados um sistema social complexo para a inovação, aspectos que podem acelerar a inovação também podem sufocar a difusão de novas práticas e tecnologias (DUBOIS e GADDE, 2002). Neste contexto, a difusão preocupa-se com processos de inovação que se desdobram dentro das empresas, entre projetos e mercados (GARUD et al., 2013).

Alguns projetos são classificados como sistemas complexos porque neles estão envolvidos amplos fatores organizacionais, os quais se encontram fora do controle do gerente de projetos (WHITTY; MAYLOR, 2009). Perminova, Gustafsson e Wikström (2008) apontam que grande parte dos projetos possuem restrições de tempo, custos, escopo e qualidade. Nesse sentido, os projetos são complexos e incertos, fato que gera a necessidade de maior flexibilidade e reflexão em como gerenciá-los. 
Segundo Maximiano (2008), o número de variáveis de um projeto pode indicar a sua complexidade, como: multidisciplinaridade, localização física, diversidade e volume de informações no processo, condições do ambiente envolvido, volume de pessoas e organizações envolvidas. De acordo com Wideman (1991), projetos complexos possuem características específicas de raridade, restrições, multidisciplinaridade, complexidade tecnológica, administrativa e de objetivos das partes interessadas. Dessa forma, o projeto necessita ser gerenciado de forma integrada, o que facilita seu monitoramento e o processo de tomada de decisão dos gestores. Segundo Hertogh e Westerveld (2010), um projeto complexo é aquele que combina seis dimensões de complexidade: tecnológica, social, financeira, legal, organizacional e temporal.

É possível encontrar na literatura alguns modelos que visam mensurar a complexidade de projetos. D’Herbemont e César (1996) propõem duas tipologias de complexidade, uma é a análise técnica e a outra a relacional, que são apresentadas em um plano cartesiano bidimensional, no qual a abscissa é a relacional e ordenada é a técnica. Nicholas (1990) adaptado por Slack, Chambers e Johnston (2002), apresentam uma classificação dos projetos, que decorre da análise de complexidade e a incerteza, no eixo da abscissa se encontra a complexidade e no eixo da ordenada está a incerteza, ambas podem ser classificadas em níveis que vão de baixa a alta, porém sem estabelecer uma escala quantitativa a fim de haver uma maior compreensão do processo de classificação. Shenhar e Wideman (2000), propõem uma matriz que demonstra o relacionamento das variáveis complexidade e incerteza. Para os autores, as dimensões são divididas na tipologia tecnológica do projeto, dimensão que impacta na incerteza do projeto, e a outra é a dimensão da complexidade do projeto, o enfoque que é dado à incerteza é aquele que a relaciona com a tecnologia, ou seja, se refere à medida do grau de incerteza tecnológica que pode ser ilustrado na figura 6. 
Figura 6 - Classificação de projetos por complexidade versus incerteza

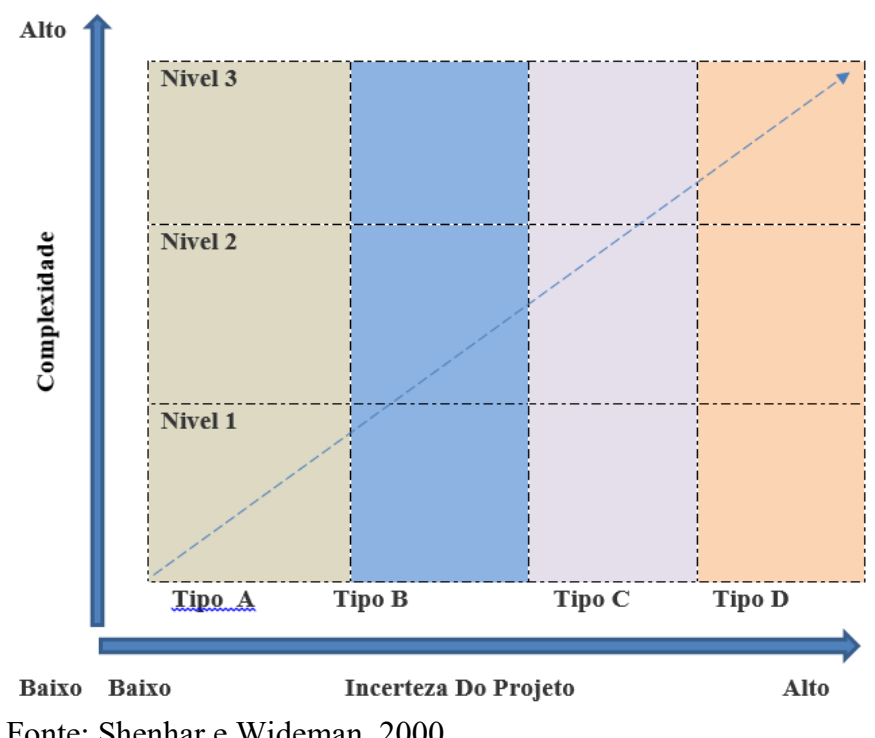

Fonte: Shenhar e Wideman, 2000

Slack et al. (2008) propuseram o modelo que indica a dificuldade de gerenciamento dos projetos baseando-se no seu tamanho, complexidade e incerteza, o que resulta em classificar um projeto pelo nível de dificuldade de gerenciamento, assim se estabelece uma análise tridimensional dos projetos, conforme figura 7.

Figura 7 - Matriz de relacionamento: complexidade, tamanho e incerteza

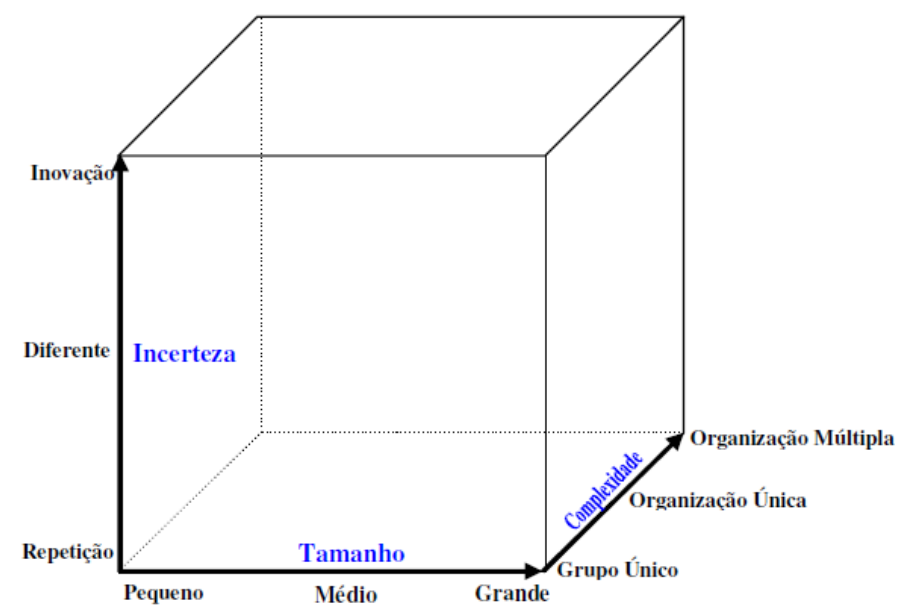

Fonte: Slack et al., 2008

De acordo com as dimensões apresentadas é possível verificar a existência de três aspectos para cada uma das dimensões, conforme quadro 1 . 
Quadro 1 - Desdobramento das dimensões da classificação de projetos

\begin{tabular}{|c|c|c|}
\hline Incerteza & Tamanho & Complexidade \\
\hline Repetição & Pequeno & Grupo único \\
\hline Diferente & Médio & Organização única \\
\hline Inovação & Grande & Organização múltipla \\
\hline
\end{tabular}

Fonte: Slack et al., 2008

De acordo com o quadro 1, é possível notar que os autores associam a complexidade ao número de pessoas ou organizações que se relacionam com o projeto, com relação ao tamanho esses associam ao porte do projeto, já a dimensão incerteza está associada ao nível de inovação do escopo do projeto.

De acordo com os conceitos de projeto discutidos neste capítulo, é possível notar a importância de utilizá-los para avaliar a assimilação de tecnologia no ambiente de projetos complexos.

\subsection{MODELO DE PESQUISA}

Levando em consideração o contexto exposto até aqui, o presente trabalho de pesquisa busca desenvolver um estudo de caso múltiplos para analisar os fatores que afetam a assimilação de tecnologia na gestão de ativos em projetos de construção civil, que são associados a projetos complexos. Com base em perspectivas teóricas sobre os contextos de assimilação, busca-se um modelo integrativo para examinar os fatores que afetam a assimilação no contexto da gestão de ativos em projetos complexos e para isso foi utilizado o modelo fundamentado no framework TOE para analisar o contexto empresarial e o modelo TAM 2 para analisar o contexto do indivíduo. A figura 8, apresenta de forma sintética o modelo de pesquisa proposto. 
Figura 8 - Modelo de pesquisa

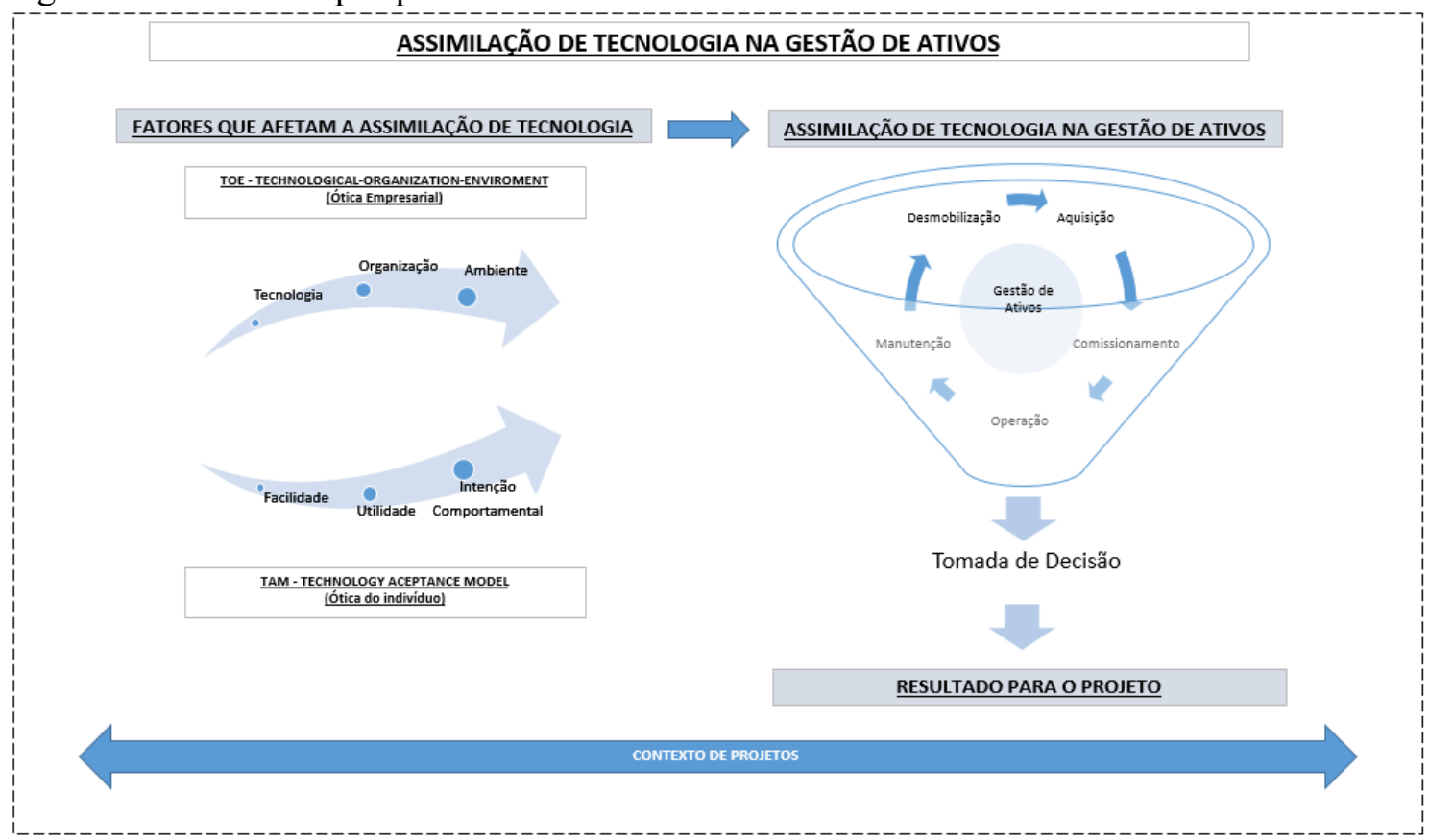

Fonte: Autor

Conforme observado no capítulo 2, o uso de tecnologia no ciclo de vida dos ativos, dentro do contexto de projeto, pode trazer efeitos benéficos para as empresas. Dessa forma, os fatores que afetam a assimilação de tecnologias se tornam importantes para que as partes envolvidas possam se preparar para essa assimilação. O modelo de pesquisa indicado na figura 8, compreende na análise dos fatores que afetam a assimilação de tecnologia na gestão de ativos em projetos complexos, neste modelo é utilizando o conceito TOE sob a ótica empresarial e o conceito TAM sob a ótica do indivíduo de forma que as teorias se complementam no contexto proposto nesta pesquisa.

O estudo de caso, como estratégia de pesquisa, possibilita investigar um tópico empírico, seguindo um conjunto de procedimento e predefinições (YIN, 2005). Seu objetivo é aprofundar o conhecimento acerca de um problema não suficientemente definido (MATTAR, 1996). O estudo de casos múltiplos fornece a oportunidade de construir a teoria de forma independentemente de uma organização, sendo considerada mais convincente e tornando a pesquisa mais robusta (HERRIOTT; FIRESTONE, 1983). A escolha do estudo de caso baseouse na convicção da complexidade do estudo, que requer contextualização e aprofundamento. A adoção de vários estudos de caso oferece oportunidades para estudar a implementação prática exaustivamente, decifrar a invariância (padrões comuns), cruzar casos e gerar explicações lógicas para explicar um fenômeno particular (EISENHARDT, 1989). 
De acordo com Yin (2005), os estudos de casos podem ser classificados por seu conteúdo e objetivo final (exploratórios, explanatórios ou descritivos) ou quantidade de casos (caso único - holístico ou incorporado ou casos múltiplos - também categorizados em holísticos ou incorporados). O mesmo autor ainda indica que a principal tendência em todos os tipos de estudo de caso, é que estes tentam esclarecer o motivo pelo qual uma decisão ou um conjunto de decisões foram tomadas, como foram implementadas e com quais resultados alcançados.

\subsubsection{Quadro Teórico}

Levando em consideração a revisão bibliográfica, é possível sintetizar no quadro 2 os principais fatores que influenciaram na assimilação de tecnologia nos estudos realizados pelos respectivos autores. 
Quadro 2 - Fatores que afetam a assimilação de tecnologia (TOE e TAM)

\begin{tabular}{|c|c|c|c|c|c|c|c|c|c|c|c|c|c|c|c|c|c|c|c|c|c|c|c|c|c|}
\hline \multirow[b]{2}{*}{ Contexto } & \multirow[b]{2}{*}{ Fatores } & \multicolumn{24}{|c|}{ Autores } \\
\hline & & 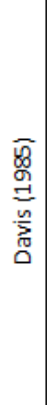 & 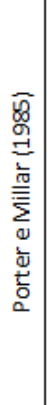 & 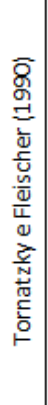 & 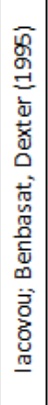 & 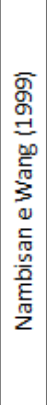 & 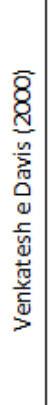 & 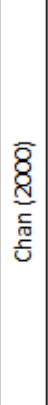 & 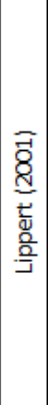 & 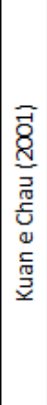 & 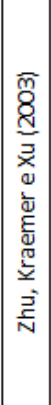 & 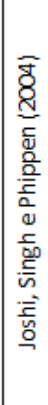 & 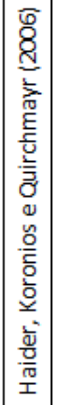 & 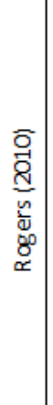 & 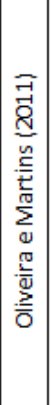 & 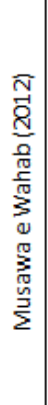 & 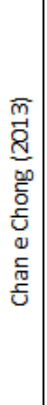 & 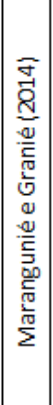 & 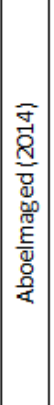 & 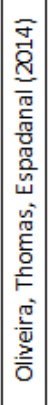 & 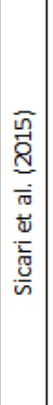 & 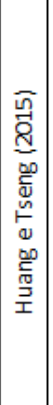 & 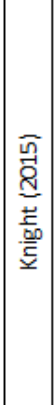 & 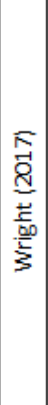 & 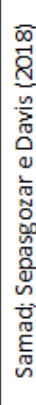 \\
\hline \multirow{8}{*}{ Tecnologia } & Vantagem relativa & $\mathrm{x}$ & & $\mathrm{x}$ & & $\mathrm{x}$ & $\mathrm{x}$ & $\mathrm{x}$ & & $\mathrm{x}$ & & & & $\mathrm{x}$ & $\mathrm{x}$ & & $\mathrm{x}$ & $\mathrm{x}$ & $\mathrm{x}$ & & $\mathrm{x}$ & $\mathrm{x}$ & & $\mathrm{x}$ & $\mathrm{x}$ \\
\hline & Compatibilidade & & & $\mathrm{x}$ & & & & & & $\mathrm{x}$ & $\mathrm{x}$ & $\mathrm{x}$ & & & \begin{tabular}{|l|l|}
$x$ & \\
\end{tabular} & & $\mathrm{x}$ & & \begin{tabular}{|l|l|}
$x$ & \\
\end{tabular} & & $\mathrm{x}$ & $\mathrm{x}$ & & & \\
\hline & Complexidade & $\mathrm{x}$ & & $\mathrm{x}$ & & $\mathrm{x}$ & $\mathrm{x}$ & & $\mathrm{x}$ & $\mathrm{x}$ & $\mathrm{x}$ & $\mathrm{x}$ & $\mathrm{x}$ & $\mathrm{x}$ & $\mathrm{x}$ & & - & $\mathrm{x}$ & $\mathrm{x}$ & & 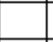 & 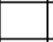 & & & \\
\hline & Disponibilidade tecnológica & & & $\mathrm{x}$ & & $\mathrm{x}$ & & & $\mathrm{x}$ & $\mathrm{x}$ & $\mathrm{x}$ & & $\mathrm{x}$ & $\mathrm{x}$ & $\mathrm{x}$ & & $\mathrm{x}$ & & $\mathrm{x}$ & & $\mathrm{x}$ & $\mathrm{x}$ & & $\mathrm{x}$ & $\mathrm{x}$ \\
\hline & Infraestrutura de TI & & & $\mathrm{x}$ & & $\mathrm{x}$ & & & $\mathrm{x}$ & $\mathrm{x}$ & $\mathrm{x}$ & $\mathrm{x}$ & $\mathrm{x}$ & & $\mathrm{x}$ & & $\mathrm{x}$ & & $\mathrm{x}$ & & $\mathrm{x}$ & $\mathrm{x}$ & $\mathrm{x}$ & & $\mathrm{x}$ \\
\hline & Beneficios diretos percebidos & $\mathrm{x}$ & $\mathrm{x}$ & $\mathrm{x}$ & $\mathrm{x}$ & $\mathrm{x}$ & $\mathrm{x}$ & $\mathrm{x}$ & $\mathrm{x}$ & $\mathrm{x}$ & $\mathrm{x}$ & & $\mathrm{x}$ & $\mathrm{x}$ & $\mathrm{x}$ & & $\mathrm{x}$ & $\mathrm{x}$ & $\mathrm{x}$ & & $\mathrm{x}$ & $\mathrm{x}$ & $\mathrm{x}$ & & \\
\hline & Beneficios indiretos percebidos & & & $\mathrm{x}$ & $\mathrm{x}$ & $\mathrm{x}$ & $\mathrm{x}$ & $\mathrm{x}$ & $\mathrm{x}$ & $\mathrm{x}$ & $\mathrm{x}$ & $\mathrm{x}$ & $\mathrm{x}$ & & $\mathrm{x}$ & & $\mathrm{x}$ & $\mathrm{x}$ & $\mathrm{x}$ & & $\mathrm{x}$ & $\mathrm{x}$ & $\mathrm{x}$ & & $\mathrm{x}$ \\
\hline & Riscos percebidos & & & $\mathrm{x}$ & & $\mathrm{x}$ & & $\mathrm{x}$ & $\mathrm{x}$ & $\mathrm{x}$ & $\mathrm{x}$ & $\mathrm{x}$ & $\mathrm{x}$ & & $\mathrm{x}$ & & 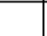 & & $\mathrm{x}$ & & $\mathrm{x}$ & $\mathrm{x}$ & & & $\mathrm{x}$ \\
\hline \multirow{7}{*}{ Organizacional } & Atitudes em relação à inovação & $\mathrm{x}$ & $\mathrm{x}$ & $\mathrm{x}$ & & & $\mathrm{x}$ & & & $\mathrm{x}$ & & & 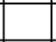 & $\mathrm{x}$ & $\mathrm{x}$ & $\mathrm{x}$ & $\mathrm{x}$ & $\mathrm{x}$ & $\mathrm{x}$ & $\mathrm{x}$ & & $\mathrm{x}$ & $\mathrm{x}$ & & $\mathrm{x}$ \\
\hline & Recursos financeiros & & & $\mathrm{x}$ & $\mathrm{x}$ & $\mathrm{x}$ & & $\mathrm{x}$ & & & & & $\mathrm{x}$ & $\mathrm{x}$ & $\mathrm{x}$ & $\mathrm{x}$ & $\mathrm{x}$ & & $\mathrm{x}$ & $\mathrm{x}$ & & & $\mathrm{x}$ & $\mathrm{x}$ & $\mathrm{x}$ \\
\hline & Tamanho organizacional & & & $\mathrm{x}$ & & & & $\mathrm{x}$ & & $\mathrm{x}$ & & & & $\mathrm{x}$ & $\mathrm{x}$ & $\mathrm{x}$ & $\mathrm{x}$ & & $\mathrm{x}$ & $\mathrm{x}$ & & & $\mathrm{x}$ & & $\mathrm{x}$ \\
\hline & Cultura compartilhamento de informações & & & $\mathrm{x}$ & & & & $\mathrm{x}$ & & $\mathrm{x}$ & & & & $\mathrm{x}$ & $\mathrm{x}$ & $\mathrm{x}$ & $\mathrm{x}$ & & $\mathrm{x}$ & $\mathrm{x}$ & & $\mathrm{x}$ & $\mathrm{x}$ & $\mathrm{x}$ & \\
\hline & Cultura de aprendizagem & & & $\mathrm{x}$ & & & & & & & & & & $\mathrm{x}$ & $\mathrm{x}$ & $\mathrm{x}$ & $\mathrm{x}$ & & $\mathrm{x}$ & $\mathrm{x}$ & & & $\mathrm{x}$ & & \\
\hline & Apoio da alta gerência & & & $\mathrm{x}$ & & & & $\mathrm{x}$ & & & & & & $\mathrm{x}$ & $\mathrm{x}$ & $\mathrm{x}$ & $\mathrm{x}$ & & $\mathrm{x}$ & $\mathrm{x}$ & & & $\mathrm{x}$ & $\mathrm{x}$ & $\mathrm{x}$ \\
\hline & Conhecimento & & & $\mathrm{x}$ & $\mathrm{x}$ & & & $\mathrm{x}$ & & $\mathrm{x}$ & & & & $\mathrm{x}$ & $\mathrm{x}$ & $\mathrm{x}$ & $\mathrm{x}$ & & $\mathrm{x}$ & $\mathrm{x}$ & $\mathrm{x}$ & $\mathrm{x}$ & $\mathrm{x}$ & & $\mathrm{x}$ \\
\hline \multirow{5}{*}{ Ambiente } & Pressão competitiva & & $\mathrm{x}$ & $\mathrm{x}$ & $\mathrm{x}$ & $\mathrm{x}$ & & $\mathrm{x}$ & & $\mathrm{x}$ & & $\mathrm{x}$ & $\mathrm{x}$ & & $\mathrm{x}$ & & & & $\mathrm{x}$ & $\mathrm{x}$ & & & & & $\mathrm{x}$ \\
\hline & Incerteza ambiental & & & $\mathrm{x}$ & & & & & & & $\mathrm{x}$ & $\mathrm{x}$ & & $\mathrm{x}$ & $\mathrm{x}$ & & $\mathrm{x}$ & & $\mathrm{x}$ & $\mathrm{x}$ & $\mathrm{x}$ & & & & $\mathrm{x}$ \\
\hline & Suporte regulatório & & $\mathrm{x}$ & $\mathrm{x}$ & & & & & & & & $\mathrm{x}$ & $\mathrm{x}$ & & $\mathrm{x}$ & & & & $\mathrm{x}$ & & & & & & $\mathrm{x}$ \\
\hline & Prontidão parceiro comercial & & & $\mathrm{x}$ & & & & & & & $\mathrm{x}$ & & & $\mathrm{x}$ & $\mathrm{x}$ & & & & $\mathrm{x}$ & & & & & & $\mathrm{x}$ \\
\hline & $\mathrm{O}$ apoio de fornecedores de tecnologia & & & $\mathrm{x}$ & & $\mathrm{x}$ & & & & & $\mathrm{x}$ & & & & $\mathrm{x}$ & & & & $\mathrm{x}$ & $\mathrm{x}$ & & & & & $\mathrm{x}$ \\
\hline TAM & Facilidade percebida, Utilidade e intenção comportamental & $\mathrm{x}$ & & & & & $\mathrm{x}$ & & & & & & & & & & & $\mathrm{x}$ & & & & & & & \\
\hline
\end{tabular}

Fonte: Autor 


\section{METODOLOGIA DE PESQUISA}

Quanto a abordagem, a pesquisa pode ser qualitativa ou quantitativa. A abordagem qualitativa não se preocupa com a representação numérica, dessa forma, busca-se o porquê das coisas, com a objetivação do fenômeno. A abordagem quantitativa é recomendada para as pesquisas onde as variáveis podem ser mensuradas, dessa forma ela recorre a uma linguagem matemática para descrever a causa de um fenômeno. Também existem pesquisas que utilizam as duas abordagens, quantitativa e qualitativa, no mesmo trabalho (MIGUEL, 2007). Neste trabalho foi utilizada a abordagem qualitativa e o método estudo de caso para compreender a questão de pesquisa proposta.

Através de uma análise qualitativa e utilizando o estudo de caso múltiplos como método, foi desenvolvida a presente pesquisa com objetivo de avaliar a assimilação de tecnologia digital na gestão de ativos e para isso foram analisados 04 casos que estão inseridos no ambiente de grandes projetos de infraestrutura. Para coleta das informações, foram realizadas entrevistas semiestruturadas com os gestores do projeto e documentos foram analisados, como: relatórios, apresentações, indicadores de desempenho, procedimentos e os softwares que fizeram a interface com as ferramentas tecnológicas. De acordo com Alkalbani (2013), a técnica de entrevista semiestruturada foi escolhida como uma das melhores ferramentas para coleta de dados, pois permite que o pesquisador obtenha dados detalhados sobre o processo que está sendo estudado. Esse tipo de entrevista é uma ferramenta flexível que permite ao pesquisador gerar dados ricos para avançar no entendimento e, consequentemente, desenvolver um argumento empírico e teoricamente fundamentado. No entanto, este tipo de entrevista é mais demorado e complexo. A entrevista semiestruturada é uma ferramenta para coletar dados ricos, que está aberta à decisão dos participantes sobre o que é importante e relevante para discutir. A flexibilidade dos participantes pode permitir a expressão do processo com base nos fatos, em vez de concordar ou rejeitar com questões estruturadas.

Entrevistas semiestruturadas têm sido aplicadas em muitos estudos de pesquisa (SAMAD, SEPASGOZAR; DAVIS, 2018). Por exemplo, Samuelson e Björk (2013), investigaram fatores que afetam as decisões de implementar diferentes técnicas de tecnologia da informação na construção, eles justificaram a escolha de entrevistas semiestruturadas, pois permitiram uma discussão mais ampla.

Neste capítulo são apresentadas a estrutura proposta para pesquisa, o detalhamento de como foi construído o referencial teórico, as proposições de pesquisa, o critério utilizado para a escolha dos casos, a delimitação da pesquisa e o seu roteiro. 


\subsection{ESTRUTURA DA PESQUISA}

De acordo com Miguel (2007), o desenvolvimento de uma pesquisa, utilizando o estudo de caso como método, pode ser subdividido em etapas: a primeira etapa visa definir a estrutura conceitual teórica, onde deve ser feito o mapeamento da literatura, delinear as proposições e definir as fronteiras da pesquisa; a segunda fase compreende a etapa de planejamento dos casos, nesta etapa deve ser identificada a unidade de análise, os meios de coleta de dados e as formas de controle da pesquisa; a terceira etapa consiste na elaboração de um teste piloto, onde deve ser testado o procedimento de aplicação, verificar a qualidade dos dados para que os ajustes necessários possam ser realizados; a quarta fase compreende na coleta dos dados, onde o pesquisador executa o que foi planejado para pesquisa, efetivando o contato com os casos, registrando os dados e limitando os efeitos do pesquisador; a quinta etapa analisa os dados coletados na etapa anterior, nela o pesquisador deve produzir uma narrativa, consolidar os dados e identificar causalidade; na sexta e última fase da pesquisa, o relatório de pesquisa deve ser gerado, desenhando as implicações teóricas e provendo a estrutura para replicação.

Figura 9 - Estrutura da pesquisa

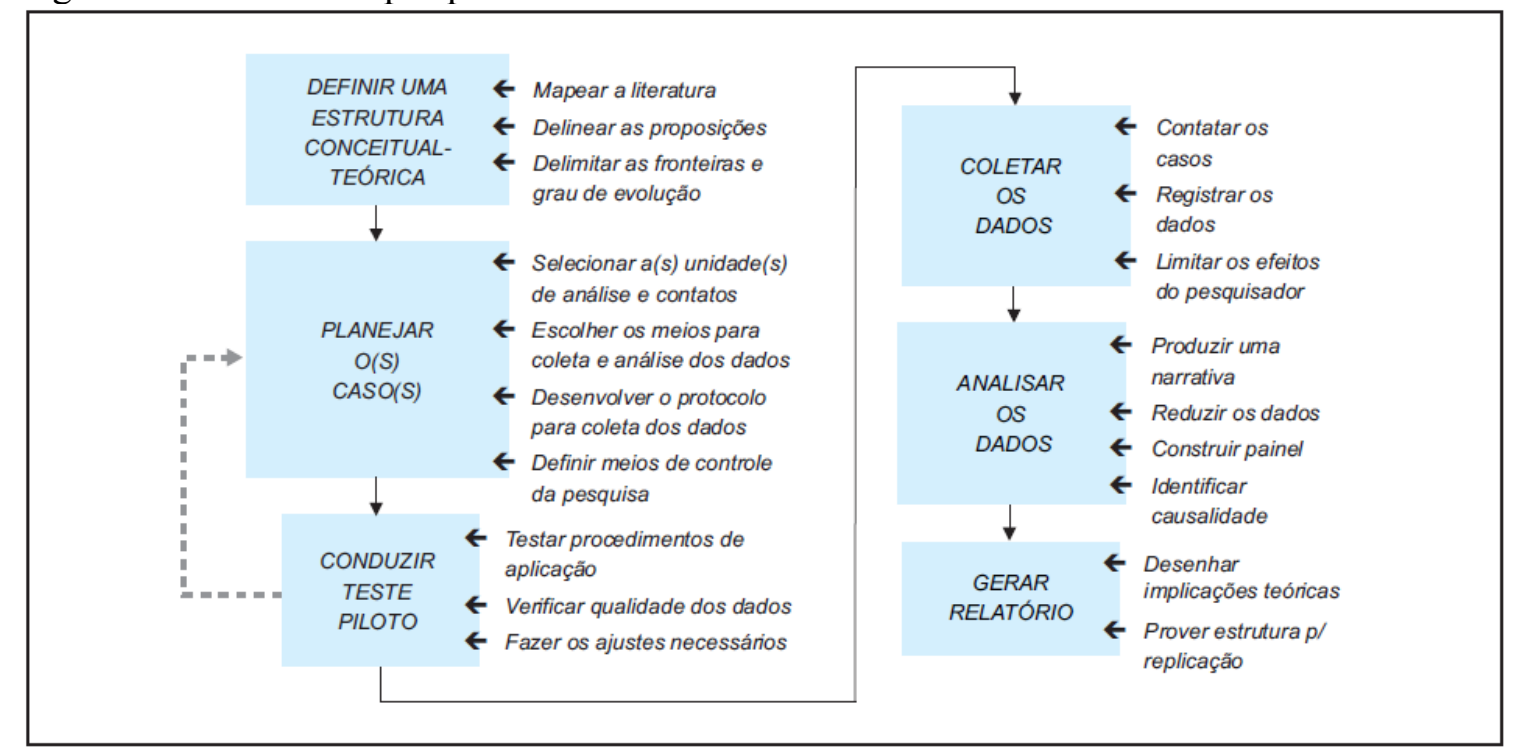

Fonte: Miguel, 2007

Seguindo a estrutura de pesquisa ilustrada na figura 9, foi desenvolvido no presente trabalho a estrutura conceitual teórica, tendo como foco a gestão de ativos, a assimilação de tecnologia e o conceito de projeto; posteriormente buscou-se o planejamento dos casos com o 
desenvolvimento do protocolo de pesquisa, a identificação dos casos e a definição dos meios de controle; um teste piloto foi conduzido para testar os procedimentos e para fazer os ajustes necessários; os dados foram coletados através de entrevistas e análise de documentos e softwares; a análise dos dados foi realizada e o trabalho foi concluído com a indicação das implicações teóricas, práticas e sugestões de novos estudos a serem desenvolvidos.

\subsection{CONSTRUÇÃO DO REFERENCIAL TEÓRICO}

A revisão da literatura possibilita a construção do referencial teórico da pesquisa, é nesta etapa que as bases de conhecimento são construídas e os questionamentos são estruturados para que a pesquisa seja desenvolvida (MIGUEL, 2007).

A construção do referencial teórico deste trabalho, foi elaborada utilizando as bases de dados: Portal Capes, Scopus, Web of Science, Google Acadêmico e Proquest. Foram utilizadas como palavras chaves: "assimilação de tecnologia", "gestão de ativos", "smart asset management", "tecnologia digital" e "projetos complexos". As buscas foram complementadas a partir das referências bibliográficas indicadas nos artigos encontrados nas bases pesquisadas. A leitura do material permitiu uma seleção prévia dos artigos que foram utilizados na pesquisa, identificando as tendências teóricas e as lacunas de pesquisa.

A figura 10, indica de forma esquemática a sequência de atividades desenvolvidas no processo de desenvolvimento do referencial teórico. 
Figura 10 - Processo de revisão teórica

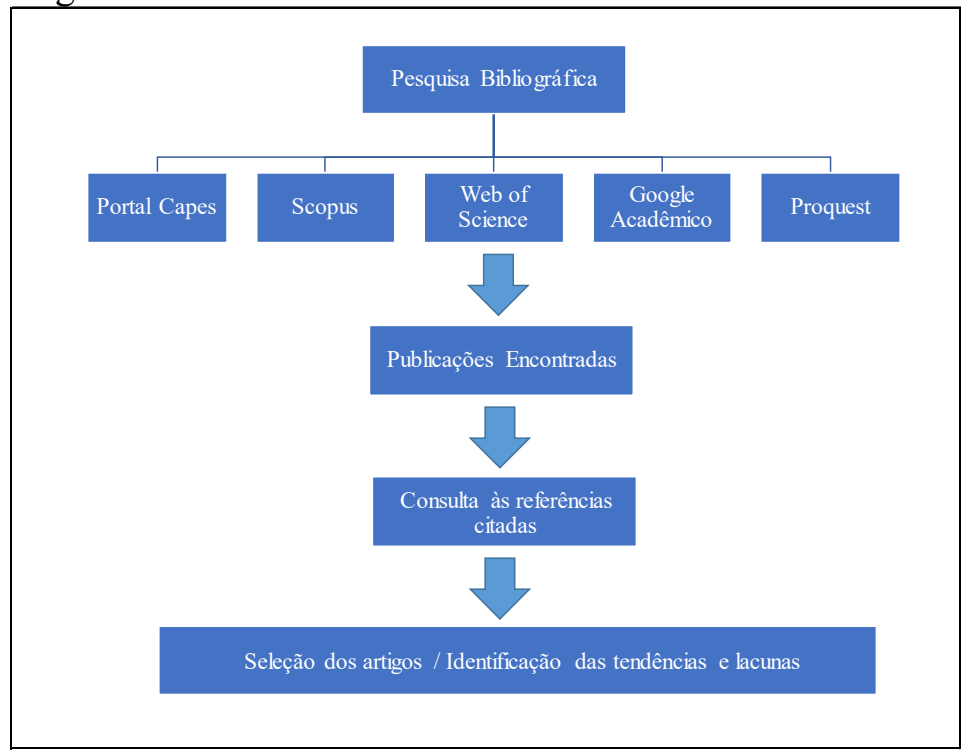

Fonte: Autor

De acordo com os estudos realizados, foi identificada uma lacuna no que tange a assimilação de tecnologia digital na gestão de ativos. Foi possível encontrar estudos que abordam a assimilação de tecnologia em diversos segmentos, contudo não foi identificado um estudo específico sobre a assimilação de tecnologia na gestão de ativos, mais especificamente, ativos ligados a construção civil no contexto de projetos. Sendo assim, o trabalho foi estruturado para preencher essa lacuna de forma a contribuir com a teoria e a aplicação prática do tema.

O referencial teórico foi subdividido de forma a preencher os conceitos relacionados a gestão de ativos, assimilação de tecnologia na gestão de ativos, o contexto de projetos complexos e o modelo de pesquisa. Foi possível descrever os conceitos de gestão de ativos inteligentes, as tecnologias digitais utilizadas na gestão de ativos, a análise de dados para tomada de decisão. No contexto de assimilação de tecnologia, o trabalho aborda as principais teorias de assimilação de tecnologia, onde foi possível identificar o enquadramento do framework - TOE no objeto de pesquisa sob a ótica das empresas e o enquadramento do framework - TAM 2 sob a ótica do indivíduo. O contexto de projetos, traz mais um fator a ser avaliado no processo de assimilação de tecnologia, pois as suas particularidades temporais e de escopo precisam ser consideradas para que se possa obter sucesso no uso das tecnologias. Por fim, o referencial teórico respalda o modelo de pesquisa adotado neste trabalho, indicando o modelo teórico e as respectivas proposições de pesquisa. 


\subsection{PROPOSIÇÕES}

As proposições de pesquisa são apresentadas levando em consideração o referencial teórico deste trabalho. Foram apresentadas, as questões chaves evidenciadas na literatura que fazem referência a gestão de ativos inteligentes, a assimilação de tecnologia baseada no

framework TOE e TAM, e as particularidades do contexto de projetos complexos. Com base nesse cenário, as seguintes proposições de pesquisa foram elaboradas:

a) P1 - Particularidades existentes em projetos complexos têm impactos positivos e negativos na assimilação de tecnologia na gestão de ativos (DUBOIS; GADDE, 2002; GARUD et al., 2013; SAMAD; SEPASGOZAR; DAVIS, 2018)

b) P2 - As empresas não utilizam de forma efetiva as ferramentas tecnológicas disponíveis no contexto de gestão de ativos (HAIDER, 2012; HAN et al., 2018);

c) P3 - As empresas no contexto de projetos complexos, muitas vezes, não se preparam para correta implantação e assimilação de tecnologia (JACOBSSON; LINDEROTH, 2010; SAMAD; SEPASGOZAR; DAVIS, 2018).

As proposições elaboradas, estão alinhadas com o objetivo geral do estudo que consiste em analisar a assimilação das tecnologias digitais relacionadas a gestão de ativos no contexto de projeto, através de um estudo de caso múltiplos, identificando as tecnologias utilizadas assim como os possíveis fatores que afetam a assimilação de tecnologia na gestão de ativos. E também estão diretamente relacionadas a questão geral de pesquisa que busca entender como as empresas, no ambiente de projeto, podem se preparar para assimilar as tecnologias na gestão de ativos.

\subsection{CRITÉRIO DE ESCOLHA DOS PROJETOS}

O critério adotado teve como base a matriz proposta por Shenhar e Wideman (2000), a qual demonstra o relacionamento das variáveis complexidade e incerteza. As dimensões são divididas na tipologia tecnológica do projeto, dimensão que impacta na incerteza do projeto, e a outra é a dimensão da complexidade do projeto conforme a figura 11. 
Shenhar e Wideman (2000) efetuaram uma subdivisão em três níveis no que se refere ao nível de complexidade do escopo de gerenciamento de programas/projetos:

a) Nível 1 - são projetos simples;

b) Nível 2 - são projetos complexos - sistemas, consistindo de uma coleção complexa de elementos interativos e subsistemas;

c) Nível 3 - é um programa ou uma série de projetos, no lugar de um único projeto.

Em relação aos tipos de Projetos Shenhar e Wideman (2000) descrevem conforme a seguir:

a) Tipo A - são projetos com baixa-tecnologia;

b) Tipo B - são os projetos com tecnologia mediana - tecnologia da maior parte do projeto já estabelecida, estes são semelhantes ao tipo A, porém, de modo geral o projeto usa de alguma tecnologia nova;

c) Tipo C - são projetos de alta tecnologia (high-tech) - utilizam tecnologias que foram desenvolvidas antes da fase de iniciação de projeto (tecnologia avançada), mas que são utilizadas pela primeira vez;

d) Tipo D - são projetos de tecnologia altamente avançada - utilizam tecnologias novas.

Figura 11 - Classificação de projetos por complexidade versus incerteza

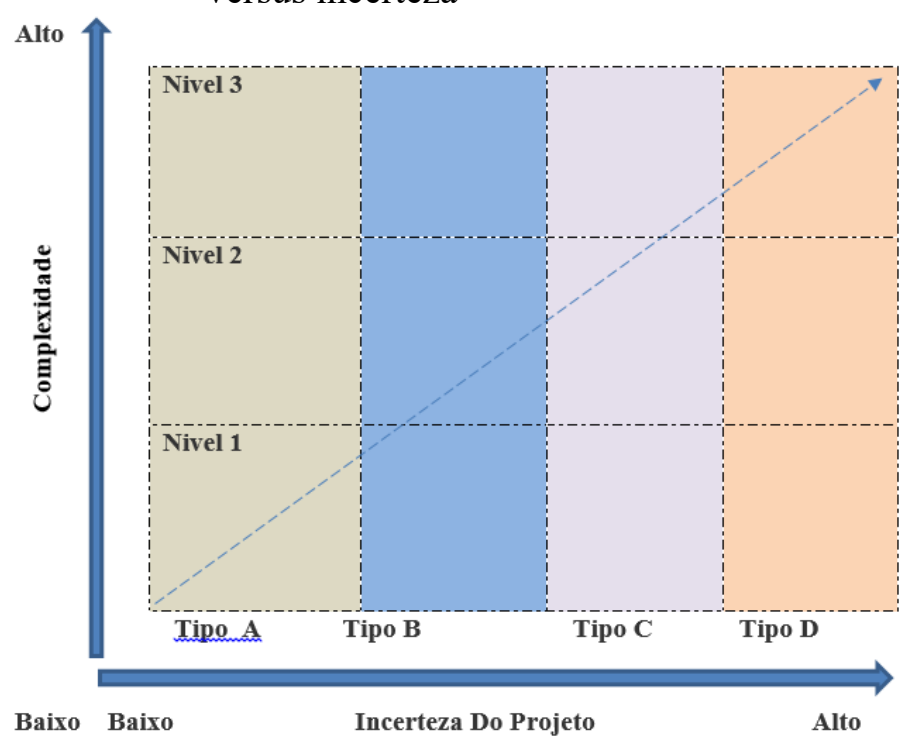

Fonte: Shenhar e Wideman, 2000 
Para atender o propósito da pesquisa, foram identificadas 04 empresas do mercado de construção e que atuaram em grandes projetos de infraestrutura no Brasil, os projetos classificados como projetos complexos e que reuniram um grande número de equipamentos de construção (ativos) com consequente aplicação de tecnologias, reúnem os elementos necessários para pesquisa proposta.

Devido à complexidade, alto risco e caráter conservador das empresas construtoras, as tecnologias digitais avançadas não se tornam amplamente adotadas no curto prazo, enquanto os fornecedores fazem esforços determinados para superar isso e disseminar suas tecnologias (SAMAD; SEPASGOZAR; DAVIS, 2018). Os autores reforçam a urgente necessidade de entender o processo de adoção de tecnologia, uma vez que o aumento contínuo da variedade e do valor das novas tecnologias de construção, aliado à aceleração do avanço tecnológico de suas funções, produziu um apetite crescente por facilitar o processo de adoção da tecnologia pelas empresas.

Para mensurar a importância desse mercado, a figura 12 indica o montante de equipamentos novos comercializados pelos principais fabricantes, esses equipamentos e valores estão diretamente relacionados ao mercado de tecnologia na gestão de ativos.

Figura 12 - Mercado global de equipamentos de construção 2017

\section{Venda global de equipamentos de construção 2017}

(bilhões - U.S.D)

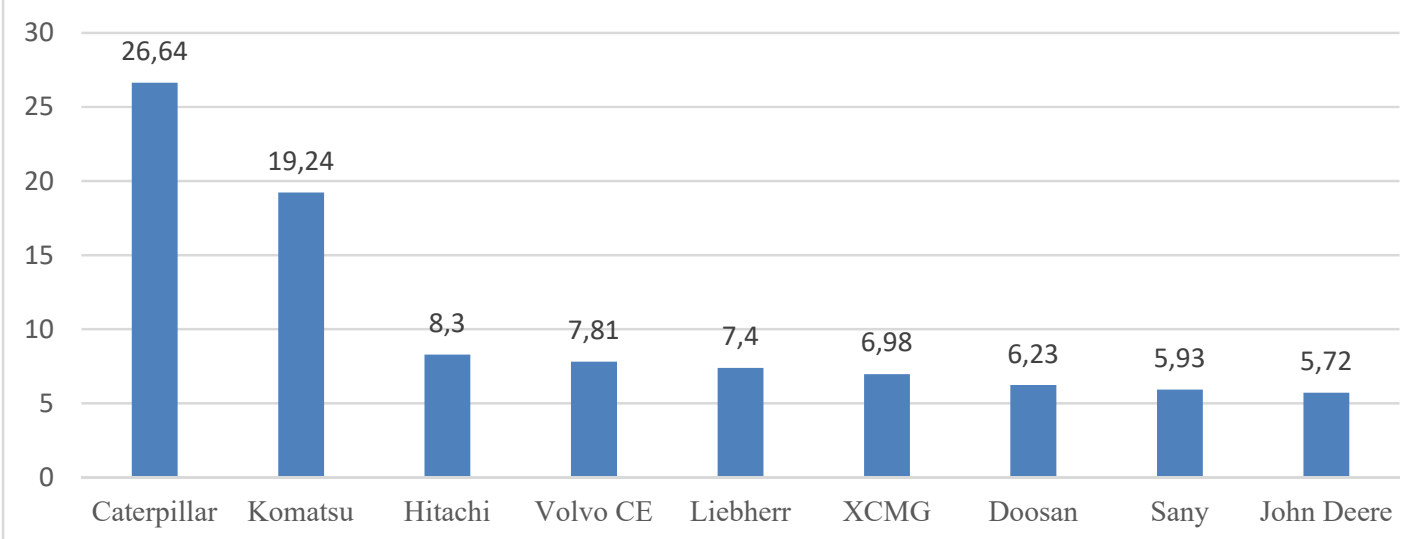

Fonte: Statista, 2019

Os casos selecionados, correspondem a projetos de infraestrutura do setor energético brasileiro, todos os projetos possuem um número superior a 200 equipamentos de construção que nesse trabalho também são denominados como ativos e fizeram uso de uma ou mais tecnologias no gerenciamento dos ativos. Os projetos estudados correspondem a construção de quatro usinas hidrelétricas que foram construídas na última década. Esses projetos foram 
símbolo de desafios de engenharia nos últimos anos e fizeram uso de equipamentos de alta tecnologia para atingir os objetivos de prazo e custo. Os projetos selecionados são semelhantes no que tange o objetivo e escopo, porém cada projeto apresenta sua particularidade e foram realizados por empresas distintas, dessa forma é possível estabelecer os parâmetros de comparação entres os casos na busca de esclarecer as proposições e o questionamento geral da pesquisa.

\subsection{DELIMITAÇÃO DA PESQUISA}

A presente pesquisa apresenta características específicas, o seu escopo pode ser delimitado por alguns pontos chaves como exposto a seguir:

a) $\mathrm{O}$ estudo compreende uma amostra de 04 casos que abrangem o gerenciamento de ativos no contexto de projetos, mas especificamente no setor de construção. Dessa forma busca-se avaliar os fatores que afetam a assimilação de tecnologia no gerenciamento dos ativos. Apesar dessa limitação, busca-se com o estudo de caso múltiplos a possibilidade de generalização para projetos que apresentem características semelhantes.

b) O conceito de "ativos" é muito amplo, contudo o presente trabalho limita-se aos ativos utilizados em projetos de construção, como: escavadeiras, tratores, caminhões, guindastes, centrais de britagem, centrais de concreto, etc.;

c) Neste trabalho buscou-se avaliar a assimilação de tecnologias utilizadas no gerenciamento de ativos em projetos de construção civil. Foram avaliadas apenas as tecnologias utilizadas nos casos estudados;

d) Foi utilizado o framework TOE - Technological Organization Environmental e TAM - Technology Acceptance Model, como suporte teórico para o desenvolvimento da pesquisa. Não foram utilizadas outras teorias de assimilação e adoção de tecnologia, pois conforme demonstrado no capítulo 2, o TOE e TAM reúnem de maneira mais abrangente as características necessárias para o presente estudo. 


\subsection{PROTOCOLO DE PESQUISA}

De acordo com Miguel (2007), o protocolo de pesquisa deve conter procedimentos e regras gerais para condução da pesquisa, este não deve se resumir a um roteiro de entrevistas, mas sim em um instrumento que visa melhorar a confiabilidade da pesquisa, além de permitir que a pesquisa possa ser replicada na busca do desenvolvimento da teoria, o protocolo deve oferecer condição prática para se testar a confiabilidade do estudo, de forma a obter resultados semelhantes em aplicações sucessivas a um mesmo caso. Dessa forma, o protocolo é essencial para garantir a confiabilidade da pesquisa e serve de orientação ao pesquisador na coleta de dados (YIN, 2005). De acordo com o mesmo autor, o protocolo de pesquisa deve conter: visão geral do projeto do estudo de caso; procedimento de campo; questões do estudo de caso; e guia do relatório.

Voss, Tsikriktsis e Frohlich (2002) destacam que pesquisas científicas devem conter procedimentos e regras gerais que devem ser usados nos processos de coleta de dados e evidências, indicar quem ou onde as informações poderão ser coletadas. Os autores ressaltam que o núcleo do protocolo de pesquisa são as questões que serão utilizadas nas entrevistas.

No "Apêndice A" pode ser encontrado o protocolo de pesquisa desenvolvido para o presente trabalho.

\subsection{ROTEIRO DE PESQUISA}

As entrevistas formais, são a fonte primária para coleta de dados no desenvolvimento da pesquisa, contudo fontes auxiliares também devem ser utilizadas, como: registros, documentos, observação direta, observação de participantes e artefatos físicos (YIN, 2005). O roteiro de pesquisa é destinado ao entrevistado e tem o objetivo principal de coletar os dados de forma estruturada para possibilitar a análise do tema estudado.

As entrevistas serão baseadas em um questionário semiestruturado, conforme quadro 3. 
Quadro 3 - Características do questionário utilizado na pesquisa

\begin{tabular}{|c|c|c|}
\hline Seção & Descrição & Referências \\
\hline 1. Dados do entrevistado & $\begin{array}{l}\text { Cargo na empresa, tempo de trabalho, experiências externas, } \\
\text { nível de formação. }\end{array}$ & - \\
\hline 2. Tecnologias & $\begin{array}{l}\text { A seção tecnologia é subdividida em três seções: inovação } \\
\text { tecnológica, uso das ferramentas tecnológicas e } \\
\text { aperfeiçoamento das tecnologias. }\end{array}$ & \multirow{8}{*}{$\begin{array}{c}\text { (JOHN } \\
\text { WOODHOUSE, 2006; } \\
\text { OUERTANI M, } \\
\text { KUMAR A, } \\
\text { MCFARLANE D, 2008; } \\
\text { TORNATZKY; } \\
\text { FLEISHER, 1990; } \\
\text { ARPACI et al., 2012; } \\
\text { ABOELMAGED M, } \\
\text { 2014). }\end{array}$} \\
\hline 2.1. Inovação tecnológica & $\begin{array}{l}\text { Ferramentas tecnológicas utilizadas na gestão de ativos, os } \\
\text { desafios de implantação e os seus benefícios e malefícios. }\end{array}$ & \\
\hline $\begin{array}{l}\text { 2.2. Uso das ferramentas } \\
\text { tecnológicas }\end{array}$ & $\begin{array}{l}\text { Nível de aproveitamento das ferramentas tecnológicas na } \\
\text { gestão de ativos. }\end{array}$ & \\
\hline $\begin{array}{l}\text { 2.3. Aperfeiçoamento das } \\
\text { tecnologias }\end{array}$ & $\begin{array}{l}\text { Evolução esperada para as ferramentas disponíveis no } \\
\text { mercado. }\end{array}$ & \\
\hline $\begin{array}{l}\text { 3. Assimilação de } \\
\text { tecnologias (Ótica Empresarial } \\
\text { ). }\end{array}$ & $\begin{array}{l}\text { Baseado na análise dos fatores que afetam a assimilação da } \\
\text { tecnologia na organização, essa seção é subdividida em três } \\
\text { seções: tecnologia, organização e ambiente. }\end{array}$ & \\
\hline 3.1. Tecnologia & $\begin{array}{l}\text { Características tecnológicas que afetam a assimilação } \\
\text { tecnológica (infraestrutura, confiabilidade, interface com o } \\
\text { usuário, custo, processo de implantação, etc.). }\end{array}$ & \\
\hline 3.2. Organização & $\begin{array}{l}\text { Características da empresa que influenciam a assimilação de } \\
\text { tecnologia (pessoas, comunicação, processos, envolvimento da } \\
\text { alta liderança, etc.). }\end{array}$ & \\
\hline 3.3. Ambiente & $\begin{array}{l}\text { Características do ambiente interno e externo à empresa que } \\
\text { interferem na assimilação de tecnologia (redução de custo, } \\
\text { melhoria de produtividade, redução de prazos, nível de } \\
\text { exigência do cliente, etc.). }\end{array}$ & \\
\hline $\begin{array}{l}\text { 4. Assimilação de } \\
\text { tecnologias (Ótica do } \\
\text { indivíduo) }\end{array}$ & $\begin{array}{l}\text { Baseado nos fatores que afetam a assimilação de tecnologia } \\
\text { sob o aspecto do indivíduo, essa seção é dividida em três: } \\
\text { facilidade de uso, utilidade percebida e intenção } \\
\text { comportamental }\end{array}$ & \multirow{4}{*}{$\begin{array}{l}\text { (Davis, 1985; } \\
\text { Venkatesh e Davis, } \\
\text { 2000; Marangunié e } \\
\text { Granié, 2014). }\end{array}$} \\
\hline $\begin{array}{l}\text { 4.1 Facilidade de uso } \\
\text { percebida }\end{array}$ & $\begin{array}{l}\text { Fatores que indicam a facilidade de uso percebida pelo } \\
\text { usuário. }\end{array}$ & \\
\hline 4.2 Utilidade percebida & $\begin{array}{l}\text { Fatores que colaboram para utilidade percebida, além de } \\
\text { variáveis externas como: norma subjetiva, imagem, relevância } \\
\text { no trabalho, qualidade de saída e demonstrabilidade do } \\
\text { resultado. }\end{array}$ & \\
\hline $\begin{array}{l}4.3 \text { Intenção } \\
\text { Comportamental }\end{array}$ & Fatores intrínsecos a intenção comportamental do indivíduo. & \\
\hline
\end{tabular}

Fonte: autor 


\subsubsection{Perfil dos entrevistados}

Para que a análise dos casos possa ser realizada de forma ampla e que permita a análise sob diferentes pontos de vistas, as entrevistas foram realizadas com pessoas que atuaram nos respectivos projetos, contudo em funções e níveis hierárquicos diferentes. Buscou-se entrevistar pessoas com domínio no tema e que participaram de forma efetiva do projeto. Para possibilitar uma maior amostragem, três pessoas foram entrevistadas em cada estudo de caso.

O quadro abaixo indica o perfil dos entrevistados em cada caso. De forma a preservar a privacidade das pessoas, o trabalho se refere a pessoa entrevistada, como: entrevistado 1, entrevistado 2 e entrevistado 3.

Quadro 4- Perfil dos entrevistados

\begin{tabular}{|c|l|l|c|}
\hline \multicolumn{4}{|c|}{ Quadro de Entrevistas } \\
\hline Projeto & Entrevistado & \multicolumn{1}{|c|}{ Função } & Experiência Profissional \\
\hline \multirow{4}{*}{ A } & Entrevistado 1 & Gerente Equipamentos & 35 anos \\
\cline { 2 - 4 } & Entrevistado 2 & Engenheiro & 12 anos \\
\cline { 2 - 4 } & Entrevistado 3 & Técnico & 10 anos \\
\hline \multirow{4}{*}{ B } & Entrevistado 1 & Gerente Equipamentos & 15 anos \\
\cline { 2 - 4 } & Entrevistado 2 & Engenheiro & 25 anos \\
\cline { 2 - 4 } & Entrevistado 3 & Técnico & 15 anos \\
\hline \multirow{4}{*}{ C } & Entrevistado 1 & Gerente Equipamentos & 30 anos \\
\cline { 2 - 4 } & Entrevistado 2 & Gerente Corporativo & 20 anos \\
\cline { 2 - 4 } & Entrevistado 3 & Técnico & 12 anos \\
\hline \multirow{3}{*}{ D } & Entrevistado 1 & Gerente Equipamentos & 15 anos \\
\cline { 2 - 4 } & Entrevistado 2 & Gerente Corporativo & 20 anos \\
\cline { 2 - 4 } & Entrevistado 3 & Engenheiro & 12 anos \\
\hline
\end{tabular}

Fonte: autor 


\section{ESTUDOS DE CASO}

Neste capítulo serão apresentados os estudos de caso que foram realizados com o objetivo de testar o modelo teórico e as proposições de pesquisa elaboradas. Foram conduzidos 04 estudos de caso em projetos de construção civil ligados ao setor de infraestrutura energética no Brasil. Nesta seção, os projetos e as tecnologias utilizadas serão descritas caso a caso, e na sequencia uma análise global será realizada.

\subsection{O PROJETO A}

Para melhor compreensão do caso estudado, será apresentado uma descrição do projeto, em seguida as tecnologias que foram utilizadas e uma análise parcial será realizada levando em consideração o modelo teórico proposto para pesquisa, no capítulo seguinte os resultados serão explorados.

\subsubsection{Descrição do projeto}

O projeto A, compreende a construção civil de uma hidrelétrica com capacidade de geração de aproximadamente 3.568 Megawatts de energia elétrica, que é suficiente para atender o consumo de mais de quarenta e cinco milhões de pessoas. A construção desse projeto teve início no ano de 2008 e foi concluído em 2016, conduzida por um consórcio de duas empresas privadas, a construção civil gerou cerca de 13.000 empregos diretos e foram utilizados aproximadamente 1.000 equipamentos de construção, também denominados como ativos neste estudo.

\subsubsection{Tecnologias utilizadas na gestão de ativos}

Com o objetivo de aumentar a eficiência dos processos produtivos, no decorrer do projeto, foram implantadas ferramentas tecnológicas na gestão de ativos que estão descritas a seguir:

a) Sistema de Monitoramento de Caminhões: Esse sistema integra o rastreamento, gerenciamento e logística de frota, permitindo uma rápida localização do veículo, através de coordenadas geográficas obtidas pelo Sistema de Posicionamento Global (GPS) além do monitoramento de até 20 eventos do veículo em tempo real, que 
possibilitam um amplo acompanhamento da operação via Internet. Utilizando tecnologia digital com base em uma constelação de 48 satélites de baixa órbita e 70 estações terrestres, o sistema garante uma cobertura eficiente em áreas remotas. O sistema permite coletar dados do veículo, como o posicionamento geográfico obtido por GPS incorporado e o status de eventos programados, gerando mensagens em pacotes e as transmitindo via satélite. O pacote de mensagens é capturado pelo satélite mais próximo e retransmitido à estação terrena de satélite de sua área. $\mathrm{Na}$ estação terrena de satélite, a mensagem é recebida, decodificada e enviada para o sistema central via Internet. No sistema central as mensagens são recebidas, enviadas, processadas, armazenadas e disponibilizadas na plataforma digital para acesso dos usuários. Ainda é possível interagir com o veículo, monitorando, rastreando, enviando e recebendo mensagens e comandos. Em cada veículo são instalados antenas e módulos que permitem a conexão via satélite com a central de controle. O módulo além de efetuar a conexão com a rede de satélites, possui também a função de registrar todas as informações a respeito da forma como o veículo está sendo conduzido. Através de eventos pré-definidos (excesso de velocidade, excesso de rotação no motor, aquecimento, curva perigosa, etc.) o módulo é programado para armazenar as informações de violação destes eventos. As violações graves são transmitidas a central de controle em tempo real, permitindo assim uma ação imediata em relação ao motorista. Além disso, todas as violações são armazenadas no módulo e periodicamente enviadas a central de controle, possibilitando a emissão de relatórios de acompanhamento da performance do veículo e do condutor.

b) Sistema de Monitoramento de Máquinas: Essa tecnologia foi aplicada nos equipamentos como escavadeiras, tratores, pá-carregadeiras entre outros equipamentos e utiliza uma rede de satélites de baixa órbita terrestre para a coleta e transmissão dos dados relacionados ao desempenho desses ativos. O sistema coleta informações detalhadas da máquina em uma base diária e ocorrências instantâneas, que são fornecidas através de relatórios diários, semanais, mensais e anuais sobre os aspectos básicos e mais avançados de desempenho da máquina. Através de uma plataforma na internet, uma variedade de dados é disponibilizada para gestão dos ativos, como:

- Leitura de horas trabalhadas; 
- Localização;

- Mapa de operação (tempo do dia que a máquina ficou com o motor ligado/desligado);

- Média horária do consumo de combustível;

- Nível de combustível residual;

- Máxima temperatura do liquido de arrefecimento durante o dia de operação;

- Registro de atenção (indicadores do painel monitor);

- Notificações / avisos de manutenção;

- Bloqueio imediato do motor;

- Bloqueio noturno do motor;

- Bloqueio por período do motor;

- Delimitação geográfica;

- Relatório de movimentação;

- Horas reais de trabalho (Tempo de motor ligado sem estar em marcha lenta);

- Horas de trabalho do implemento;

- Horas de operação em cada modo de;

- Horas de escavação;

- Horas de carregamento;

- Horas de deslocamento;

- Horas de utilização do martelete;

- Horas em alta pressão do sistema hidráulico;

- Frequência de carregamento (Horas gastas em 4 diferentes níveis de carregamento determinado através da pressão da bomba ou do torque do motor);

- Relatórios Mensais e Anuais;

- Alertas via e-mail.

c) Sistema de apontamento via celular: Para o controle das atividades de cada ativo, foi utilizado um sistema de apontamento eletrônico, onde o operador do equipamento faz o lançamento das informações através de um aparelho celular que transmite os dados em tempo real para uma plataforma na internet. O sistema permite aos gestores saber em tempo real se o equipamento está trabalhando e qual atividade está desempenhando ou se está parado e qual é o motivo de parada, como: falha de manutenção, aguardando frente de trabalho, em fila, entre outros. Em um projeto de 
infraestrutura dinâmico e com um número elevado de interferências, a possibilidade de gerir em tempo real um mapa de todos os recursos aplicados e o seu respectivo status, permite um ganho expressivo de eficiência operacional. Esse sistema tem a vantagem de ser econômico pois utiliza rede de telefonia celular ou wifi para transmitir os dados em tempo real, entretanto ele possui algumas limitações relacionadas a área de cobertura da rede de telefonia, assim para minimizar esse problema, o sistema é capaz de armazenar os dados no aparelho e enviá-los quando a transmissão dos dados for reestabelecida.

d) Outras tecnologias: Também foram utilizadas outras tecnologias que foram baseadas em soluções de RFID, uma delas foi a liberação de acesso a equipamentos através de cartão codificado, que permitiu fazer o controle de acesso dos equipamentos e garantir que somente pessoas habilitadas tivessem acesso.

\subsubsection{Análise do projeto $A$}

Para gerir todas as ferramentas tecnológicas, o projeto contou com uma equipe dedicada de pessoas que foi responsável pela gestão das informações, pela manutenção dos hardwares e pelo treinamento dos usuários. Além da estrutura dedicada, o projeto ainda contou com a assessoria das empresas provedoras de tecnologia para implantação e customização das ferramentas.

O projeto é considerado de grande porte e alta complexidade, haja visto o tamanho do investimento, o número de pessoas envolvidas e a sua duração. De acordo com a classificação de O'Brien et al. (2016), as tecnologias utilizadas neste projeto podem ser classificadas como ferramentas avançadas de sensoriamento para levantamento e coleta de dados e ferramentas de gerenciamento de dados para gerenciamento de fluxo de trabalho digital.

Levando em consideração a matriz proposta por Shenhar e Wideman (2000), que demonstra o relacionamento das variáveis complexidade e incerteza, o projeto A se enquadra no nível 2, que corresponde a projetos complexos com uma coleção complexa de elementos interativos e subsistemas e ao tipo $b$, que corresponde a projetos de tecnologia mediana, conforme ilustrado na figura 13. 

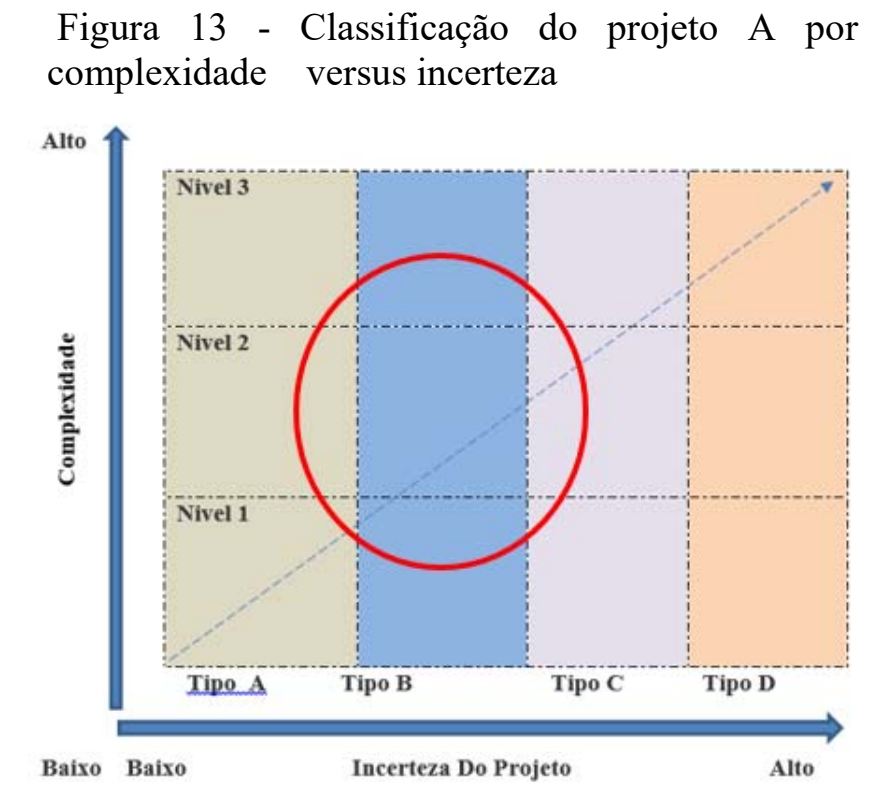

Fonte: Shenhar e Wideman, 2000

A análise empírica do projeto que foi baseada em entrevistas, documentos, sistemas e informações compartilhadas, demonstrou que a assimilação de tecnologia teve um aproveitamento limitado neste projeto. Como características positivas foi possível notar a existência de estrutura dedicada ao uso e aplicação das tecnologias e a implantação de mecanismo que obrigavam o uso das tecnologias por parte dos usuários (operadores e motoristas) garantindo assim um alto nível de coleta de dados, também foi demonstrado que programas de reconhecimento aos bons usuários estimulou a assimilação da tecnologia. Por outro lado, ficou evidente que os dados poderiam ser melhor aproveitados por todos os envolvidos no processo. Os resultados financeiros decorrentes de ganho de performance e redução do custo de manutenção não foram demonstrados de forma evidente, apenas análises pontuais foram geradas no decorrer do projeto. As ferramentas tecnológicas utilizadas, não foram concebidas na fase de planejamento, mas somente após o início do projeto, dessa forma existiram restrições decorrentes de especificações de equipamentos, infraestrutura de rede e adequação de processos já implantados. Por se tratar de um projeto de construção de grandes dimensões e com alto número de interferências em seu planejamento, a implantação de novas tecnologias nem sempre é a prioridade da empresa. Outro fator que contribuiu para o aproveitamento mediano das ferramentas foi a baixa qualificação da mão-de-obra, o projeto em questão foi concebido em um período de escassez de mão-de-obra, dessa forma grande parte do quadro de funcionários da empresa foi constituído por mão-de-obra sem qualificação e sem experiência prévia nas funções, esse fato obrigou o desenvolvimento de programas de 
treinamento e qualificação, porém o prazo de formação não foi suficiente para extrair o máximo de resultado dos ativos. Não existiu uma plataforma consolidada para gerir todas as informações oriundas das ferramentas tecnológicas implantadas, basicamente foram utilizadas as ferramentas ofertadas por cada fabricante de equipamento, dessa forma, observa-se que o uso de várias ferramentas tornou a rotina operacional do usuário complexa. As entrevistas e análises complementares sinalizaram que apesar das informações necessárias estarem disponíveis nas plataformas eletrônicas, ainda existia o uso de papel para fazer alguns apontamentos, dessa forma o sistema era uma ferramenta adicional e não a única provedora de dados, o que prejudica ainda mais o processo de assimilação da tecnologia.

Esses fatos corroboram para confirmação da proposição 1 e 3 da pesquisa que indicam que projetos complexos apresentam particularidades que devem ser consideradas no processo de implantação/assimilação de tecnologia (DUBOIS; GADDE, 2002; GARUD et al., 2013; SAMAD; SEPASGOZAR; DAVIS, 2018), e que as empresas no contexto de projetos complexos, muitas vezes, não se preparam para correta implantação e assimilação de tecnologia (JACOBSSON; LINDEROTH, 2010; SAMAD; SEPASGOZAR; DAVIS, 2018). A proposição 2 de pesquisa que indica que as empresas não utilizam de forma efetiva as ferramentas tecnológicas disponíveis no contexto de gestão de ativos (HAIDER, 2012; HAN et al., 2018) demonstrou estar aderente ao contexto deste projeto, uma vez que as ferramentas tecnológicas foram utilizadas de forma bastante eficiente até o processo de coleta dos dados, entretanto a fase de análise e gestão das informações demonstrou baixa eficiência no contexto de gestão de ativos.

\subsection{O PROJETO B}

Para melhor compreensão do caso, será apresentado uma descrição do projeto, em seguida as tecnologias que foram utilizadas e uma análise parcial será realizada levando em consideração o modelo teórico proposto para pesquisa.

\subsubsection{Descrição do projeto}

O projeto B, compreende a construção de uma Usina Hidrelétrica 3.750 Megawatts, que iniciou em 2009 e foi concluído em 2016. Constituído por um consórcio de empresas privadas o projeto teve grandes dimensões com cerca de 20 mil funcionários no seu pico produtivo e mais de 1.200 equipamentos de construção. Realizado em um momento de alta demanda por 
mão-de-obra, em uma região remota e sem infraestrutura básica, o projeto representou um desafio para engenharia brasileira.

\subsubsection{Tecnologias utilizadas na gestão de ativos}

Neste projeto foram utilizadas ferramentas para o controle de abastecimento da frota e para o apontamento e coleta de informações dos ativos de forma integrada ao sistema ERP implantado no projeto.

a) Sistema de controle automático de abastecimento: foi aperfeiçoado no projeto em parceria com os fabricantes e permitiu a quebra de paradigmas no que tange o controle de um insumo que representa um dos maiores custos operacionais deste tipo de projeto. $\mathrm{O}$ sistema permite que o equipamento que está sendo abastecido envie de forma automatizada, através de uma rede sem fio, as informações como horas trabalhadas e consumo de combustível no período, além da sua função de controle automatizado, essa tecnologia também tem um papel de segurança, uma vez que o insumo somente é liberado da fonte abastecedora se o tag do ativo que receberá o insumo estiver devidamente cadastrado e apto para receber aquele combustível. Essa tecnologia, bastante simples em seu conceito, faz com que o apontamento manual seja descartado e permite ainda que relatórios operacionais sejam realizados em tempo real.

b) Sistema de apontamento e coleta de dados: tem como função principal coletar os dados apontados pelos operadores de forma eletrônica, eliminando dessa forma o apontamento em papel. O sistema implantado possui comunicação via satélite o que permite operar em áreas remotas e sem infraestrutura de telecomunicação. Essa é uma característica importante em projetos de infraestrutura que normalmente são executados em áreas remotas, com limitação de rede de comunicação via celular e via rádio. Apesar do sistema possuir baixo nível de automatização na coleta de dados, uma vez que depende das informações apontadas por seus operadores, ele garante uma comunicação instantânea com os gestores de ativos possibilitando a tomada de decisão. O sistema é composto por um painel de interface que está instalado na cabine do equipamento e o operador registra as atividades realizadas e as informações necessárias para cada atividade, através de comunicação via satélite 
os dados são enviados a uma plataforma na internet que permite a análise dos dados e a tomada de decisão. Esse sistema é integrado ao sistema ERP do projeto e além de permitir a análise de eficiência operacional dos ativos, ele permite a apropriação de custos e o controle das atividades realizadas com os respectivos ativos. Vale destacar que o sistema somente foi implantado dois anos após o início do projeto, antes desse período foram realizadas tentativas de implantação de sistemas similares, porém com o sistema de comunicação através de telefonia celular e sem fio, como: wifi, zigbee e bluetooth. Essas tentativas de implantação fracassaram devido a baixa qualidade da rede de comunicação devido a topografia e as grandes distâncias das frentes de trabalho do projeto.

c) Outras tecnologias: foram realizados testes pontuais com outras tecnologias neste projeto, entretanto não foram implantadas devido à falta de resultados expressivos nos testes realizados.

\subsubsection{Análise do projeto $B$}

Para gestão das ferramentas tecnológicas implantadas, uma sala de controle e uma equipe dedicada foi mantida no projeto. Apesar das tecnologias não terem sido consideradas na fase de planejamento, após a sua implantação, as ferramentas tecnológicas foram incorporadas ao processo e ao sistema ERP da empresa, sendo essa a única fonte de dados, tornando assim o seu uso obrigatório. Neste projeto foi possível notar que ferramentas de telemetria disponíveis no mercado não foram utilizadas em decorrência de que a prioridade dos gestores do projeto foi a de possuir uma apropriação de custos e o controle de insumos eficiente, para posteriormente se investir em ferramentas de telemetria.

Assim como o projeto "A", o projeto "B" possui características de alta complexidade e pode ser classificado de acordo com a matriz proposta por Shenhar e Wideman (2000), como sendo de nível 2 e tipo b, que corresponde a projetos complexos com nível tecnológico mediano.

Através de entrevistas e dos documentos disponibilizados, foi possível concluir de maneira empírica que foram implantados poucos recursos tecnológicos na gestão de ativos, entretanto as ferramentas implantadas foram bem assimiladas. Uma característica observada é que os gestores do projeto optaram por não utilizar algumas ferramentas que estavam disponíveis no mercado pois tinham o objetivo de focar no que, para eles, era o mais importante. De acordo com o gerente de equipamentos do projeto, as ferramentas de telemetria que foram avaliadas não estavam maduras o suficiente para justificar a sua implantação, os fabricantes 
provedores de outras tecnologias, segundo essa avaliação, não apresentaram de forma consistente a mensuração dos resultados provenientes da implantação da tecnologia e por isso o projeto utilizou apenas dois recursos tecnológicos de maneira efetiva.

$\mathrm{Na}$ fase de planejamento deste projeto, não foi levado em consideração o dimensionamento das ferramentas tecnológicas que seriam utilizadas, dessa forma perdeu-se muito tempo para testar algumas ferramentas que posteriormente foram substituídas, essas mudanças no andamento do projeto dificultaram a assimilação da tecnologia por parte dos usuários que conviveram com constantes alterações. Também foi relatado que as análises de investimento realizadas, levaram em consideração apenas o uso do equipamento durante o projeto, no entanto concluiu-se que o correto seria avaliar o investimento pensando na vida completa do ativo, ou seja, desde a fase de aquisição, passando pela fase de operação, manutenção e a fase final da vida do ativo, independentemente do tempo que esse equipamento permaneça no projeto, pois dessa forma o investimento pode ser diluído em um período de tempo maior, os resultados podem ser comparados entre os projeto, além de agregar valor ao ativo no momento em que for vendido.

Após a implantação das duas ferramentas tecnológicas utilizadas na gestão de ativos do projeto, destacaram de forma positiva o fato dessas ferramentas estarem sincronizadas ao sistema ERP da empresa, fazendo parte do processo produtivo do projeto. Antes da implantação, os principais problemas estavam relacionados com a demora na consolidação dos dados e a baixa confiabilidade das informações devido à dificuldade de apuração e possibilidade de erro na digitação dos dados.

As proposições indicadas podem ser confirmadas neste projeto. A proposição "1" que diz que projetos complexos apresentam particularidades que devem ser consideradas no processo de implantação/assimilação de tecnologia (DUBOIS; GADDE, 2002; GARUD et al., 2013; SAMAD; SEPASGOZAR; DAVIS, 2018) é confirmada quando se observa as características do projeto, como baixa qualidade de mão-de-obra, grande número de trabalhadores, alta rotatividade de mão-de-obra e constantes alterações no cronograma que dificultam a assimilação das tecnologias. A proposição "2" que diz que as empresas não utilizam de forma efetiva as ferramentas tecnológicas disponíveis no contexto de gestão de ativos (HAIDER, 2012; HAN et al., 2018) também foi confirmada, pois nota-se um baixo uso de tecnologia neste projeto. A proposição "3" que sugere que as empresas no contexto de projetos complexos, muitas vezes, não se preparam para correta implantação e assimilação de tecnologia (JACOBSSON; LINDEROTH, 2010; SAMAD; SEPASGOZAR; DAVIS, 2018) foi 
também evidenciada de maneira clara, pois não houve um planejamento prévio ao início do projeto para a implantação e uso de tecnologia na gestão de ativos.

\subsection{O PROJETO C}

Para melhor compreensão do caso estudado, será apresentado uma descrição do projeto, em seguida as tecnologias que foram utilizadas e uma análise parcial será realizada levando em consideração o modelo teórico proposto para pesquisa.

\subsubsection{Descrição do projeto}

O terceiro caso estudado, utiliza como unidade de análise um projeto de infraestrutura no setor energético, representado por uma hidrelétrica com capacidade de geração de 11.233 Megawatts, iniciado em 2011 e com o término previsto para 2021, o projeto teve em seu pico produtivo cerca de 5.000 equipamentos de construção e mais de 35.000 trabalhadores. Foram adquiridos exclusivamente para o projeto cerca de 2.400 equipamentos.

\subsubsection{Tecnologias utilizadas na gestão de ativos}

Para gestão desses ativos, assim como os demais casos estudados, o projeto contou com sistema integrado ERP (Enterprise Resource Planning) que tem o papel de controlar todas as informações correspondentes à gestão da empresa inclusive os dados relacionados ao ciclo de vida dos ativos, como: cadastro contendo informações técnicas e comerciais; controle de manutenção; controle das produção e produtividade; controle de abastecimento; controle contábil e de custos (mão-de-obra, materiais, taxas e impostos).

Nesse projeto o sistema ERP é alimentado por apontamento via celular que permite a transmissão e apuração dos dados em tempo real. De forma complementar ao sistema integrado, também foram utilizados sistemas embarcados nos ativos que contribuíram para sua gestão, entretanto esses sistemas complementares não estavam integrados ao sistema ERP e esse fato evidenciou um problema à assimilação dessas tecnologias. Foram utilizadas tecnologias conforme descrito a seguir:

a) Monitoramento de máquinas e caminhões fora-de-estrada: Esse sistema é uma solução de monitoramento remoto que permite o gerenciamento de frota, desenvolvido 
pelo fabricante do equipamento, esse recurso tecnológico foi utilizado no projeto na gestão de 498 ativos, o que representa 58,9\% dos ativos dessa classe de equipamentos. Essa ferramenta transmite as informações via satélite para o seu aplicativo baseado na internet permitindo a geração de relatórios de consumo de combustível, falhas cometidas na operação do equipamento, falhas mecânicas e elétricas, localização, velocidade média, horário de início e término das atividades, delimitação de área de trabalho entre outros. O software também é integrado ao sistema de análise de fluidos concentrando nesta plataforma as informações correspondentes à saúde da frota.

b) Monitoramento de caminhões rodoviários: Essa ferramenta de telemetria, desenvolvida e gerenciada pelo fabricante dos caminhões, utiliza as facilidades da integração da informática com os recursos da internet e telefonia móvel, essa tecnologia permite monitorar os dados relacionados a forma de condução do veículo indicando possíveis falhas operacionais e atribuindo uma nota de classificação para os motoristas, também monitora os códigos de falha mecânica e elétrica de forma integrada aos módulos eletrônicos do equipamento e indica as informações relativas à localização, velocidade, trajetos entre outros. Os dados são enviados através de telefonia móvel de um módulo instalado no caminhão para uma plataforma na internet, essa forma de transmissão de dados apesar de representar uma redução de cobertura, garante um baixo custo de operação. Neste projeto 388 ativos foram monitorados através desta tecnologia, cerca de $59 \%$ da frota de caminhões. Os dados coletados nessas plataformas são avaliados por controladores e engenheiros gerando inputs para as equipes responsáveis pela operação e manutenção dos equipamentos.

c) Sistema de controle de despacho: Diferente dos demais projetos estudados, neste caso foi possível observar um alto investimento em tecnologia, com a implantação de um sistema de controle operacional de terraplenagem, onde através de uma rede de rádio frequência e sistema de posicionamento por satélite, cerca de 900 equipamentos foram monitorados e controlados. Esse sistema teve como objetivo otimizar o processo produtivo de terraplenagem reduzindo filas e perdas operacionais, uma vez que ele permite a visualização de todo o ciclo produtivo dos ativos em tempo real estabelecendo através de monitores instalados nas cabines dos equipamentos uma interface entre a sala de controle e os operadores dos equipamentos. 
d) Outras tecnologias: Além das ferramentas tecnológicas já citadas, também foram utilizados sistemas de controle automático de nível em tratores de esteira que através de sistema receptor GPS/GNSS RTK e o projeto de terraplanagem embarcado no computador de bordo do equipamento, permite o envio automático de sinais elétricos para as válvulas hidráulicas do trator fazendo assim o nivelamento automático da lâmina do equipamento, aplicando de forma automatizada o projeto concebido pela engenharia para a realidade de campo. Tecnologias baseadas no sistema RFID também foram empregadas em sistemas de controle operacionais e de segurança como o sistema de controle de entrada e saída de operadores e sistema de prevenção de atropelamento.

\subsubsection{Análise do projeto $C$}

Para a gestão das ferramentas tecnológicas aplicadas no projeto, foram dimensionadas equipes dedicadas a cada grupo de tecnologia. Uma equipe dedicada a gestão das ferramentas de telemetria (monitoramento de máquinas e caminhões), outra equipe dedicada ao controle de despacho e uma equipe dedicada ao controle de apontamento via celular. Essas equipes atuavam em salas de controle com o monitoramento em tempo real das tecnologias e dos processos atribuídas a cada ferramenta.

Esse projeto possui características de alta complexidade e pode ser classificado de acordo com a matriz proposta por Shenhar e Wideman (2000), como sendo de nível 2 e tipo b, que corresponde a projetos complexos com nível tecnológico mediano. O tamanho e a alta complexidade desse projeto motivaram a sua divisão em subprojetos, cada subprojeto possuiu a sua estrutura de gestão de ativos, que por sua vez compartilhava as informações e decisões com uma equipe corporativa. Essa subdivisão permitiu avaliar que mesmo com as mesmas ferramentas implantadas, em condições similares, a assimilação da tecnologia foi distinta em cada subprojeto, de acordo com os relatos apresentados, essa diferença foi motivada principalmente pelo apoio da alta gerência e a cultura de inovação do indivíduo que estava à frente das equipes.

No início do projeto foram criadas estruturas descentralizadas para a gestão das ferramentas de telemetria, essas equipes eram responsáveis pela manutenção dos hardwares, pela coleta dos dados, interpretação e compartilhamento das informações provenientes dos ativos para respaldar a tomada de decisão, essas equipes também eram responsáveis pela avaliação dos operadores e junto com uma equipe de treinamento atuavam para identificar e corrigir as falhas de operação através de instrutores operacionais em campo. Com relação a 
saúde dos ativos, essas equipes também forneciam informações para os responsáveis pela manutenção para correção de falhas mecânicas, elétricas e hidráulicas identificas através de telemetria. A ferramenta de despacho eletrônico, teve uma equipe independente para cada subprojeto, e atuava diretamente com a equipe responsável pelo fluxo operacional de terraplenagem, essa equipe era responsável por analisar os fluxos de processo de carregamento, transporte e descarga e se comunicavam com os operadores e líderes com o objetivo de otimizar o processo, reduzindo as perdas operacionais e fornecendo informações relevantes para tomada de decisão. Apesar de existir uma estrutura dedicada, em alguns momentos do projeto a estrutura estava subdimensionada e restrições orçamentárias motivaram a subutilização de algumas ferramentas.

A utilização das ferramentas tecnológicas apresentou características distintas de acordo com cada fase do projeto, e de acordo com o ciclo de vida dos ativos. $\mathrm{Na}$ fase inicial do projeto, caracterizada por baixa infraestrutura e um grande número de novos funcionários com baixa experiência, fez com que as tecnologias fossem subutilizadas, após essa fase os relatos indicam que as ferramentas foram assimiladas de forma mais efetiva, já na fase de conclusão do projeto, onde muitos ativos foram disponibilizados para venda e um grupo pequeno de ativos permaneceu em operação, as ferramentas tecnológicas deixaram de ser utilizadas, esse fato indica um conflito à assimilação da tecnologia e foi motivado pelo alto custo de manutenção das tecnologias, e pelo fato dos ativos deixarem de ser a atividade principal do projeto e passarem a representar uma atividade de relevância secundária, tendo em vista o faturamento da empresa.

Apesar de ser considerado um projeto de grande uso de tecnologias, onde os principais provedores de tecnologia estiveram presentes, não foi possível ter acesso a indicadores e relatórios capazes de mensurar de forma efetiva os ganhos provenientes do uso dessas ferramentas. Por se tratar de um processo muito dinâmico e com variáveis distintas, não é possível atribuir os ganhos de produtividade às tecnologias utilizadas de forma direta, muitos dos ganhos são indiretos e poderão ser percebidos apenas ao longo do tempo.

As tecnologias implantadas neste projeto, representam um verdadeiro emaranhado de ferramentas fornecidas por diferentes empresas e que utilizaram diferentes sistemas de telecomunicação. Essa diversidade favoreceu o aumento de problemas relacionados a infraestrutura de comunicação e a dificuldade dos usuários em utilizar diferentes plataformas, uma para telemetria, uma para apropriação de custos e outra ferramenta para o controle operacional, também denominada como sistema de despacho. De acordo com o gestor do projeto, o elevado número de ferramentas utilizadas se deve pela falta de uma tecnologia no 
mercado que atenda todas as necessidades dos usuários no que tange a gestão de ativos, essa é uma carência que deve ser superada com a evolução tecnológica. Atualmente os fabricantes de equipamentos oferecem ferramentas tecnológicas voltadas para telemetria e não se preocupam com as variáveis operacionais como apropriação de custo e sistema de despacho, por outro lado, as empresas provedoras de sistemas de apropriação e despacho não possuem acesso ao módulo de controle dos equipamentos para atender as demandas de controle da saúde dos ativos.

Esse projeto, assim como os demais estudados, está localizado em um local sem infraestrutura de comunicação e por isso no início da sua implantação somente as ferramentas via satélite eram utilizadas, após a implantação dos canteiros e construção de torres de telefonia celular as demais ferramentas puderam ser utilizadas de forma plena, mas mesmo assim problemas de falta de comunicação ao longo do projeto dificultaram o uso dessas ferramentas.

Neste projeto foi possível confirmar as proposições indicadas na pesquisa. A complexidade do projeto afeta diretamente a assimilação de tecnologia, pois o número de interferências e variáveis dificulta o processo de assimilação, o fato de se tratar de um projeto temporário também converge para a proposição "1" que diz que projetos complexos apresentam particularidades que devem ser consideradas no processo de implantação/assimilação de tecnologia (DUBOIS; GADDE, 2002; GARUD et al., 2013; SAMAD; SEPASGOZAR; DAVIS, 2018). A proposição "2" que diz que as empresas não utilizam de forma efetiva as ferramentas tecnológicas disponíveis no contexto de gestão de ativos (HAIDER, 2012; HAN et al., 2018) pode ser confirmada pois apesar do grande número de tecnologias utilizadas neste projeto, o seu uso poderia ser mais efetivo em todas as fases do ciclo de vida dos ativos. A proposição "3" que indica que as empresas no contexto de projetos complexos, muitas vezes, não se preparam para correta implantação e assimilação de tecnologia (JACOBSSON; LINDEROTH, 2010; SAMAD; SEPASGOZAR; DAVIS, 2018) foi validada pois as tecnologias utilizadas não foram consideradas na fase de planejamento do projeto, elas foram implantadas ao longo do projeto e com restrições de infraestrutura o que dificulta o processo de assimilação.

\subsection{O PROJETO D}

Para melhor compreensão do caso estudado, será apresentado uma descrição do projeto, em seguida as tecnologias que foram utilizadas e uma análise parcial será realizada levando em consideração o modelo teórico proposto para pesquisa. 


\subsubsection{Descrição do Projeto}

O quarto projeto avaliado também faz referência a um projeto de construção de uma usina hidrelétrica com capacidade de 350 Megawatts, o projeto iniciou em 2013 e foi concluído em maio de 2019. O projeto foi realizado por uma empresa privada e contou com uma equipe de aproximadamente 3.000 pessoas e 200 equipamentos de construção. Dentre os casos estudos, esse foi o menor projeto e o mais recente, entretanto também apresentou um alto nível de complexidade e fez uso de ferramentas tecnológicas na gestão dos ativos.

\subsubsection{Tecnologias utilizadas na gestão de ativos}

Para gestão dos ativos deste projeto foram utilizadas ferramentas tecnológicas que já estavam implantadas em outros projetos o que facilitou a sua assimilação, dentre as tecnologias utilizadas, temos:

a) Sistema de Monitoramento de Caminhões: Esse sistema é o mesmo sistema de monitoramento utilizado no projeto "A", que é baseado no sistema de posicionamento global de satélites e permite o rastreamento e o compartilhamento de informações em tempo real dos parâmetros operacionais do equipamento, como: localização, velocidade, consumo de combustível, códigos de falhas operacionais e mecânicas que são enviadas, processadas, armazenadas e disponibilizadas para o usuário em uma plataforma na internet. O sistema também permite o envio de mensagens oriundas da sala de controle para os operadores dos equipamentos, facilitando assim a correção de problemas em tempo real. Esse sistema foi aplicado em caminhões responsáveis pela movimentação de solo, rocha e concreto.

b) Sistema de Monitoramento de Energia Elétrica: Para obter o máximo aproveitamento da demanda de energia ativa contratada junto à concessionária de energia elétrica, foi implantado um controle automatizado sobre as cargas por meio de um controlador digital CLP (controlador lógico programável). No gerenciamento de energia elétrica temos no controle da demanda, um dos pontos de grande potencial de economia, dessa forma implantou-se neste projeto um sistema de gestão e supervisão via internet, contemplando assim, eventos e alarmes via e-mail, disponibilizando relatórios e possibilitando melhores análises de energia. O sistema possui diversas ferramentas 
como: comunicação via porta serial, celular ou ethernet; controle de demanda, fator de potência e consumo; sincronismo com a concessionária para os períodos de tarifação; medições de energia elétrica através do medidor da concessionária; e simulações de tendências de consumo. Esse sistema permitiu ainda o gerenciamento dos ativos instalados no sistema como banco de capacitores, reguladores de tensão e os próprios geradores que eram utilizados em horário de pico de demanda.

c) Monitoramento Central de Britagem: O projeto também contou com outras tecnologias que foram aplicadas, como o monitoramento remoto da central de britagem, com uma planta automatizada, onde o controle e os parâmetros podiam ser monitorados a distância. O sistema permitiu o acompanhamento de produção assim como indicava as falhas através dos sensores instalados nos equipamentos.

\subsubsection{Análise do projeto $D$}

Para o gerenciamento das tecnologias implantadas, uma pequena equipe foi dimensionada para atuar de forma dedicada, essa equipe tinha como objetivo principal manter as ferramentas operando, tratar e compartilhar as informações provenientes das ferramentas e treinar os usuários para garantir o uso adequado da ferramenta e dos equipamentos.

Esse projeto apresentou algumas vantagens quando comparado aos demais casos estudados, pois foi concebido por apenas uma empresa que já possuía experiência com algumas ferramentas que foram utilizadas. No entanto assim como os demais projetos, este possui características de alta complexidade e pode ser classificado como sendo de nível 2 e tipo b de acordo com a matriz proposta por Shenhar e Wideman (2000), que corresponde a projetos complexos com nível tecnológico mediano.

Foi evidenciado nas entrevistas que na fase inicial do projeto foram encontradas algumas barreiras para aceitação das ferramentas, no entanto o processo de treinamento e reconhecimento dos operadores fez com que os usuários assimilassem a importância da tecnologia e dessa forma a alta liderança também começou a enxergar valor no sistema.

Assim como alguns casos estudados, as principais tecnologias utilizadas neste projeto atuaram de forma paralela e acessória aos processos produtivos, esse fato contribui para que o uso da tecnologia fosse colocado em segundo plano. A ferramenta de monitoramento de caminhões, exigia que o operador se habilitasse a ferramenta para iniciar a operação, esse fato foi positivo, no entanto as informações provenientes do sistema também eram colhidas através 
de outras fontes que não eram automatizadas, dessa forma o sistema de monitoramento era utilizado em alguns momentos apenas para confirmar os dados colhidos pelo sistema de apropriação.

As entrevistas evidenciaram que apesar de existir o uso efetivo das ferramentas na coleta dos dados, a fase de análise e tomada de decisão ainda tinham possibilidade de ser melhor exploradas. Na fase crítica do projeto que compreende o pico de produção e onde se exige maior eficiência dos ativos, o uso da tecnologia se demonstrou mais eficiente. Dessa forma o processo de assimilação passa a ser reativo e não proativo. Nas fases iniciais e finais do projeto se vê uma menor aderência ao uso das tecnologias.

Os documentos analisados e as entrevistas reforçaram um problema identificado em todos os casos estudados, que é a falta de mensuração dos resultados decorrentes da implantação da tecnologia. A falta de mensuração dos resultados, afeta a importância que os envolvidos no projeto dão às ferramentas e isso muitas vezes leva ao corte de custos, prejudicando a estrutura mínima necessária para fazer com que a ferramenta seja utilizada. Além disso, os custos de implantação das ferramentas são elevados o que limitou o uso de algumas ferramentas que estavam disponíveis no mercado, porém não foram utilizadas. Segundo o responsável pela gestão de ativos do projeto, a análise de viabilidade das tecnologias deve ser realizada levando em consideração a vida completa do ativo e não levando em consideração o tempo de duração do projeto, dessa forma acredita-se que o investimento possa ser melhor analisado.

No contexto do indivíduo também foi observado uma barreira cultural com relação a assimilação de tecnologia, uma vez que as pessoas envolvidas no processo preferiam manter os processos produtivos da forma que sempre fizeram, indicando um certo medo por mudanças. $\mathrm{O}$ nível de escolaridade também foi um fator negativo observado neste projeto, pois a falta de pessoas com um nível básico de instrução dificulta o acesso a algumas tecnologias.

A análise do caso nos permite afirmar que a proposição "1" que diz que projetos complexos apresentam particularidades que devem ser consideradas no processo de implantação/assimilação de tecnologia (DUBOIS; GADDE, 2002; GARUD et al., 2013; SAMAD; SEPASGOZAR; DAVIS, 2018) foi confirmado. A proposição "2" que diz que as empresas não utilizam de forma efetiva as ferramentas tecnológicas disponíveis no contexto de gestão de ativos (HAIDER, 2012; HAN et al., 2018) também foi validada, pois nota-se que na fase inicial e final do projeto o uso das tecnologias foi irrisório. A proposição "3" que indica que as empresas no contexto de projetos complexos, muitas vezes, não se preparam para correta implantação e assimilação de tecnologia (JACOBSSON; LINDEROTH, 2010; SAMAD; 
SEPASGOZAR; DAVIS, 2018) também foi confirmada uma vez que não houve um planejamento prévio para implantação e utilização dessas tecnologias. 


\section{RESULTADOS E DISCUSSÕES}

A análise dos casos foi feita levando em consideração todo o estudo teórico explorado neste trabalho, dessa forma é possível contribuir com o aprimoramento da teoria e identificar novas oportunidades de estudos futuros.

De forma complementar, a partir das entrevistas conduzidas, utilizou-se o software WEBQDA para amparar a análise dos dados. O WEBQDA é um software de análise de textos, vídeos, áudios e imagens que funciona num ambiente colaborativo e distribuído com base na internet. O Software permite editar, visualizar, interligar e organizar documentos. Pode criar categorias, codificar, controlar, filtrar, fazer pesquisas e questionar os dados com o objetivo de responder às suas questões de investigação (COSTA et al., 2012). O WEBQDA apresenta-se como uma ferramenta específica à investigação qualitativa em geral (NERI DE SOUZA, COSTA, \& MOREIRA, 2011). A estrutura básica do software é dividida em três partes:

a) Fontes: inserção e organização dos dados;

b) Codificação: permite criar as dimensões, categorias e depois indicadores, sejam elas interpretativas ou descritivas;

c) Questionamento: é disponibilizado um conjunto de ferramentas que ajudarão o usuário a questionar os dados, com base na configuração atribuída nos dois primeiros sistemas, de forma iterativa e interativa.

Alinhado ao objetivo desta pesquisa, as entrevistas e coleta de dados permitiram a identificação dos fatores que influenciaram o processo de assimilação de tecnologia na gestão dos ativos. Conforme mencionado, foi estabelecido um roteiro de pesquisa abordando os construtos: tecnologia, organização, ambiente e aceitação da tecnologia na perspectiva do usuário.

\subsection{RESULTADOS}

A indústria da construção apresenta características únicas que a diferenciam de outras indústrias, os projetos de construção ocorrem durante um período de tempo limitado, envolvendo a produção no local, com um grande número de pessoas, com alta rotatividade de 
mão-de-obra, com interferências diretas do clima e com constantes alterações de escopo. De acordo com Whitty e Maylor (2009), os grandes projetos de construção civil, representam um ambiente complexo para inovação pois possuem diversos fatores organizacionais e ambientais que são variáveis e que muitas vezes estão fora do controle do gerente. Além disso, durante o ciclo de vida do projeto, uma enorme quantidade de documentos com dados relevantes é produzida e trocada. Esses dados têm formatos diversos e são armazenados em diferentes bancos de dados, aplicativos e até mesmo em papel. Essa complexidade dificulta o gerenciamento de ativos nos projetos. Frente à estas características, a adoção de novas tecnologias, torna-se relevante e necessária, mas também bastante desafiadora, pois não é a presença da tecnologia que deve garantir melhores resultados aos projetos, mas sim a forma como ela está sendo utilizada.

\subsubsection{Projeto A}

A partir dos dados analisados, evidenciou-se que para este projeto os entrevistados possuem posições convergentes em relação ao processo de assimilação de tecnologia na gestão dos ativos. Os entrevistados relatam as questões relacionadas com a parte tecnológica, organizacional, planejamento e aspectos relacionados com a formação e conhecimento dos usuários. A figura 14 apresenta os termos mais frequentes levantados durante as entrevistas.

Figura 14 - Palavras mais frequentes (fonte: WEBQDA)

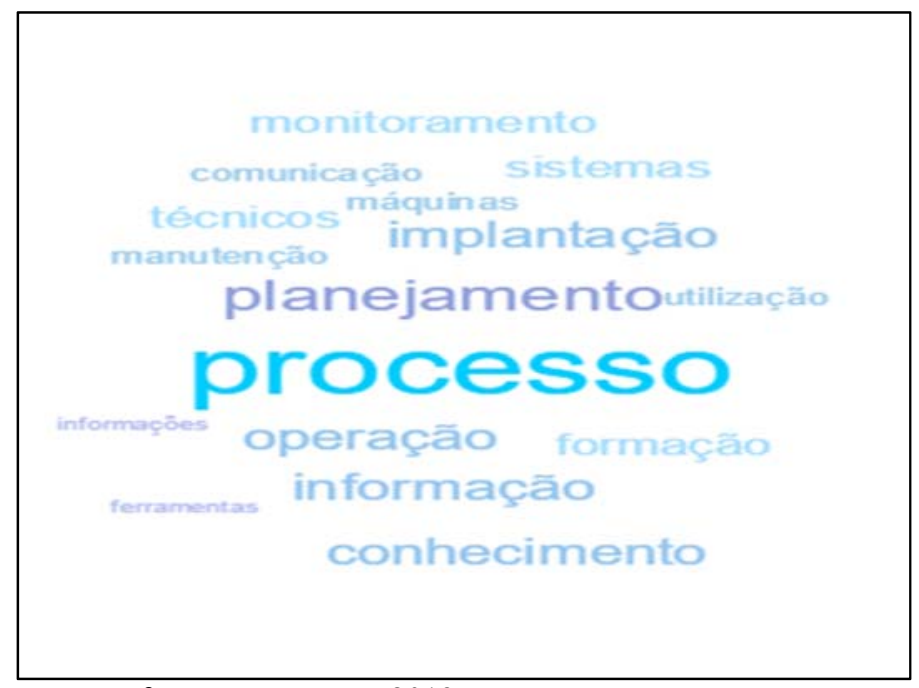

Fonte: Software WEBQDA, 2019 
Os termos processo e planejamento são mencionados várias vezes, e os mesmos aparecem como explicação de fatores que os entrevistados destacaram como pontos fundamentais que suportam a assimilação da tecnologia. Para este projeto os gestores mencionam que a tecnologia deve fazer parte do processo e não apenas ser um acessório, todas as áreas envolvidas devem fazer uso das tecnologias para que então elas sejam assimiladas. A falta de planejamento prévio e alinhamento de expectativas entre todas as áreas envolvidas (operação, manutenção, planejamento e engenharia) impactaram diretamente na assimilação de tecnologia no projeto. Destacaram também, a falta de conhecimento operacional dos usuários para aproveitar o potencial das tecnologias adotadas para a gestão dos ativos.

Os entrevistados enfatizaram a perspectiva do usuário das tecnologias em vários trechos, como pode ser evidenciado a seguir:

“...falta de instrução de conhecimento, até mesmo de nível básico de leitura, é um fator que prejudica, do ponto de vista da pessoa, para ela poder entender a realidade da tecnologia e assimilação. Do ponto de vista estratégico, tem às vezes aqueles diretores-gerentes que não conhecem, não querem conhecer, têm um preconceito com algumas soluções tecnológicas..."

(Técnico responsável pela gestão das ferramentas tecnológicas)

Em alinhamento com o modelo teórico proposto, o estudo do caso permitiu identificar os fatores que mais influenciaram a assimilação de tecnologia neste projeto, o quadro 5 correlaciona todos os fatores identificados com as teorias TOE e TAM 2. 
Quadro 5 - Fatores que impactaram a assimilação de tecnologia

\begin{tabular}{|c|c|c|c|c|}
\hline \multirow{2}{*}{\multicolumn{2}{|c|}{ Contexto Teórico }} & \multirow{3}{*}{$\begin{array}{l}\text { Fatores Observados - Projeto A } \\
\text { Compatibilidade }\end{array}$} & \multicolumn{2}{|c|}{ Impacto } \\
\hline & & & \multirow[t]{2}{*}{ Positivo } & \multirow{2}{*}{$\frac{\text { Negativo }}{\mathrm{x}}$} \\
\hline \multirow{14}{*}{ TOE } & \multirow{5}{*}{ Tecnologia } & & & \\
\hline & & Complexidade & $x$ & \\
\hline & & Disponibilidade tecnológica & $x$ & \\
\hline & & Infraestrutura de TI & & $\mathrm{x}$ \\
\hline & & Benefícios diretos percebidos & & $\mathrm{x}$ \\
\hline & \multirow{6}{*}{ Organização } & Atitudes em relação à inovação & $x$ & \\
\hline & & Tamanho organizacional & & $\mathrm{x}$ \\
\hline & & Cultura de aprendizagem & & $\mathrm{x}$ \\
\hline & & Apoio da alta gerência & $x$ & \\
\hline & & Conhecimento & & $\mathrm{x}$ \\
\hline & & Integração de processos & & $\mathrm{x}$ \\
\hline & \multirow{3}{*}{ Ambiente } & Suporte regulatório & $x$ & \\
\hline & & Prontidão parceiro comercial & $x$ & \\
\hline & & O apoio de fornecedores de tecnologia & $x$ & \\
\hline & \multirow{3}{*}{ TAM } & Facilidade de uso percebida & $x$ & \\
\hline & & Utilidade percebida & & $\mathrm{x}$ \\
\hline & & Intenção comportamental & & $\mathrm{X}$ \\
\hline
\end{tabular}

Fonte: Autor

Esses fatores foram relacionados ao modelo teórico proposto nesta pesquisa e podem ser confirmados através das entrevistas realizadas e dos documentos analisados. Como destaque, foi possível notar que, no contexto tecnológico, a complexidade proveniente do número elevado de ferramentas disponibilizadas para gestão de ativos foi um fator que impactou significativamente o processo de assimilação, no contexto organizacional, o fator que se destacou foi a falta de integração e uso das informações provenientes do sistema que está relacionada ao tamanho da empresa e a cultura de aprendizagem, no contexto ambiental, o apoio dos fornecedores foi um aspecto positivo ressaltado, e com relação ao indivíduo, a facilidade de uso percebida foi o principal fator que impactou a assimilação de tecnologia na gestão de ativos do projeto. 


\subsubsection{Projeto B}

Foi evidenciado neste caso que os gestores do projeto optaram por restringir o uso de algumas tecnologias, com a intenção de manter o foco nas informações que julgaram ser de maior importância, como a apropriação, controle de custos e controle do insumo combustível. Dessa forma, foi possível observar que as poucas ferramentas implantadas foram bem assimiladas no projeto.

O software WEBQDA indicou a ocorrência mais constante de alguns termos que estão indicados na figura 15.

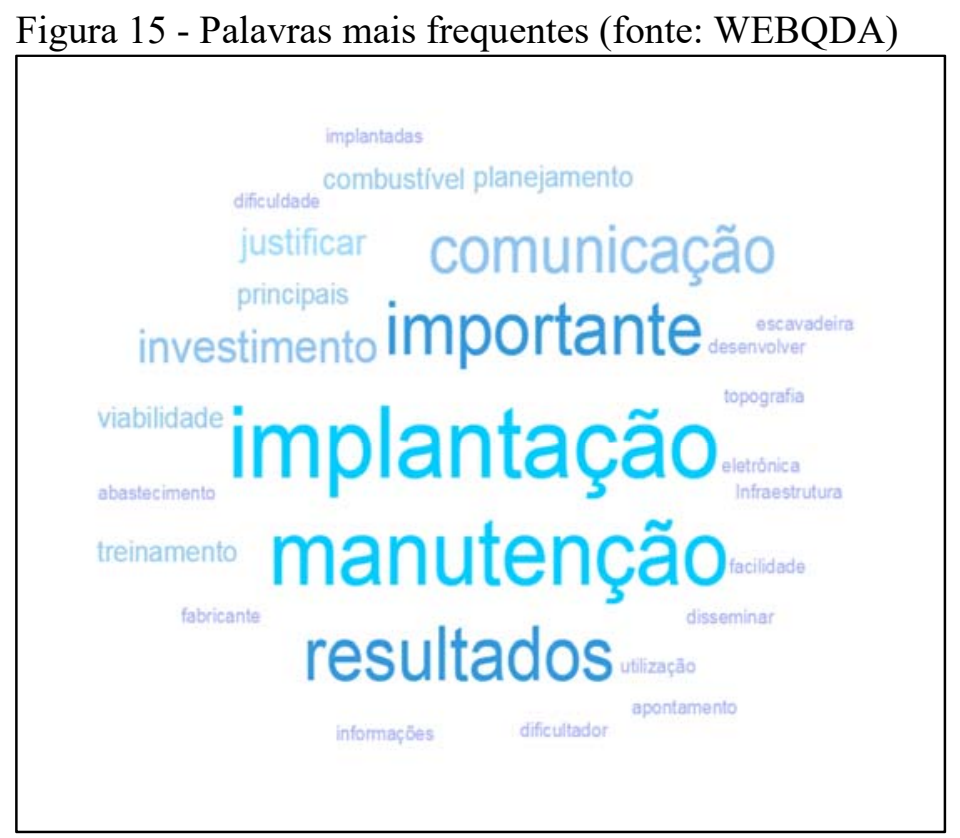

Fonte: Software WEBQDA, 2019

Os termos que tiveram maior destaque nas entrevistas foram: implantação, manutenção e resultados. Esses termos convergem com a preocupação exposta pelos entrevistados no que se refere a mensuração de resultados, o cuidado necessário para o correto planejamento e para implantação das tecnologias, assim como a limitação das ferramentas oferecidas pelos fabricantes de equipamentos de construção que focam na saúde do equipamento e desconsideram o processo produtivo.

“...os fabricantes de equipamentos estão trabalhando para desenvolver algumas ferramentas, que são um pouco limitadas se analisarmos com uma visão de usuários, as ferramentas são muito direcionadas para saúde do equipamento, porém em nosso dia-a-dia a informação mais 
importante está ligada a produção da máquina, é ali que está o dinheiro, por isso focamos nas tecnologias de apontamento..."

(Engenheiro responsável pela área de equipamentos)

Os fatores que impactaram a assimilação da tecnologia no projeto estão descritos no quadro 6.

Quadro 6 - Fatores que impactaram a assimilação de tecnologia

\begin{tabular}{|c|c|c|c|c|}
\hline \multirow{2}{*}{\multicolumn{2}{|c|}{ Contexto Teórico }} & \multirow{2}{*}{ Fatores Observados - Projeto B } & \multicolumn{2}{|c|}{ Impacto } \\
\hline & & & Positivo & Negativo \\
\hline \multirow{11}{*}{ TOE } & \multirow{5}{*}{ Tecnologia } & Infraestrutura de TI & & $\mathrm{x}$ \\
\hline & & Complexidade & & $\mathrm{x}$ \\
\hline & & Disponibilidade tecnológica & & $\mathrm{x}$ \\
\hline & & Benefícios diretos percebidos & & $\mathrm{x}$ \\
\hline & & Benefícios indiretos percebidos & $\mathrm{x}$ & \\
\hline & \multirow{4}{*}{ Organização } & Atitudes em relação à inovação & $\mathrm{x}$ & \\
\hline & & Tamanho organizacional & $x$ & \\
\hline & & Cultura de aprendizagem & & $\mathrm{x}$ \\
\hline & & Integração de processos & $x$ & \\
\hline & \multirow{2}{*}{ Ambiente } & Prontidão parceiro comercial & $x$ & \\
\hline & & O apoio de fornecedores de tecnologia & $x$ & \\
\hline \multirow{3}{*}{\multicolumn{2}{|c|}{ TAM }} & Facilidade de uso percebida & $x$ & \\
\hline & & Utilidade percebida & & $\mathrm{x}$ \\
\hline & & Intenção comportamental & & $\mathrm{x}$ \\
\hline
\end{tabular}

Fonte: Autor

De acordo com a experiência vivenciada no projeto, os seus gestores destacaram que os fatores que mais influenciaram a assimilação de tecnologia foram: a cultura de inovação das pessoas que fazem parte da organização; os benefícios percebidos por parte dos usuários; e a disciplina na implantação através de treinamento e gestão dos processos. Outros fatores também foram evidenciados nas entrevistas e nos documentos analisados, conforme quadro 6.

\subsubsection{Projeto C}

Os entrevistados mencionam que a gestão do fluxo do processo viabilizado pelas ferramentas embarcadas nos equipamentos agregou valor ao negócio. Destacaram o desempenho de ferramentas em diferentes processos, por exemplo, o sistema de despacho, que utilizou uma rede de rádio que foi implantada exclusivamente para essa ferramenta e esse 
sistema fez toda a gestão do processo de terraplenagem controlando o carregamento, transporte e descarregamento. Foi mencionado que o maior benefício dessa ferramenta foi a redução de filas no processo de forma automática, apenas analisando o painel de controle e enviando orientações aos motoristas e operadores. Embora os entrevistados tenham relatado situações de sucesso, eles indicam que o aproveitamento das tecnologias foi mediano, pois havia muita informação, mas os usuários não eram capazes de tratar todos os dados que foram gerados. Para este projeto destacam-se os termos processo, projetos e ferramenta, conforme figura 16.

Figura 16 - Palavras mais frequentes (fonte: WEBQDA)

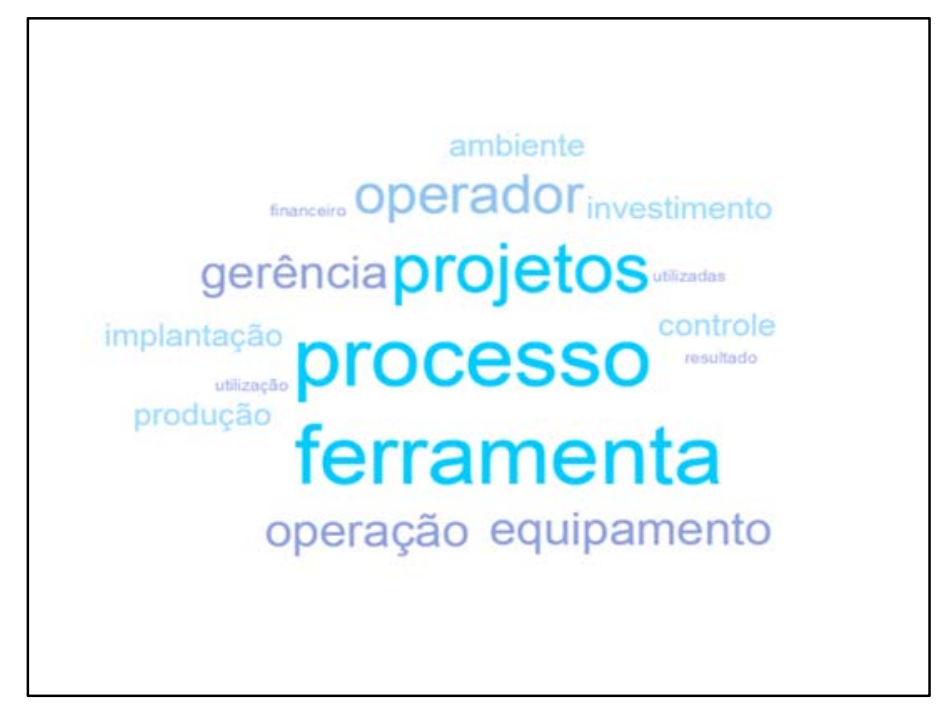

Fonte: Software WEBQDA, 2019)

O redimensionamento de processos tendo em vista o uso de tecnologia e pessoas dedicadas para gerir as ferramentas e analisar os dados no sentido de tomar decisão, demonstraram-se necessários.

“...as tecnologias que foram utilizadas neste projeto, geraram milhares de informações preciosas e se você não estiver dimensionado para gerir essas informações e atacar a causa raiz dos principais problemas identificados por essas tecnologias, tudo perde o sentido..."

(Gerente responsável pela área de equipamentos)

Através da análise das entrevistas e dos materiais disponibilizados, foi possível identificar os fatores que mais influenciaram a assimilação de tecnologia neste caso, conforme o quadro 7. 
Quadro 7 - Fatores que impactaram a assimilação de tecnologia

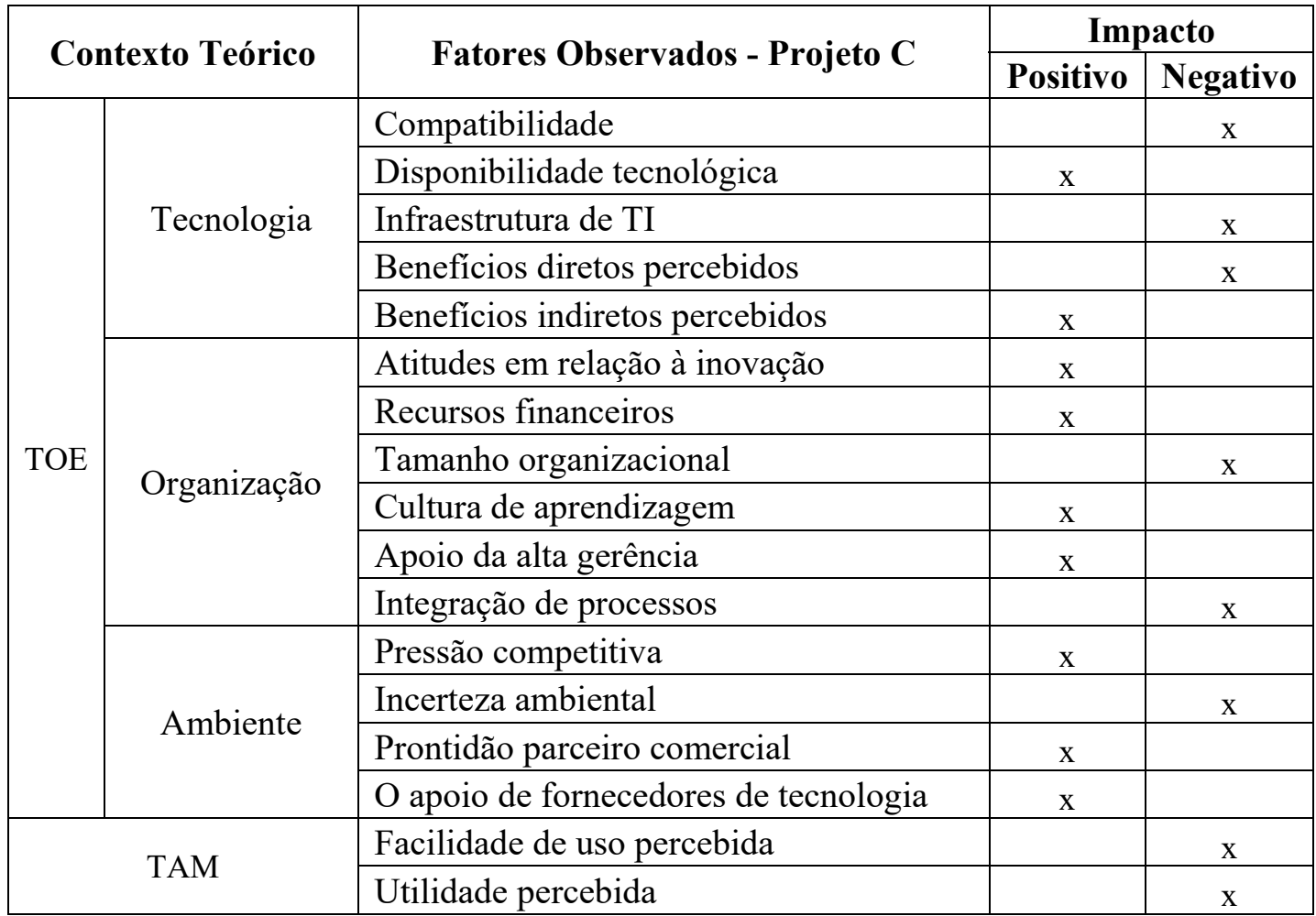

Fonte: Autor

Os fatores tecnológicos que se destacaram foram a incompatibilidade entre sistemas o que obrigou o uso de diversas ferramentas para a gestão dos ativos, esse fato também está diretamente relacionado com a disponibilidade tecnológica; a infraestrutura de TI é um ponto de evidência neste caso e em todos os casos estudados, principalmente na fase inicial do projeto onde as condições são ainda mais precárias; os benefícios diretos e indiretos percebidos representam outro fator de importância pois a complexidade das atividades dificulta a comparação de eficiência dos processos produtivos com ou sem a tecnologia. No contexto organizacional, ficou evidente que a atitude em relação à inovação e o apoio da alta gerência foram fatores que impactaram a assimilação, principalmente quando se comparam os resultados dos subprojetos; os recursos financeiros também foram decisivos neste projeto pois foi realizado um alto nível de investimento em tecnologia; a cultura de aprendizagem foi outro fator que se destacou de forma positiva, pois as pessoas responsáveis pelas ferramentas tecnológicas estimulavam o desenvolvimento e aprendizagem das demais equipes; dentro do contexto organizacional o fator que apresentou maior criticidade foi a integração de processos, os entrevistados deixaram claro que as ferramentas tecnológicas que faziam parte do processo da empresa de maneira obrigatória, como é o caso do sistema de apropriação, foram melhores 
assimiladas do que as ferramentas que trabalhavam como um recurso adicional como é o caso das ferramentas de telemetria, conclui-se que a estruturação do processo produtivo precisa ser concebida tendo em vista o uso de tecnologia. De acordo com o contexto ambiental, a prontidão do parceiro comercial e o apoio dos provedores de tecnologia demonstraram sua importância principalmente na fase de implantação; a pressão competitiva foi evidenciada quando o projeto decidiu investir e implantar o sistema de despacho no pico produtivo do projeto e com a necessidade de melhorar a eficiência das atividades para o cumprimento do cronograma; a incerteza ambiental influenciou de maneira negativa pois as constantes alterações prejudicam o dimensionamento dos recursos e a preparação para o uso de tecnologia de forma efetiva. De acordo com o conceito TAM 2, os fatores do indivíduo que foram evidenciados na assimilação de tecnologia deste projeto foram: a utilidade percebida, que foi observada com o aumento de uso da tecnologia a medida que os indicadores eram divulgados entre os usuários e a intenção comportamental que foi uma barreira na assimilação de tecnologia pois representava a mudança de alguns processos e as pessoas mais experientes preferiam manter o processo da forma como aprenderam no passado e como estavam acostumados a fazer.

\subsubsection{Projeto D}

Foi possível evidenciar através das entrevistas com os gestores do projeto que, os aspectos relacionados com o alinhamento entre processos e tecnologia são fundamentais. $\mathrm{O}$ treinamento, o compartilhamento de resultados e o reconhecimento das equipes envolvidas com uso da tecnologia, influenciaram de maneira positiva. Os fatores relacionados a tecnologia, ambiente, organização e aspectos relacionados ao indivíduo, também foram evidenciados neste caso, contribuindo para a convergência dos casos com relação ao modelo teórico proposto nesta pesquisa. Na figura 17, é possível observar as palavras que mais se destacaram nas entrevistas realizadas. 
Figura 17 - Palavras mais frequentes (fonte: WEBQDA)

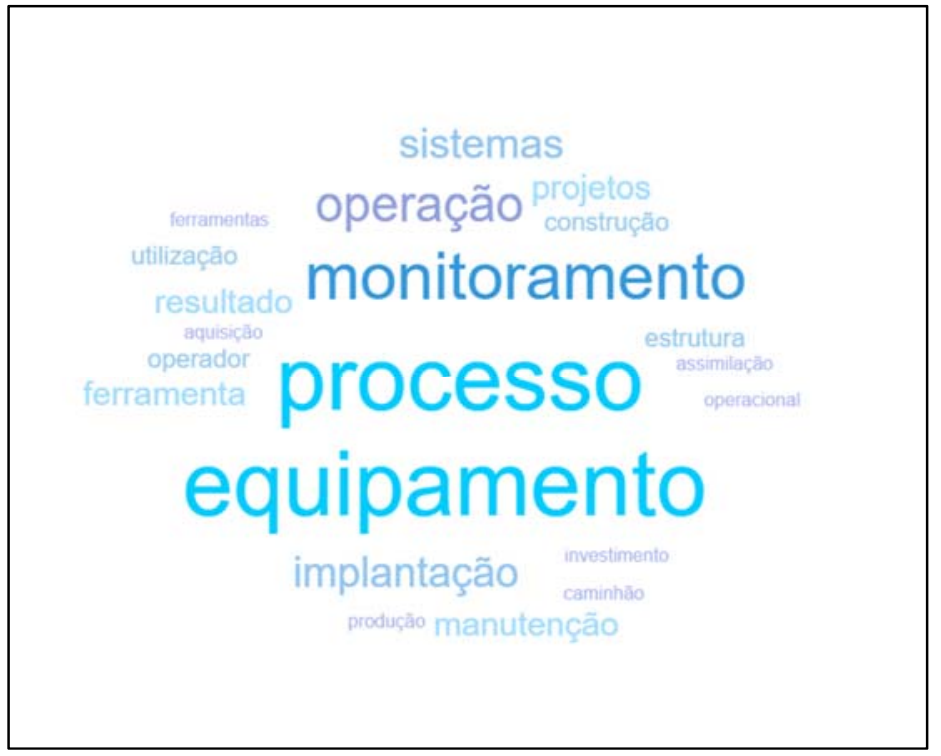

Fonte: Software WEBQDA, 2019)

Os entrevistados enfatizaram que, quando se consegue inserir a tecnologia no processo e as informações geradas se transformam em ação, o resultado é notório.

“...poderia ter sido melhor utilizado na construtora se tivéssemos inserido melhor a tecnologia dentro do processo..."

(Gerente de equipamentos corporativo)

Os fatores que influenciaram a assimilação de tecnologia neste projeto podem ser relacionados à teoria estudada conforme o quadro 8 . 
Quadro 8 - Fatores que impactaram a assimilação de tecnologia

\begin{tabular}{|c|c|c|c|c|}
\hline \multirow{2}{*}{\multicolumn{2}{|c|}{ Contexto Teórico }} & \multirow{3}{*}{$\begin{array}{l}\text { Fatores Observados - Projeto D } \\
\text { Disponibilidade tecnológica }\end{array}$} & \multicolumn{2}{|c|}{ Impacto } \\
\hline & & & \multirow{2}{*}{$\begin{array}{c}\text { Positivo } \\
\mathrm{x} \\
\end{array}$} & \multirow{2}{*}{ Negativo } \\
\hline \multirow{9}{*}{ TOE } & \multirow{3}{*}{ Tecnologia } & & & \\
\hline & & Benefícios diretos percebidos & $\mathrm{x}$ & \\
\hline & & Benefícios indiretos percebidos & $\mathrm{x}$ & \\
\hline & \multirow{5}{*}{ Organização } & Atitudes em relação à inovação & & $\mathrm{x}$ \\
\hline & & Recursos financeiros & $\mathrm{x}$ & \\
\hline & & Tamanho organizacional & $\mathrm{x}$ & \\
\hline & & Apoio da alta gerência & & $\mathrm{x}$ \\
\hline & & Integração de processos & $\mathrm{x}$ & \\
\hline & Ambiente & O apoio de fornecedores de tecnologia & $\mathrm{x}$ & \\
\hline \multirow{3}{*}{\multicolumn{2}{|c|}{ TAM }} & Facilidade de uso percebida & & $\mathrm{x}$ \\
\hline & & Utilidade percebida & $\mathrm{x}$ & \\
\hline & & Intenção comportamental & & $\mathrm{x}$ \\
\hline
\end{tabular}

Fonte: Autor

Foi observado que a disponibilidade de tecnologia e os benefícios diretos e indiretos percebidos representaram os fatores relacionados a tecnologia que tiveram maior influência no projeto; a atitude em relação a inovação, os recursos financeiros, o tamanho da organização, o apoio da alta gerência e a integração de processos representam os fatores relacionados a organização, com destaque especial para a integração de processos que segundo os entrevistados foi considerado um dos fatores mais relevantes; no contexto ambiental foi observado o apoio de fornecedores de tecnologia principalmente para a customização das ferramentas às necessidades do projeto. No aspecto do indivíduo os três fatores que sustentam a teoria TAM foram observados (facilidade de uso percebida, utilidade percebida e intenção comportamental).

\subsubsection{Sumário dos resultados}

A partir dos estudos realizados, elaborou-se um quadro resumindo os principais fatores identificados que suportam a discussão da assimilação das tecnologias digitais de forma integrada ao ciclo de vida do ativo. Os fatores foram identificados a partir dos modelos TOE e TAM 2. Conforme mencionado, o framework TOE (Technology-Organization-Environment) é baseado nas dimensões tecnológica, organizacional e ambiental no contexto dos projetos, combinado com o framework TAM 2, que analisa a aceitação de tecnologia no âmbito do usuário, sendo elas: facilidade de uso percebida; utilidade percebida e intenção 
comportamental, podem suportar o entendimento dos fatores que contribuem para assimilação das tecnologias digitais e para uma implementação bem-sucedida. De forma convergente, para os projetos estudados, a categorização feita a partir das entrevistas está apresentada na figura 18.

Figura 18 - Categorias da investigação qualitativa

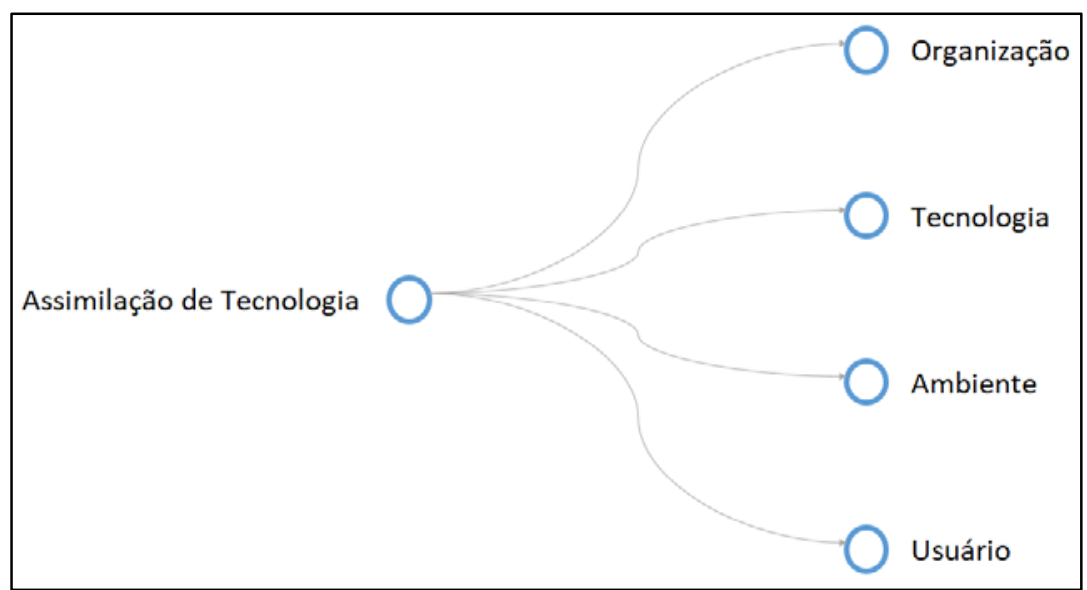

Fonte: Software WEBQDA, 2019)

Os fatores identificados que impactaram a assimilação de tecnologia nos casos avaliados, estão consolidados no quadro 9.

Foi possível notar que alguns fatores foram evidenciados em todos os casos avaliados, como: disponibilidade tecnológica, benefícios diretos percebidos, atitude em relação à inovação, tamanho organizacional, integração de processos, apoio de fornecedores de tecnologia, facilidade de uso percebida e utilidade percebida. 
Quadro 9 - Fatores que impactaram a assimilação de tecnologia

\begin{tabular}{|c|c|c|c|c|c|c|}
\hline \multirow{2}{*}{\multicolumn{2}{|c|}{\begin{tabular}{|l|} 
Contexto Teórico \\
\end{tabular}}} & \multirow{2}{*}{ Fatores } & \multicolumn{4}{|c|}{ Fatores / Casos } \\
\hline & & & \multirow{2}{*}{$\begin{array}{l}\mathrm{A} \\
\mathrm{x}\end{array}$} & \multirow[t]{2}{*}{$\mathbf{B}$} & \multirow{2}{*}{$\begin{array}{l}\mathrm{C} \\
\mathrm{x} \\
\end{array}$} & \multirow[t]{2}{*}{$\mathbf{D}$} \\
\hline \multirow{18}{*}{ TOE } & \multirow{6}{*}{ Tecnologia } & Compatibilidade & & & & \\
\hline & & Complexidade & $\mathrm{x}$ & $\mathrm{x}$ & & \\
\hline & & Disponibilidade tecnológica & $\mathrm{x}$ & $\mathrm{x}$ & $\mathrm{x}$ & $\mathrm{x}$ \\
\hline & & Infraestrutura de TI & $\mathrm{x}$ & $\mathrm{x}$ & $\mathrm{x}$ & \\
\hline & & Benefícios diretos percebidos & $\mathrm{x}$ & $\mathrm{x}$ & $\mathrm{x}$ & $\mathrm{x}$ \\
\hline & & Benefícios indiretos percebidos & & $\mathrm{x}$ & $\mathrm{x}$ & $\mathrm{x}$ \\
\hline & \multirow{7}{*}{ Organização } & Atitudes em relação à inovação & $\mathrm{x}$ & $\mathrm{x}$ & $\mathrm{x}$ & $\mathrm{x}$ \\
\hline & & Recursos financeiros & & & $\mathrm{x}$ & $\mathrm{x}$ \\
\hline & & Tamanho organizacional & $\mathrm{x}$ & $\mathrm{x}$ & $\mathrm{x}$ & $\mathrm{x}$ \\
\hline & & Cultura de aprendizagem & $\mathrm{x}$ & $\mathrm{x}$ & $\mathrm{x}$ & \\
\hline & & Apoio da alta gerência & $\mathrm{x}$ & & $\mathrm{x}$ & $\mathrm{x}$ \\
\hline & & Conhecimento & $\mathrm{x}$ & & & \\
\hline & & Integração de processos & $\mathrm{x}$ & $\mathrm{x}$ & $\mathrm{x}$ & $\mathrm{x}$ \\
\hline & \multirow{5}{*}{ Ambiente } & Pressão competitiva & & & $\mathrm{x}$ & \\
\hline & & Incerteza ambiental & & & $\mathrm{x}$ & \\
\hline & & Suporte regulatório & $\mathrm{x}$ & & & \\
\hline & & Prontidão parceiro comercial & $\mathrm{x}$ & $\mathrm{x}$ & $\mathrm{x}$ & \\
\hline & & O apoio de fornecedores de tecnologia & $\mathrm{x}$ & $\mathrm{x}$ & $\mathrm{x}$ & $\mathrm{x}$ \\
\hline \multirow{3}{*}{\multicolumn{2}{|c|}{ TAM }} & Facilidade de uso percebida & $\mathrm{x}$ & $\mathrm{x}$ & $\mathrm{x}$ & $\mathrm{x}$ \\
\hline & & Utilidade percebida & $\mathrm{x}$ & $\mathrm{x}$ & $\mathrm{x}$ & $\mathrm{x}$ \\
\hline & & Intenção comportamental & $\mathrm{x}$ & $\mathrm{x}$ & & $\mathrm{x}$ \\
\hline
\end{tabular}

Fonte: Autor

Analisando a assimilação de tecnologia e o ciclo de vida dos ativos, ficou evidente que o uso das ferramentas tecnológicas foi efetivo apenas nas fases de operação e manutenção, sendo minimamente utilizado nas fases de aquisição, comissionamento e desmobilização. Esse fato, contribuiu de maneira negativa à assimilação de tecnologia nos projetos estudados. De acordo com a literatura e levando em consideração as entrevistas realizadas, pode ser relacionado fatores que podem ser considerados relevantes em cada fase do ciclo de vida dos ativos, conforme quadro 10 . 
Quadro 10 - Ciclo de vida dos ativos e fatores que podem impactar a assimilação de tecnologia.

\begin{tabular}{|c|c|c|}
\hline Fase do Ciclo de Vida & Aspecto & Fator Impactante \\
\hline \multirow{11}{*}{ Aquisição } & \multirow{4}{*}{ Tecnológico } & Infraestrutura de TI \\
\hline & & Disponibilidade Tecnológica \\
\hline & & Compatibilidade \\
\hline & & Riscos percebidos \\
\hline & \multirow{4}{*}{ Organizacional } & Recursos financeiros \\
\hline & & Conhecimento \\
\hline & & Estruturação de processos \\
\hline & & Atitudes em relação à inovação \\
\hline & \multirow{2}{*}{ Ambiental } & Apoio de fornecedores \\
\hline & & Pressão Competitiva \\
\hline & Indivíduo & Utilidade percebida \\
\hline \multirow{5}{*}{ Comissionamento } & Tecnológico & Infraestrutura de TI \\
\hline & \multirow{2}{*}{ Organizacional } & Apoio alta gerência \\
\hline & & Treinamento \\
\hline & Ambiente & Suporte fornecedores \\
\hline & Indivíduo & Intenção comportamental \\
\hline \multirow{16}{*}{ Operação e Manutenção } & \multirow{5}{*}{ Tecnológico } & Compatibilidade \\
\hline & & Complexidade \\
\hline & & Infraestrutura de TI \\
\hline & & Benefícios diretos percebidos \\
\hline & & Benefícios indiretos percebidos \\
\hline & \multirow{4}{*}{ Organizacional } & Atitudes em relação à inovação \\
\hline & & Cultura de aprendizagem \\
\hline & & Apoio da alta gerência \\
\hline & & Conhecimento \\
\hline & \multirow{4}{*}{ Ambiental } & Pressão competitiva \\
\hline & & Suporte regulatório \\
\hline & & Prontidão parceiro comercial \\
\hline & & O apoio de fornecedores de tecnologia \\
\hline & \multirow{3}{*}{ Indivíduo } & Facilidade de uso percebida \\
\hline & & Utilidade percebida \\
\hline & & Intenção comportamental \\
\hline \multirow{9}{*}{ Desmobilização } & \multirow{3}{*}{ Tecnológico } & Vantagem relativa \\
\hline & & Benefícios diretos percebidos \\
\hline & & Benefícios indiretos percebidos \\
\hline & \multirow{3}{*}{ Organizacional } & Recursos financeiros \\
\hline & & Cultura compartilhamento de informações \\
\hline & & Cultura de aprendizagem \\
\hline & \multirow{2}{*}{ Ambiental } & Pressão competitiva \\
\hline & & Incerteza ambiental \\
\hline & Indivíduo & Utilidade percebida \\
\hline
\end{tabular}

Fonte: Autor 


\subsection{DISCUSSÃO DOS RESULTADOS}

De forma geral, as variáveis discutidas relacionadas à assimilação da tecnologia foram confirmadas na pesquisa de campo realizada. Trazendo a discussão com base no modelo TAM 2 os casos indicam a importância de compreender fatores do comportamento humano em direção ao potencial de aceitação ou rejeição da tecnologia, os resultados confirmam o papel mediador das variáveis facilidade de uso percebida e utilidade percebida em uma relação complexa entre características do sistema (variáveis externas) e o uso potencial do sistema. Em consonância com Edmondson Et Al., (2018a) e Bouleau et Al., (2008), a integração destaca-se como fator importante para a assimilação da tecnologia. Os sistemas modernos, onde sistemas devem ser integrados a sistemas maiores para permitir soluções que forneçam melhor controle dos dados e um gerenciamento mais eficaz. A sinergia e integração dos ativos permite que eles operem numa rede de ativos, gerando troca de informações entre eles e contribuindo para análise e tomada de ação decorrente das informações geradas por essa rede. Os gestores dos projetos mencionam fatores que estão alinhados com O'Donovan et al., (2015) destacando que as soluções orientadas para dados contribuem para o desenvolvimento de operações e manutenções de ativos, porém falta capacitação e planejamento para um aproveitamento eficaz das tecnologias e das informações geradas, enfatizando a falta de uma equipe para analisar as informações e tomar as decisões. Os projetos analisados convergem de forma conclusiva indicando que a tomada de decisão baseada em dados representa um aumento de produtividade e maior retorno sobre o ativo, conforme postulado pelos autores Mandinach (2012) e Brynjolfsson, Hitt e Kim (2011). Vale ressaltar que lacunas no entendimento da assimilação de tecnologia de construção no nível organizacional foram identificadas, particularmente no que diz respeito a importância do envolvimento do fornecedor no processo.

De maneira convergente, os casos estudados confirmaram as proposições de pesquisa. A proposição "1" que indica que particularidades existentes em projetos complexos têm impactos positivos e negativos na assimilação de tecnologia na gestão de ativos (DUBOIS; GADDE, 2002; GARUD et al., 2013; SAMAD; SEPASGOZAR; DAVIS, 2018) foi evidenciada na pesquisa, uma vez que algumas características impactaram a assimilação da tecnologia, como: constante alteração de cronograma, interferências externas, curto período de duração, ausência de mão-de-obra capacitada, descontinuidade do processo produtivo, etc.

A proposição " 2 " que sugere que as empresas não utilizam de forma efetiva as ferramentas tecnológicas disponíveis no contexto de gestão de ativos (HAIDER, 2012; HAN et al., 2018) também foi validada nos casos estudados, pois além de não haver um uso continuado 
de tecnologia em todas as fases do ciclo de vida dos ativos, é possível notar que não existe um uso efetivo dos dados provenientes das tecnologias implantadas para a tomada de decisão.

A proposição " 3 " que indica que as empresas no contexto de projetos complexos, muitas vezes, não se preparam para correta implantação e assimilação de tecnologia (JACOBSSON; LINDEROTH, 2010; SAMAD; SEPASGOZAR; DAVIS, 2018) foi validada nos quatro casos estudados, pois ficou evidente que não houve planejamento prévio ao início do projeto para escolha das tecnologias, implantação de infraestrutura de comunicação, dimensionamento dos processos e dos recursos necessários para o uso efetivo da tecnologia. Todas as tecnologias estudadas foram consideradas após o início do projeto.

Respondendo à questão geral de pesquisa, o trabalho demonstrou que a assimilação de tecnologia é realizada de maneira distinta em cada fase do ciclo de vida do ativo. Poucas empresas consideram a importância da tecnologia e se planejam para o seu uso efetivo nas fases de aquisição e comissionamento, nas fases de operação e manutenção a assimilação da tecnologia ocorre de maneira mais intensa, na última fase do ciclo de vida do ativo a tecnologia muitas vezes deixa de ser considerada. A pesquisa demonstra os principais fatores que influenciam a assimilação em cada fase do ciclo de vida do ativo, e podemos concluir que as empresas deixam de aproveitar de forma efetiva as ferramentas que estão disponíveis no mercado pois não consideram alguns fatores importantes para assimilação e também não visualizam a importância da tecnologia nas fases iniciais e finais do seu ciclo de vida

A contribuição teórica da pesquisa está relacionada à integração do conceito de Gestão de Ativos Inteligentes com os modelos de adoção de Tecnologia TOE e TAM 2. A gestão dos ativos inteligentes pode oferecer uma estrutura para validar e melhorar o desempenho de ativos, coletando e incorporando informações para o processo decisório. Os casos indicaram a adoção de uma variedade de ativos embarcados com diferentes tecnologias em suas operações, no entanto, as empresas utilizam métodos ineficientes e acabam tendo um aproveitamento limitado das mesmas. A gestão de ativos com tecnologia embarcada permite melhorar a precisão e fornecer informações em tempo real, reduzindo assim a mão de obra, tempo e custo para o trabalho de gerenciamento, porém isto deve ser bem desenhado e alinhado aos conceitos da gestão dos ativos. A integração dos conceitos de gestão de ativos e assimilação de tecnologia permite estruturar um framework teórico de assimilação de tecnologias em projetos complexos, alavancando o potencial das tecnologias da informação em suas atividades de negócios e estratégias. 
Vários modelos de assimilação de TI foram desenvolvidos e testados em áreas de negócio, mas observa-se que ainda é um campo que está em evolução. Estudos têm sido desenvolvidos buscando melhorar a gestão dos ativos inteligentes, porém há muitos fatores a serem investigados que contribuam para uma compreensão mais rica da TI na gestão dos ativos. Neste sentido, o estudo proposto e avaliado nos projetos descritos, suportam um planejamento a ser aplicado na prática, instrumentalizando os profissionais a avaliar e demonstrar a efetividade de uma tecnologia embarcada em ativos. Foi possível observar que existe uma ausência de ferramentas tecnológicas integradas ao processo e que supram todas as demandas de dados necessárias para a gestão do ativo, de forma a facilitar a rotina dos usuários. A dificuldade de mensuração dos resultados provenientes das tecnologias representa outro fator de destaque, pois inibe o investimento em tecnologia dentro do contexto analisado.

\subsection{CONCLUSÃO}

A taxa de automação no gerenciamento de ativos ganhou destaque no atual contexto de negócios. A introdução de tecnologias da informação para gerenciar o ciclo de vida dos ativos, no entanto, é fundamentalmente desafiadora, exigindo um gerenciamento de mudanças efetivo que permita obter uma vantagem sobre o uso da tecnologia. Com base no objetivo geral da pesquisa, observou-se a necessidade de uma mudança substancial nas organizações que envolve uma ruptura com as rotinas existentes e uma mudança para novos tipos de competências que desafiam, complementam e aprimoram o conhecimento organizacional. A implementação da tecnologia é multidimensional e sua implementação bem-sucedida depende de vários fatores. Além das questões de padronização e integração de novas tecnologias com a infraestrutura tecnológica existente, há muitas questões humanas, sociais e culturais que impedem a utilização ideal da tecnologia. Assimilação de tecnologia da informação é considerada como um resultado importante nos esforços das empresas para alavancar o potencial das tecnologias em suas atividades de negócios e estratégias. Assim, o estudo permitiu a identificação de variáveis que afetam a assimilação de tecnologias com foco para a gestão de ativos em projetos complexos, o que permite aos gestores estabelecer melhores práticas em relação a adoção destas tecnologias. Analisando a assimilação de tecnologia e o ciclo de vida dos ativos, os casos estudados indicam que o uso das ferramentas tecnológicas foi efetivo apenas nas fases de operação e manutenção, sendo minimamente utilizado nas fases de aquisição, comissionamento e desmobilização. 
Para estudos futuros, sugere-se um estudo longitudinal em projetos complexos aplicando o conceito integrado da gestão dos ativos com os modelos de assimilação de tecnologia, permitindo analisar a forma de inserção de ferramentas tecnológicas na gestão de ativos. Assimilar tecnologias requer ampla adaptação da organização, portanto testar a aplicação dos conceitos de forma integrada pode contribuir para o desenvolvimento de um modelo de adoção tecnológica para gerenciamento de ativos de engenharia e infraestrutura. Ainda como sugestão de pesquisas futuras, torna-se relevante um estudo voltado para o alinhamento entre processos e tecnologia e seu impacto no desempenho dos projetos. $\mathrm{O}$ desenvolvimento de um estudo quantitativo buscando validar os fatores de assimilação discutidos ao longo desta pesquisa consiste também, uma oportunidade de estudo futuro. Finalmente, como propostas de pesquisas futuras, vale destacar estudos que reforcem análises que indicam o nível tecnológico dos equipamentos e do gerenciamento de ativos e sua relação com a rentabilidade nas empresas ou projetos.

Como limitações, primeiro por se tratar de uma pesquisa qualitativa, não se deve considerar a generalização dos resultados obtidos, considerando-se que o presente estudo tem por base quatro projetos de infraestrutura. Outra limitação que pode ser apontada é a representatividade da fala individual em relação a um coletivo maior. Na tentativa de minimizar os impactos dessas limitações, foram utilizados dados secundários, relatórios dos projetos e contatos com fornecedores dos equipamentos como forma de fundamentar as entrevistas realizadas. 


\section{REFERÊNCIAS}

ABOELMAGED, M. G. Predicting e-readiness at firm-level: An analysis of technological, organizational and environmental (TOE) effects on e-maintenance readiness in manufacturing firms. International Journal of Information Management, 34, p. 639-651, 2014.

AGNELlUTTI, C. Big Data: An Exploration of Opportunities, Values, and Privacy Issues. Nova Science Publishers, Inc., 2014.

AJZEN, I. From intentions to actions: A theory of planned behavior, Berlin: Springer, 1985.

AJZEN, I. The theory of planned behavior. Organizational Behavior and Human Decision Processes, v. 50, p. 179-211, 1991.

AL QADY, M.; KANDIL, A. Document discourse for managing construction project documents. J. Comput. Civ. Eng., 10.1061/(ASCE)CP.1943-5487.0000201, p. 466-475, 2013.

ALKALBANI, S.; REZGUI, Y.; VORAKULPIPAT, C.; WILSON, I. E. ICT adoption and diffusion in the construction industry of a developing economy: The case of the sultanate of Oman. Archit. Eng. Des. Manag. n. 9, p. 62-75, 2013.

ARCHETTI, F., GIORDANI, I.; CANDELIERI, A. Data science and environmental management in smart cities. Environmental Engineering and Management Journal, v. 14, n. 9, p. 2095-2102, 2015.

ARPACI, I.; YARDIMCI, Y. C.; OZKAN, S.; TURETKEN, O. Organizational adoption of information technologies: A literature review. International Journal of eBusiness and eGovernment Studies, 4(2), p. 37-50, 2012.

ARTIKIS, A.; BABER, C.; BIZARRO, P.; CANUDAS-DE-WIT, C.; ETZION, O.; FOURNIER, F.; GOULART P.; HOWES, A.; LYGEROS, J.; PALIOURAS, G.; SHARFMAN, I.; SCHUSTER, A. Scalable proactive event-driven decision-making. Technology and Society Magazine, IEEE, v. 33, n. 3, p. 35-41, 2014.

ASHTON, K. That 'Internet of Things’ Thing. RFiD Journal, 22(7), p. 97-114, 2009.

AWA, H. O.; UKOHA, O.; IGWE, S. R. Revisiting technology-organization-environment (TO-E) theory for enriched applicability. The Bottom Line, v. 30, Issue 1, p. -, doi: 10.1108/BL12-2016-0044, 2017.

BERGER, D. Ensuring maintenance data is good enough to trust: Understanding the characteristics of data quality. International Association for Information and Data Quality, 7(1), 2011.

BERGER, D. Plant Services Asset Manager. Website. 2010. Disponível em: $<$ https://www.plantservices.com/articles/2010/02AssetManager>. Acesso em: 2 ago. 2019.

BOUlEAU, C.; GUTIERREZ, F.; GEHIN, H.; LANDGREN, K.; MILlER, G., The Big Picture: Integrated Asset Management. Columbia, 2008. 
BOOS, D.; GUENTER, H.; GROTE, G.; ANDKINDER, K. Controllable accountabilities: the internet of things and its challenges for organizations. Behaviour \& Information Technology, v. 32, n. 5, p. 449-467, 2013.

BOUSDEKIS, A.; MAGOUTAS, B.; APOSTOLOU, D.; MENTZAS, G. A proactive decision making framework for condition-based maintenance. Industrial Management \& Data. Systems, v. 115, issue 7, p. 1225-1250, 2015. Disponível em: <https://doi.org/10.1108/IMDS03-2015-0071>. Acesso em: 2 ago. 2019.

BRITISH STANDARDS INSTITUTE, PAS 55: Asset Management. Part 1: Specification for the Optimized Management of Physical Infrastructure Asset, 2004.

BROUS, P.; JANSSEN, M.; HERDER, P. Internet of Things adoption for reconfiguring decision-making processes in asset management. Business Process Management Journal, 2018.

BROUS, P., HERDER, P.; JANSSEN, M. Towards Modelling Data Infrastructures in the Asset Management Domain, Procedia Computer Science, v. 61, p. 274-280, 2015.

BROUS, P.; JANSSEN, M. Advancing e-government using the internet of things: a systematic review of benefits. In: TAMBOURIS, E.; JANSSEN, M.; SCHOLL, H. J.; WIMMER, M. A.; TARABANIS, K.; GASCÓ, M.; PARYCEK, P. (Eds.) Electronic Government. Springer International Publishing, Thessaloniki, p. 156-169, 2015. Disponível em: $<$ http://link.springer.com/chapter/10.1007/978-3-319-22479-4_12>. Acesso em: 2 ago. 2019.

BROUS, P.; JANSSEN, M. SCHRAVEN, D.; SPIEGELER, J.; DUZGUN, B. C. Factors Influencing Adoption of IoT for Data-driven Decision Making in Asset Management Organizations. Delft University of Technology, Jaffalaan 5, 2628 BX, Delft, Netherlands, 2017.

BRYNJOLFSSON, E.; HITT, L. M.; KIM, H. H. Strength in numbers: How does data-driven decision making affect firm performance. SSRN, 2011. Disponível em: $<$ http://ssrn.com/abstract $=1819486>$. Acesso em: 2 ago. 2019.

CAMPOS, J.; JANTUNEN, E.; BAGLEE, D.; FUMAGALLI, L.; EMMANOUILIDIS, C.; GILABERT, E. Mobile Information Systems in Maintenance Engineering and Asset Management. Socialinių mokslų studijos, n. 8, v. 2, p. 180-197, 2016.

CAMPOS, J.; SHARMA, P.; GABIRIA, U. G.; JANTUNEN, E.; BAGLEE, D. A big data analytical architecture for the asset management. Elsevier B.V. DOI: 10.1016/j.procir.2017.03.019, 2017.

CARR, N. G. IT doesn't matter. Harv. Bus. Rev., 81 (5), p. 41-49, 2005.

COStA, A. P., LINHARES, R., \& SOUZA, F. D. (2012). Possibilidades de Análise Qualitativa no webQDA e colaboração entre pesquisadores em educação em comunicação. Anais $3^{\circ}$ Simpósio Educação e Comunicação: Infoinclusão possibilidades de ensinar e aprender, 276-286.

CHAN, F. T. S.; CHONG, A. Y.-L. Determinants of mobile supply chain management system diffusion: a structural equation analysis of manufacturing firms. Int. J. Prod. Res., 51(4), p. 1196-1213, 2013. 
CHAN, Y. E. IT Value: The Great Divide Between Qualitative and Quantitative and Individual and Organizational Measures... J. Manag. Inf. Syst. 16 (4), p. 225-261, 2000.

CURRAS-PEREZ, R.; RUIZ-MAFE, C.; SANZ-BLAS, S. Determinants of user behavior and recommendation in social networks: an integrative approach from the uses and gratifications perspective. Industrial Management \& Data Systems, v. 114, n. 9, p. 1477-1498, 2014.

DAVIS, F. D. A technology acceptance model for empirically testing new end-user information systems: Theory and results. Sloan School of Management, Massachusetts Institute of Technology, 1986.

DAVIS, F. D. Perceived usefulness, perceived ease of use, and user acceptance of information technology, MIS Quarterly, v. 13, n. 3, p 319-340, 1989.

DELMAS, M. A. The Diffusion of Environmental Management Standards in Europe and in the United States: An Institutional Perspective. Policy Sciences, 35(1), p. 91-119, 2002.

DUBOIS, A.; GADDE, L.-E. The construction industry as a loosely coupled system: implications for productivity and innovation. Construction Management \& Economics, 20(7), p. 621, 2002.

D'HERBEMONT, O.; CÉSAR, B. A Estratégia do Projecto Lateral: como triunfar na mudança quando as forças políticas e sociais dela duvidam ou a ela se opõem. Lisboa: Instituto Piaget, 1996.

EDMONDSONA, V.; CERNYA, M.; LIMA, M.; GLEDSONA, B.; LOCKLEYB, S. A smart sewer asset information model to enable an 'Internet of Things for operational wastewater management. Automation in Construction, v. 91, p. 193-205, 2018.

EISENHARDT, K. M. Building theories from case study research. Acad. Manage. Rev. 14(4): p. 532-550, 1989. Disponível em: <https://doi.org/10.5465/AMR.1989.4308385>. Acesso em: 2 ago. 2019.

ERIKSSON, P. E.; LEIRINGER, R.; SZENTES, H. The role of co-creation in enhancing explorative and exploitative learning in project-based settings. Proj. Manag. J., 48(4), p. 22$38,2017$.

FITZGERALD, M.; KRUSCHWITZ, N.; BONNET, D.; WELCH, M. Embracing Digital Technology: A New Strategic Imperative. MIT Sloan Management Review, Research Report, 2013.

GARUD, R.; TUERTSCHER, P.; VAN DE VEN, A. H. Perspectives on innovation processes. Academy of Management Annals, 7(1), p. 775-819, 2013.

GIEZEN, M. Keeping it simple? A case study into the advantages and disadvantages of reducing complexity in mega project planning. Int. J. Proj. Manag., 30(7), p. 781-790, 2012.

GIL, N.; MIOZZO, M.; MASSINI, S. The innovation potential of new infrastructure development: an empirical study of Heathrow Airport's T5 project. Res. Policy, 41(2), p. 452466, 2012. 
GOLPARVAR-FARD, M.; PEÑA-MORA, F.; SAVARESE, S. Automated progress monitoring using unordered daily construction photographs and IFC-based building information models. J. Comput. Civ. Eng., 10.1061/(ASCE)CP.1943-5487.0000205, $04014025,2015$.

GUSTAVSSON, T. K.; HALLIN, A. Rethinking dichotomization: a critical perspective on the use of "hard" and "soft" in project management. Int. J. Proj. Manag., v. 32, n. 4, p. 568-577, 2014.

HAIDER, A. Information Systems Implementation for Asset Management: A Theoretical Perspective. In: AMADI-ECHENDU, J.; WILLETT, R.; BROWN, K.; MATHEW, J. (eds) Asset Condition, Information Systems and Decision Models. Engineering Asset Management Review. London: Springer, 2012.

HAIDER, A.; KORONIOS, A.; QUIRCHMAYR, G. You Cannot Manage What You Cannot Measure: An Information Systems Based Asset Management Perspective. In: MATHEW, J.; KENNEDY, J.; MA, L.; TAN, Engineering Asset Management, 2006.

HAN, M.; KIM, Y.; PARK, H.; KIM, D. H. A study on the asset smart management system based on IOT. International Journal of Engineering and Technology (UAE), v. 7, n. 2, p. 110-114, 2018.

HANNON, J. J. Emerging technologies for construction delivery. Washington, DC: Transportation Research Board, 2007.

HASSANAIN, M.; FROESE, T.; VANIER, D. Framework model for asset maintenance management. Journal of Performance of Constructed Facilities, v. 17, n. 1, p. 51-64, 2003. Disponível em: <https://doi.org/10.1061/(ASCE)0887-3828(2003)17:1(51)>. Acesso em: 2 ago. 2019.

HAStingS, N. A. J. Physical Asset Management. 1 ed. London, UK: Springer, 2010.

HERRIOTT, R. E.; FIRESTONE, W. A. Multisite qualitative policy research: optimizing description and generalizability. Educational Researcher, v. 12, n. 2, p. 14-19, 1983. Disponível em: <https://doi.org/10.3102/0013189X012002014>. Acesso em: 2 ago. 2019.

HERTERICH, M. M.; UEBERNICKEL, F.; BRENNER, W. The impact of cyber-physical systems on industrial services in manufacturing. Procedia CIRP, n. 30, p. 323-328, 2015.

HERTOGH, M.; WESTERVELD, E. Playing with Complexty: management and organization of large infrastructure projects. Rotterdam, Holand: Erasmus Universiteit Rottersdam, 2010.

HOLMBERG, K.; ADGAR, A.; ARNAIZ, A.; JANTUNEN, E.; MASCOLO, J.; MEKID, S. E-maintenance, London: Springer, 2010.

HOTI, E. The technological, organizational and environmental framework of is innovation adaption in small and medium enterprises. Evidence from research over the las 10 years. International Journal of Business and Management, 2015.

HUA, L.; JUNGUO, Z.; FANTAO, L. Internet of things technology and its applications in smart grid. Indonesian Journal of Electrical Engineering and Computer Science, v. 12, n. 2, p. 940-946, 2014. 
HUANG, T. L.; TSENG, C. H. Using Augmented Reality to Reinforce Vivid Memories and Produce a Digital Interactive Experience. Journal of Electronic Commerce Research, v. 16, n. 4, p. 307, 2015.

HU, Y.; CHAN, A.; LE, Y.; JIN, R.-Z. From construction megaproject management to complex project management: bibliographic analysis. J.Manag. Eng., v. 31, n. 4, p. 1-11, 2015.

HSU, P. F.; KRAEMER, K. L.; DUNKLE, D. Determinants of e-business use in us firms. International Journal of Electronic Commerce, v. 10, n. 4, p 9-45, 2006.

IACOVOU, C. L.; BENBASAT, I.; DEXTER, A. S. Electronic data interchange and small organizations: Adoption and impact of technology. MIS Quarterly, v. 19, n. 4, p 465-485, 1995.

INTERNATIONAL Infrastructure Management Manual. IIMM. Australia/New Zealand Edition, The Institute of Public Works Engineering, Australia, 2002.

ING-LONG, W.; JIAN-LIANG, C. A stage-based diffusion of IT innovation and the BSC performance impact: A moderator of technology-organization-environment. Technological Forecasting \& Social Change, v. 88, p. 76-90, 2014.

IUNG, B. et al. Conceptual framework for e-Maintenance: Illustration by e-Maintenance technologies and platforms. Annual Reviews in Control, v. 33, Issue 2, p. 220-229, 2009. Disponível em: <https://doi.org/10.1016/j.arcontrol.2009.05.005>. Acesso em: 2 ago. 2019.

JARDINE, A. K.; LIN, D.; BANJEVIC, D. A review on machinery diagnostics and prognostics implementing condition-based maintenance. Mechanical Systems and Signal Processing, v. 20, n. 7, p. 1483-1510, 2006.

JACOBSSON, M.; LINDEROTH, H. C. J. The influence of contextual elements, actors' frames of reference, and technology on the adoption and use of ICT in construction projects: a Swedish case study. Construction Management and Economics, v. 28, n. 1, p. 13-23, 2010. DOI: 10.1080/01446190903406154.

JOSHI, P.; SINGH, H.; PHIPPEN, A. D. Web Services: Measuring Practitioner Attitude. Internet Research, v. 14, n. 5, p. 366-371, 2004.

KANAPECKIENE, L.; KAKLAUSKAS, A.; ZAVADSKAS, E.; SENIUT, M. Integrated knowledge management model and system for construction projects. Eng. Appl. Artif. Intell., v. 23, n. 7, p. 1200-1215, 2010.

KINNUNEN, S.-K.; HANSKI, J.; MARTTONEN-AROLA, S.; KÄRRI, T. A framework for creating value from fleet data ar ecosystem level. University of Technology 2VTT Technical Research Centre of Finland Ltd., 2017.

KOTHAMASU R, HUANG S, VERDUIN W. System health monitoring and prognostics -a review of current paradigms and practices Maintenance strategies and motivations for health monitoring. Int J Adv Manuf Technol, v. 28, p. 1012-1024, 2006.

KOPPENJAN, J.; VEENEMAN, W.; VAN DER VOORT, H.; TEN HEUVELHOF, E.; LEIJTEN, M. Competing management approaches in large engineering projects: the Dutch RandstadRail project. Int. J. Proj. Manag., v. 29, n. 6, p. 740-750, 2011. 
KUAN, K. K.; CHAU, P.Y. A Perception-based Model for EDI Adoption in Small Businesses using a Technology-Organization-Environment Framework. Information and Management, v. 38 , n. 8 , p. 507-521, 2001.

KNIGHT, R. Convincing Skeptical Employees to Adopt New Technology. Harvard Business Review, 2015. Disponível em: <https://hbr.org/2015/03/convincing-skeptical-employees-toadopt-new-technology>. Acesso em: 2 ago. 2019.

LEE, J.; NI, J.; DJURDJANOVIC, D., QIU, H; AND LIAO, H.. Intelligent prognostics tools and e-maintenance. Computers in Industry, v. 57, n. 6, p. 476-489, 2006.

LANGEL, T.; LIYANAGE, J. P. Smart assets through digital capabilities. IGI Global, p. 34803485, 2009.

LIPPERT, S. K. An Exploratory Study into the Relevance of Trust in the Context of Information Systems Technology. Dissertação de Doutorado. 2001. The George Washington University, Washington, D.C.

MACCHI, M.; MÁRQUEZ, A. C.; HOLGADO, M.; FUMAGALLI, L.; MARTÍNEZ, L. B. Value-driven engineering of e-maintenance platforms. Journal of Manufacturing Technology Management, v. 25, n. 4, p. 568-598, 2014.

MANDINACH, E. B. A Perfect Time for Data Use: Using Data-Driven Decision Making to Inform Practice. Washington, DC: West Ed., Published online. Apr. 2012.

MANYIKA, J.; CHUI, M.; BROWN, B.; BUGHIN, J.; DOBBS, R.; ROXBURGH, C.; HUNG BYERS, A. Big data: The Next Frontier for Innovation, Competition, and Productivity. McKinsey Global Institute, 2012.

MARANGUNIÉ, N.; GRANIÉ, A. Technology acceptance model: A literature review from 1986 to 2013, 2014. Universal Access in the Information Society, v. 14, n. 1, p. 1-15, 2014. DOI: $10.1007 / \mathrm{s} 10209-014-0348-1$.

MACCHI, M.; RODA, I.; NEGRI, E.; FUMAGALLI, L. Exploring the role of Digital Twin for Asset Lifecycle Management. IFAC PapersOnLine, v. 51, n. 11, p. 790-795, 2018.

Martinez, V.; Ouyang, A.; Neely, A.; Burstall, C.; Bisessar, D. Business Model Innovation: the digital twin technology. Conferência EUROMA. Budapeste, Hungary 24 a 26 de junho. 2018.

MARTÍNEZ-ROJAS, M.; MARÍN, N.; VILA, M. A. The Role of Information Technologies to Address Data Handling in Construction Project Management. American Society of Civil Engineers. 2015. DOI: 10.1061/(ASCE)CP.1943-548.0000538.

MATTAR, F. N. Pesquisa de Marketing: Metodologia e Planejamento. São Paulo: Atlas, 1996.

MAXIMIANO, A. C. A. Administração de Projetos: como transformar ideias em resultados. 3. ed. São Paulo: Atlas, 2008.

MIGUEL, P. A. C. Estudo de caso na engenharia de produção: estruturação e recomendações para sua condução. Produção, v. 17, n. 1, p. 216-229, jan./abr. 2007. 
Miguel, P. A. C. Metodologia de Pesquisa em Engenharia de Produção e Gestão de Operações. São Paulo: Editora Elsevier, 2010.

MULLER, A.; MARQUEZ, A. C.; IUNG, B. On the concept of e-maintenance: Review and current research. Journal of Reliability Engineering and System Safety, v. 93, n. 8, p. 11651187, 2008.

MUSAWA, M.; WAHAB, E. The adoption of EDI technology by Nigerian SMEs: a conceptual framework. Journal of Business Management and Economics, v. 3, n. 2, p. 55-68, 2012.

MU, E.; Kirsch, L. J.; Butler, B. S. The assimilation of enterprise information system: an interpretation systems perspective. Inf. Manage, v. 52, n. 3, p. 359-370, 2015. DOI: http://dx.doi.org/10.1016/j.im.2015.01.004.

NAM, D.; KANG, D.; KIM, S. Process of big data analysis adoption: Defining big data as a new IS innovation and examining factors affecting the process. 48th Hawaii International Conference on System Sciences, 2015.

NAMBISAN, S.; WANG, Y. M. Technical Opinion: Roadblocks to Web Technology Adoption? Communications of the ACM, Pearson, v. 42, p. 98-101. 1999.

NEELY, A.; GREGORY, M.; PLATTS, K. Performance measurement system design. International Journal of Operations \& Production Management, v. 15, n. 4, p. 80-98, 1995.

NEGRI, E.; FUMAGALLI, L.; Macchi, M. A Review of the Roles of Digital Twin in CPSBased Production Systems. Procedia Manufacturing, 11 (June), p. 939-48, 2017.

NEL, C. B. H.; JOOSTE, J. L. A technologically-driven asset management approach to managing physical assets-a literature review and research agenda for'smart'asset management. South African Journal of Industrial Engineering, v. 27, n. 4, p. 50-65, 2016.

NERI DE SOUZA, F., COSTA, A. P., \& MOREIRA, A. Análise de Dados Qualitativos Suportada pelo Software WebQDA. Comunicação apresentada na VII Conferência Internacional de TIC na Educação (Challenges), Universidade do Minho, 2011.

NICHOLAS, John M. Managing Business and Engineering Projects: concepts and implementation. Englewood Cliffs, New Jersey: Prentice Hall, 1990.

OLIVEIRA, T.; MARTINS, M. F. Literature Review of Information Technology Adoption Models at Firm Level. The Electronic Journal Information Systems Evaluation, v. 14, n. 1, p. 110-121, 2011.

OLIVEIRA, T.; THOMAS, M.; ESPADANAL, M. Assessing The Determinants of Cloud Computing Adoption: An Analysis of the Manufacturing and Services Sectors. Information and Management, v. 51, n. 5, p. 497-510, 2014.

OSLADIL, M; KOZUBÍK, L. Smart Asset Management in View of Recent Analytical Technologies. Global Business Services, E\&U Sector IBM Česká republika, spol. s r.o. Prague, Czech Republic, 2015. 
OUERTANI, MOHAMED ZIED, KUMAR, AJITH MCFARLANE, DUNCAN. Towards an approach to select an asset information management strategy. International Journal of Computer Science and Applications, CTechnomathematics Research Foundation, 2008.

O’Brien, W. J., B. Sankaran, F. L. Leite, N. Khwaja, I. De Sande Palma, P. Goodrum, K. Molenaar, G. Nevett, and J. Johnson. 2016. Civil integrated management (CIM) for departments of transportation, Volume 1: Guidebook. NCHRP Rep. 831.Washington, DC: Transportation Research Board, The National Academy of Sciences.

O'CONNOR, J. T., AND L.-R. YANG. 2004. "Project performance versus use of technologies at project and phase levels." J. Constr. Eng. Manage. 130 (3): 322-329. https://doi.org/10.1061/(ASCE)0733-9364(2004) 130:3(322).

O'DONOVAN, P.; LEAHY, K.; BRUTON, K. An industrial big data pipeline for data-driven analytics maintenance applications in large-scale smart manufacturing facilities. Journal of Big Data, a SpringerOpen Journal, 2015. DOI: 10.1186/s40537-015-0034-z.

OZORHON, B.; ORAL, K.; DIMERKESEN, S. Investigating the components of innovation in construction projects. J. Manag. Eng., v. 32, n. 3, p. 1-10, 2016.

PARVE, L. Understanding the benefits of 3D modeling in construction: The Wisconsin case study. 2015. Disponível em: <http://www.fhwa.dot.gov/construction/pubs/hif13050.pdf>. Acesso em: 3 mar. 2019.

PERMINOVA, O.; GUSTAFSSON, M.; WIKSTRÖM, K. Defining Uncertainty inProjects: a new perspective. International Journal of Project Management, v. 26, n. 1, p. 73-9, Jan. 2008 .

PENG, Y.; DONG, M.; ZUO, M. J. Current status of machine prognostics in condition-based maintenance: a review. The International Journal of Advanced Manufacturing Technology, v. 50, n. 1/4, p. 297-313, 2010.

PETER E. D. LOVE, JINGYANG ZHOU, JANE MATTHEWS, HARBIN LUO, Systems information modelling: Enabling digital asset management. In: Advances in Engineering Software, v. 102, p. 155-165, 2016. ISSN 0965-9978.

PORTER, M. E.; MILLAR, V. E. How information gives you competitive advantage. 1985.

POLLARD, W. C. The Soul of the Firm. Zondervan. 1996

PMI. Project Management Institute (ed.). A Guide to the Project Management Body of Knowledge - PMBOK. 4. ed. Newtown Square, Pennsylvania: PMI Publishing Division, 2008.

RADOSŁAW, W.; ANDRYCH-ZALEWSKA, M. Diagnostic telemetry system. Wroclaw University of Technology Department Vehicle Engineering, 2017.

ROBERT, K. Y. Estudo de caso: planejamento e métodos. Trad. Daniel Grassi. 3. ed. Porto Alegre: Bookman, 2005.

RODA, I.; MACCHI, M. Studying the funding principles for integrating Asset Management in Operations: an empirical research in production companies. IFAC-PapersOnLine, v. 49, Issue 
28, p. 1-6, 2016. Disponível em: <https://doi.org/10.1016/j.ifacol.2016.11.001>. Acesso em: 2 ago. 2019.

ROGERS, E. M. Diffusion of Innovation. Nova York, 1995.

ROGERS, E. M., Diffusion of Innovations, Simon and Schuster, 2010.

RYMASZEWSKA, A.; HELO, P.; GUNASEKARAN, A. IoT powered servitization of manufacturing: an exploratory case study. 2017. International Journal of Production Economics Volume, 192, p. 92-105. Disponível em: $<$ https://doi.org/10.1016/j.ijpe.2017.02.016>. Acesso em: 2 ago. 2019.

SHAH, S.; HORNE, A.; CAPELLA, J. Good data won't guarantee good decisions. Harv Bus Rev, Apr. 2012.

SAMAD M. E.; SEPASGOZAR, D. S. Construction Technology Adoption Cube: An Investigation on Process, Factors, Barriers, Drivers and Decision Makers Using NVivo and AHP Analysis. Buildings, v. 8, n. 6, p. 74, 2018.

SAMUELSON, O.; BJÖRK, B.-C. Adoption processes for EDM, EDI and BIM technologies in the construction industry. J. Civ. Eng. Manag., v. 19, Suppl. 1, p. S172-S187, 2013.

SANKARAN, B.; W. J. O'BRIEN. Impact of CIM Technologies and Agency Policies on Performance for Highway Infrastructure Projects. J. Constr. Eng. Manage., v. 144, n. 7, 2018.

SANKARAN, B.; O’BRIEN, W. J.; GOODRUM, P. M.; KHWAJA, N.; LEITE, F. L.; JOHNSON, J. Civil integrated management for highway infrastructure. Transp. Res. Rec., V. 2573, p. 10-17, 2016. Disponível em: <https://doi.org/10.3141/2573-02>. Acesso em 2 ago. 2019.

SARDROUD, J. M. Perceptions of automated data collection technology use in the construction industry. J. Civ. Eng. Manage., v. 21, n. 1, p. 54-66, 2015.

SHENHAR, A. J.; WIDEMAN, R. M. Optimizing Project Success by Matching PM Style with Project Type. Project Management Forum, 2000.

SLACK, N.; CHAMBERS, S.; JOHNSTON, R. Administração da Produção. 2. ed. São Paulo: Atlas, 2002.

SLACK, N.; CHAMBERS, S.; JOHNSTON, R.; BETTS, A. Gerenciamento de Operações e de Processos: princípios e prática de impacto estratégico. Porto Alegre: Bookman, 2008.

SILA, I. Factors Affecting the Adoption of B2B E-commerce Technologies. Electronic Commerce Research, v. 13, n. 2, p. 199-236, 2013.

SICARI, S.; RIZZARDI, A.; GRIECO, L. A.; COEN-PORISINI, A. Security, privacy and trust in Internet of Things: The road ahead. Computer Networks, v. 76, p. 146-164, 2015.

STATISTA. Mercado global de equipamentos de construção. 2017, Disponível em: $<$ https://www.statista.com/statistics/280343/leading-construction-machinery-manufacturersworldwide-based-on-sales>. Acesso em: 8 mar. 2019. 
THOMAS, S. R.; LEE, S.-H.; SPENCER, J. D.; TUCKER, R. L.; CHAPMAN, R. E. Impacts of design/information technology on project outcomes. J. Constr. Eng. Manage. v. 130, n. 4, p. 586-597, 2004. Disponível em: <https://doi.org/10.1061/(ASCE)07339364(2004)130:4(586)>. Acesso em 8 mar. 2019.

TORNATZKY, L. G.; FLEISCHER, M. The processes of technological innovation. Lexington, MA: Lexington Books, 1990.

VAN DEN BERG, F.; DE BEST, L. Smart fields: Making the most of our assets. Moscow, Russia, 2006.

VOSS, C.; TSIKRIKTSIS, N.; FROHLICH, M. Case research in operations management. International Journal Of Operations \& Production Management, v. 22, n. 2, p. 195-219, 2002.

VENKATESH, V.; MORRIS, M. G.; DAVIS, G. B.; DAVIS, F. D. User acceptance of information technology: toward a unified view. MIS Q, v. 27, n. 3, p. 425-78, 2003.

VENKATESH, V.; DAVIS, F. D. A theoretical extension of the technology acceptance model: four longitudinal field studies, Management Science, v. 46, n. 2, p. 186-204, 2000.

VENKATESH, V.; THONG, J. Y. L.; XU, X. Consumer acceptance and use of information tech- nology: Extending the unified theory of acceptance and use of technology. Management Information Systems Quarterly, v. 36, n. 1, p. 157-178, 2012.

WOODHOUSE, J. PAS-55 - Asset Management: concepts \& practices. 21st International Maintenance Conference, IMC-2006, December 5-8, Daytona Beach, Florida, USA, 2006.

WHITTY, S. J.; MAYLOR, H. And Then Came Complex Project Management. International Journal of Project Management, n. 27, p. 304-310, 2009.

WIDEMAN, R. M. A Framework for Project and Program Management Integration. Upper Darby: Project Management Institute, 1991.

WRIGHT, A. D. Few Companies Explore New Technologies. Society for Human Resource Management, 6 jun., 2017. Disponível em: <https://www.shrm.org/resourcesandtools/hrtopics/technology/pages/few-companies-explore-new-technologies.aspx $>$. Acesso em: 8 mar. 2019.

XAVIER, C. M. Gerenciamento de Projetos: como definir e controlar o escopo do projeto. 2. ed. São Paulo: Saraiva, 2009.

XU, S.; Zhu, K.; Gibbs, J. Global Technology, Local Adoption: A Cross-Country Investigation of Internet Adoption by Companies in the United States and China. Electronic Markets, v. 14, n. 1, p. 13-24, 2004.

YANG, J.; ZHANG, W.; LIU, Y. Subcycle Fatigue Crack Growth Mechanism Investigation for Aluminum Alloys and Steel (Special Session on the Digital Twin). 54th AIAA/ASME/ASCE/AHS/ASC Structures, Structural Dynamics, and Materials Conference, 1499, 2013. 
YANG, J. IT supported construction management: A comprehensive review and ongoing research. Adv. Mater. Res., v. 671, p. 1998-2004, 2013.

ZHANG, L.; KARIM, R. Big data mining in e-maintenance: An overview, Proceedings of the 3rd International workshop and congress on e-maintenance, 2014, 17-18, Lulea, Sweden

ZHU, K.; KRAEMER, K. L.; XU, S. Electronic Business Adoption by European Firms: A Cross-Country Assessment of the Facilitators and Inhibitors. European Journal of Information Systems, v. 12, n. 4, p. 251-268, 2003.

ZHU, K.; KRAEMER, K. L.; XU, S. The Process of Innovation Assimilation by Firms in Different Countries: A Technology Diffusion Perspective on E-Business. Management Science, v. 52, n. 10, p. 1557-1576, 2006. 


\section{APÊNDICE A - PROTOCOLO DE PESQUISA}

\section{Introdução}

Baseado nos autores Miguel (2010) e Yin (2005), foi desenvolvido o protocolo de pesquisa que descreve os procedimentos que devem ser utilizados no desenvolvimento da pesquisa de campo. Destinado somente ao pesquisador, deve conter todas as informações úteis para o bom andamento da pesquisa, destacando o objetivo, a questão geral de pesquisa e o roteiro detalhado para o pesquisador.

\section{Preparação prévia}

O estudo prévio da empresa, através de informações disponibilizadas em sites e outras fontes confiáveis deve ser realizado para que se possa avaliar se a empresa realmente possui as características necessárias para o desenvolvimento da pesquisa. Essa etapa também é fundamental para que o pesquisador esteja preparado para o primeiro contato a ser feito com a empresa.

O diretor/gerente responsável pela gestão de ativos nas empresas identificadas, deve ser contatado, para que possa ser apresentado de forma sintética o objetivo geral da pesquisa, a sua natureza e a sua importância teórica e prática. Dessa forma, deve ser feita a consulta sobre a possibilidade de participação da empresa.

\section{Apresentação do projeto}

Para apresentar o projeto de pesquisa para o interlocutor da empresa que será estudada, se faz necessário a elaboração de um material introdutório contendo os principais pontos da pesquisa e o seu embasamento teórico. O material pode ser enviado previamente ou apresentado no início da entrevista. 
a) Modelo de pesquisa

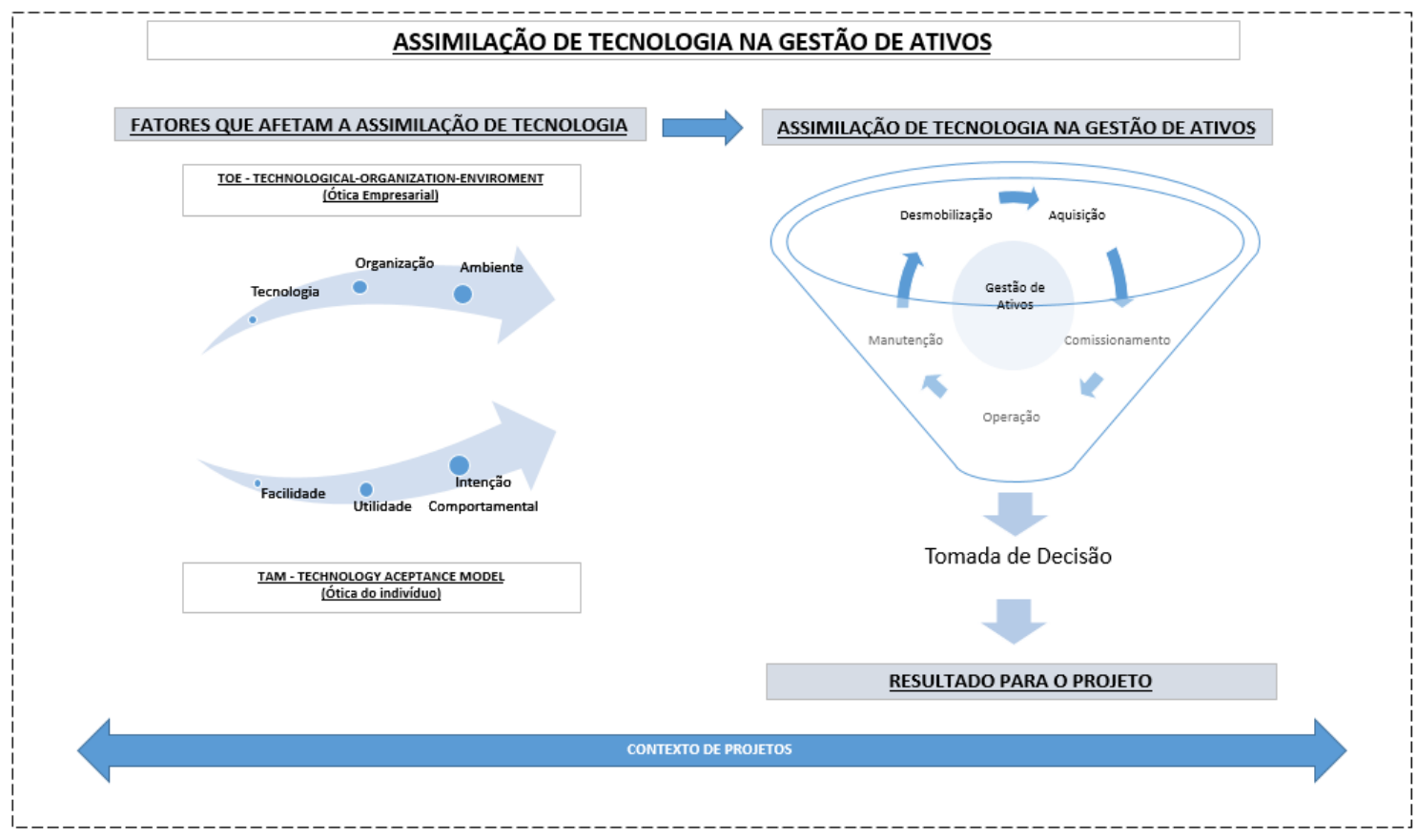

\section{b) Objetivo do projeto}

Analisar a assimilação das tecnologias digitais relacionadas a gestão de ativos no contexto de projeto, através de um estudo de caso múltiplos, identificando as tecnologias utilizadas assim como os possíveis fatores que afetam a assimilação de tecnologia na gestão de ativos

\section{c) Questão geral de pesquisa}

Como as tecnologias digitais são assimiladas em diferentes fases do ciclo de vida da gestão de ativos em projetos complexos?

\section{d) Proposições}

P1 - Particularidades existentes em projetos complexos têm impactos positivos e negativos na assimilação de tecnologia na gestão de ativos (DUBOIS; GADDE, 2002; GARUD et al., 2013; SAMAD; SEPASGOZAR; DAVIS, 2018)

P2 - As empresas não utilizam de forma efetiva as ferramentas tecnológicas disponíveis no contexto de gestão de ativos (HAIDER, 2012; HAN et al., 2018); 
P3 - As empresas no contexto de projetos complexos, muitas vezes, não se preparam para correta implantação e assimilação de tecnologia (JACOBSSON; LINDEROTH, 2010; SAMAD; SEPASGOZAR; DAVIS, 2018).

\section{e) Amostra}

Para atender o propósito da pesquisa, foram identificadas 04 empresas do mercado de construção e que atuaram em grandes projetos de infraestrutura no Brasil, os projetos classificados como projetos complexos e que reuniram um grande número de equipamentos de construção (ativos) com consequente aplicação de tecnologias, reúnem os elementos necessários para pesquisa proposta

Os casos selecionados, correspondem a projetos de infraestrutura do setor energético. Todos os projetos possuem um número superior a 200 equipamentos de construção que nesse trabalho também são denominados como ativos e fizeram uso de uma ou mais tecnologias no gerenciamento dos ativos.

\section{f) Delimitação do escopo}

- O estudo compreende uma amostra de 04 casos que abrangem o gerenciamento de ativos no contexto de projetos, mas especificamente no setor de construção. Dessa forma busca-se avaliar os fatores que afetam a assimilação de tecnologia no gerenciamento dos ativos. Apesar dessa limitação, busca-se com o estudo de caso múltiplos a possibilidade de generalização para projetos que apresentem características semelhantes.

- O conceito de "ativos" é muito amplo, contudo o presente trabalho limita-se aos ativos utilizados em projetos de construção, como: escavadeiras, tratores, caminhões, guindastes, centrais de britagem, centrais de concreto etc.;

- Neste trabalho buscou-se avaliar a assimilação de tecnologias utilizadas no gerenciamento de ativos em projetos de construção civil. Foram avaliadas apenas as tecnologias utilizadas nos casos estudados;

- Foi utilizado o framework TOE - Technological Organization Environmental e TAM

- Technology Acceptance Model, como suporte teórico para o desenvolvimento da 
pesquisa. Não foram utilizadas outras teorias de assimilação e adoção de tecnologia, pois conforme demonstrado no capítulo 2, o TOE e TAM reúnem de maneira mais abrangente as características necessárias para o presente estudo.

\section{Confidencialidade}

As informações coletadas serão tratadas com sigilo de forma a não expor as empresas e as pessoas entrevistadas. As empresas/projetos, assim como as tecnologias utilizadas serão denominadas por nomes distintos de forma a preservar a integridade de todos os envolvidos (Ex.: Empresa A, B, C e D; Tecnologia de monitoramento ...).

\section{Coleta de dados}

$\mathrm{Na}$ fase de preparação deve-se buscar a identificação das pessoas chaves a serem entrevistadas, assim como o mapeamento dos ativos e das tecnologias utilizadas no projeto.

O protocolo de pesquisa deve ser utilizado pelo pesquisador no momento da coleta de dados, afim de servir como guia geral de forma a cobrir todo o planejamento de coleta de dados que suportará o desenvolvimento da pesquisa. As entrevistas devem ser gravadas, mediante aprovação do entrevistado, e transcritas de forma a garantir que nenhuma informação seja perdida.

De forma a cooperar com o entrevistado e buscando uma comunicação mais assertiva, o roteiro de entrevista (Apêndice B), pode ser enviado previamente ao entrevistado. Contudo vale destacar que o protocolo de pesquisa não deve ser compartilhado, ele apenas deve servir como ferramenta do pesquisador.

Consulta a documentos, sistemas, observações em campo, conversas informais entre outros meios, podem ser utilizados para coleta de informações e evidências de forma a complementar as entrevistas formais realizadas.

\section{Roteiro do Protocolo}

Os questionamentos indicados a seguir visam respaldar a pesquisa no que diz respeito ao contexto do projeto e da empresa. 


\begin{tabular}{|c|c|c|}
\hline Contexto & Perguntas & $\begin{array}{l}\text { Literatura de } \\
\text { referência }\end{array}$ \\
\hline $\begin{array}{c}\text { Empresa / } \\
\text { Projeto / } \\
\text { Gestão de } \\
\text { Ativo }\end{array}$ & $\begin{array}{l}\text { Empresa: } \\
\text { Identificar a empresa responsável pelo projeto o ramo de } \\
\text { atuação e o posicionamento no mercado; } \\
\text { Há quanto tempo a empresa atua no mercado? } \\
\text { Como está estruturada a gestão de ativos da empresa? } \\
\text { Como é a interface entre a empresa e o projeto na gestão de } \\
\text { ativos? (Organograma, Política, Responsabilidades) } \\
\text { Projeto: } \\
\text { Identificar o projeto; } \\
\text { Escopo, duração, organograma do projeto; } \\
\text { como o projeto pode ser classificado? } \\
\text { Como o projeto está inserido no contexto do setor? } \\
\text { Quais foram os principais desafios? } \\
\text { Quais foram os fatos relevantes? } \\
\text { Gestão de Ativos: } \\
\text { Característica dos ativos no projeto (histograma de } \\
\text { equipamentos, característica dos equipamentos); } \\
\text { Foram adquiridos equipamentos novos para o projeto? } \\
\text { Quantos equipamentos alugados ou subcontratados foram } \\
\text { utilizados no projeto? } \\
\text { Quais foram os ativos mais críticos do projeto? } \\
\text { Como foi a interface com os fornecedores e estruturas de } \\
\text { apoio à gestão de ativos? } \\
\text { Como pode ser classificada a performance dos ativos no } \\
\text { projeto? } \\
\text { Após o projeto os ativos foram reaproveitados ou foram } \\
\text { vendidos? }\end{array}$ & $\begin{array}{l}\text { Shenhar, Wideman } \\
\text { (2000); Pmi (2008); } \\
\text { Xavier (2009); } \\
\text { Giezen (2012); Hu } \\
\text { et al.(2015) }\end{array}$ \\
\hline
\end{tabular}

Para permitir uma avaliação da assimilação de tecnologia no projeto/empresa, antes é preciso conhecer as tecnologias digitais utilizadas na gestão dos ativos. Dessa forma, os questionamentos a seguir visam compreender às tecnologias utilizadas no projeto. 


\begin{tabular}{|c|c|c|}
\hline Contexto & Perguntas & $\begin{array}{c}\text { Literatura de } \\
\text { referência }\end{array}$ \\
\hline Tecnologias & $\begin{array}{l}\text { Quais tecnologias digitais foram utilizadas no projeto no } \\
\text { contexto de gestão de ativos? } \\
\text { Quais eram as características dessas tecnologias } \\
\text { (fabricante, maturidade da tecnologia, quantidade de } \\
\text { usuários) } \\
\text { Quais tecnologias foram implantadas no projeto e quais já } \\
\text { estavam implantadas na empresa? } \\
\text { Como estava estruturada a gestão de ativos para extrair os } \\
\text { benefícios decorrentes das tecnologias? } \\
\text { Quais eram os indicadores de performance correspondente } \\
\text { às ferramentas tecnológicas? } \\
\text { Como foi estruturada a base de dados proveniente das } \\
\text { tecnologias? } \\
\text { Como era a interface com o provedor da tecnologia? } \\
\text { Foram desenvolvidos estudos de viabilidade de } \\
\text { implantação de novas tecnologia? Quais foram os } \\
\text { resultados? } \\
\text { Como a empresa e o projeto se prepararam para a } \\
\text { implantação/ uso das tecnologias disponíveis? }\end{array}$ & $\begin{array}{c}\text { Zhang (2014); } \\
\text { Aboelmaged (2014); } \\
\text { Golparvar-fard et } \\
\text { al., (2015); Wróbel } \\
\text { (2017); Brous, et al. } \\
\text { (2017). }\end{array}$ \\
\hline
\end{tabular}

De acordo com Tornatzky e Fleischer (1990) e Venkatesh e Davis (2000), os questionamentos indicados a seguir, têm como objetivo identificar os fatores que afetaram a assimilação de tecnologia nos casos estudados. 


\begin{tabular}{|c|c|c|}
\hline Contexto & Perguntas & $\begin{array}{l}\text { Literatura de } \\
\text { referência }\end{array}$ \\
\hline \multirow[t]{3}{*}{$\begin{array}{l}\text { Assimilação de } \\
\text { Tecnologia }\end{array}$} & $\begin{array}{l}\text { Qual foi o nível de aproveitamento das tecnologias disponíveis } \\
\text { no projeto? } \\
\text { Avaliar os fatores que impactaram à assimilação de tecnologia } \\
\text { no projeto sob a ótica da empresa. } \\
\text { Contexto Tecnológico: } \\
\text { Vantagem relativa } \\
\text { Compatibilidade } \\
\text { Complexidade } \\
\text { Disponibilidade tecnológica } \\
\text { Infraestrutura de TI } \\
\text { Benefícios diretos percebidos } \\
\text { Benefícios indiretos percebidos } \\
\text { Riscos percebidos } \\
\text { Contexto Organizacional: } \\
\text { Atitudes em relação à inovação } \\
\text { Recursos financeiros } \\
\text { Tamanho organizacional } \\
\text { Cultura compartilhamento de informações } \\
\text { Cultura de aprendizagem } \\
\text { Apoio da alta gerência } \\
\text { Conhecimento } \\
\text { Contexto Ambiental: } \\
\text { Pressão competitiva } \\
\text { Incerteza ambiental } \\
\text { Suporte regulatório } \\
\text { Prontidão parceiro comercial } \\
\text { O apoio de fornecedores de tecnologia }\end{array}$ & $\begin{array}{l}\text { Porter e Millar (1985); } \\
\text { Tornatzky e Fleischer } \\
\text { (1990); ; Iacovou; } \\
\text { Benbasat, Dexter } \\
\text { (1995); Nambisan e } \\
\text { Wang (1999); Chan } \\
\text { (2000; Lippert (2001); } \\
\text { Kuan e Chau (2001); } \\
\text { Delmas (2002); Zhu, } \\
\text { Kraemer e Xu (2003); } \\
\text { Zhu, Kraemer e Xu } \\
\text { (2003); Zhu, kraemer } \\
\text { e Xu, (2003); Xu, Zhu } \\
\text { e Gibbs (2004); Joshi, } \\
\text { Singh e Phippen } \\
\text { (2004); Haider, } \\
\text { Koronios e } \\
\text { Quirchmayr (2006); } \\
\text { Zhu, Kraemer, Xu } \\
\text { (2006); Rogers (2010); } \\
\text {; Oliveira e Martins } \\
\text { (2011); Musawa e } \\
\text { Wahab (2012); Sila } \\
\text { (2013); Oliveira; Chan } \\
\text { e Chong (2013); } \\
\text { Thomas, Espadanal } \\
\text { (2014); Wua e Chen } \\
\text { (2014); } \\
\text { Aboelmaged } \\
\text { (2014); Sicari et al. } \\
\text { (2015); Huang e } \\
\text { Tseng (2015); Dal- } \\
\text { woo et al. (2015); } \\
\text { Knight (2015); Mu, } \\
\text { Kirsch e Butler } \\
\text { (2015); Wright } \\
\text { (2017). }\end{array}$ \\
\hline & $\begin{array}{l}\text { Avaliar os fatores que impactaram a assimilação da tecnologia } \\
\text { no projeto sob a ótica do indivíduo. } \\
\text { Facilidade de uso percebida; } \\
\underline{\text { Utilidade Percebida; }} \\
\underline{\text { Intencão Comportamental. }}\end{array}$ & $\begin{array}{l}\text { Davis (1985); } \\
\text { Venkatesh e Davis } \\
\text { (2000); Lee et al., } \\
\text { (2006); Oliveira e } \\
\text { Martins (2011); } \\
\text { Marangunié e Granié } \\
\text { (2014). }\end{array}$ \\
\hline & $\begin{array}{l}\text { Além dos fatores indicados acima, existiu no projeto outro fator } \\
\text { significativo para assimilação da tecnologia? }\end{array}$ & \\
\hline
\end{tabular}

